\title{
Patient participation in gynaecological consultations: studying interactional patterns
}

Citation for published version (APA):

Weijts, L. B. M. (1993). Patient participation in gynaecological consultations: studying interactional patterns. [Doctoral Thesis, Maastricht University]. Rijksuniversiteit Limburg.

https://doi.org/10.26481/dis.19930618lw

Document status and date:

Published: 01/01/1993

DOI:

10.26481/dis.19930618lw

Document Version:

Publisher's PDF, also known as Version of record

\section{Please check the document version of this publication:}

- A submitted manuscript is the version of the article upon submission and before peer-review. There can be important differences between the submitted version and the official published version of record.

People interested in the research are advised to contact the author for the final version of the publication, or visit the DOI to the publisher's website.

- The final author version and the galley proof are versions of the publication after peer review.

- The final published version features the final layout of the paper including the volume, issue and page numbers.

Link to publication

\footnotetext{
General rights rights.

- You may freely distribute the URL identifying the publication in the public portal. please follow below link for the End User Agreement:

www.umlib.nl/taverne-license

Take down policy

If you believe that this document breaches copyright please contact us at:

repository@maastrichtuniversity.nl

providing details and we will investigate your claim.
}

Copyright and moral rights for the publications made accessible in the public portal are retained by the authors and/or other copyright owners and it is a condition of accessing publications that users recognise and abide by the legal requirements associated with these

- Users may download and print one copy of any publication from the public portal for the purpose of private study or research.

- You may not further distribute the material or use it for any profit-making activity or commercial gain

If the publication is distributed under the terms of Article $25 \mathrm{fa}$ of the Dutch Copyright Act, indicated by the "Taverne" license above, 
Patient participation in gynaecological consultations: studying interactional patterns 


\title{
Patient participation in gynaecological consultations: studying interactional patterns
}

\author{
Proefschrift
}

ter verkrïging van de graad van doctor aan de Rijksuniversiteit Limburg te Maastricht, op gezag van de Rector Magnificus, Prof. Mr. M.J. Cohen, volgens het besluit van het College van Dekanen, in het openbaar te verdedigen op vrijdag 18 juni 1993 om 14.00 uur

door

Louisa Bernarda Maria Weijts

geboren te 's-Hertogenbosch op 13 februari 1964 
Promotores:

Prof. dr. G.J. Kok

Prof. dr. P.D. Mullen (University of Texas, Houston)

Co-promotor:

Dr. G.A.M. Widdershoven

Beoordelingscommissie:

Prof. dr. H. Philipsen (voorzitter)

Prof. dr. L. Boon

Dr. G. Kleiverda (Flevo ziekenbuis, Almere)

Dr. L. Meeuwesen (Rijksuniversiteit Utrecht)

Dr. A. Mol

\section{CIP KONINKLIKE BIBLIOTHEEK, DEN HAAG}

Weijts, Wies

Patient participation in gynaecological consultations:

studying interactional patterns / Wies Weijts.

Maastricht: Uniprint Universitaire Drukkerij. - Ill.

Thesis Masstricht - With ref. - With summary in Dutch.

ISBN 90-9006090-1

NUGI 735

Subject headings: doctor-patient communication, gynaecology, women's studies.

Produktie en druk: Uniprint Universitaire Drukkerij, Maastricht Omslagontwerp: Jan Lamberts, Venlo

De publicatie van dit proefschrift werd mede mogelijk gemaakt door financiële steun van de Stichting Vrouw en Gezondheidszorg/Henny Verhagen Fonds. 


\section{Contents}

Acknowledgements

vii

Chapter 1 General overview

1.1 Introduction

1.2 Patient participation in medical interviews 10

1.3 Gender issues in patient participation in medical conversations

1.4 Characteristics of interaction in gynaecological consultations

1.5 'Vrouwenhulpverlening'

1.6 Provisional research questions 20

1.7 Methods

1.7.1 The approach to data 20

1.7.2 Obtaining access 22

1.7.3 Sample and data collection $\quad 22$

1.7.4 Transcription and translation $\quad 25$

1.7.5 The selection of topics: specifying the research questions

1.8 Results

1.8.1 Study 1: Seeking information $\quad 27$

1.8.2 Study 2: Expressing concerns regarding malignancy

1.8.3 Study 3: Talking about sexuality 29

1.9 Discussion and conclusions 31

1.10 Recommendations for future research 36

1.11 Recommendations for practice 37

Chapter 2 Seeking information

2.1 Introduction

2.2 Methods

2.2.1 Sample and data collection $\quad 41$

2.2.2 Operationalizations $\quad 42$

2.3 Results 43

2.3.1 Requests for new information $\quad 43$

2.3.2 Requests for elucidation $\quad 46$

2.3.3 Requests for confirmation $\quad 49$

2.3.4 Relation between form and content 51 
2.4 Discussion 60

Chapter 3 Expressing concerns about malignancy 65

3.1 Introduction 65

3.2 Methods 68

3.3 Characteristics of the respondents 68

$\begin{array}{lll}3.4 & \text { Results } & 70\end{array}$

3.4.1 Patients' expressions of anxiety 70

3.4.2 Physicians' reactions to patient anxiety 71

3.4.3 Scenarios in talking about anxiety 73

3.5 Discussion 81

3.6 Conclusion 84

$\begin{array}{lll}\text { Chapter } 4 \quad \text { Speaking about sexuality } & 87\end{array}$

4.1 Introduction $\quad 87$

4.2 Data collection and sample 89

4.3 Procedure of analysis 90

4.4 Results 91

4.4.1 Delay 91

4.4.2 Avoidance 98

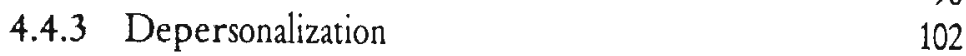

4.4.4 Tuning 103

$\begin{array}{ll}4.5 & \text { Discussion and conclusion } \\ \end{array}$

References

$\begin{array}{ll}\text { Summary } & 122\end{array}$

$\begin{array}{ll}\text { Samenvatting } & 128\end{array}$

Appendix A: Transcription symbols 134

Appendix B: Dutch transcriptions 135

$\begin{array}{ll}\text { Curriculum vitae } & 150\end{array}$ 


\section{Acknowledgements}

No piece of scholarly work is written in isolation and this thesis is no exception. In acknowledging the generosity of others and the contributions they have made to this work, I begin with the patients and gynaecologists who granted me permission to study their interactions. These data form the foundation upon which this dissertation rests.

Data, while essential, are only a beginning. For intellectual inspiration I owe thanks to my supervisors. Gerjo Kok offered me the freedom to choose for a rather different research method than he was used to. His constructive comments and the confidence he communicated in my capacities were very stimulating. So was Guy Widdershoven's enthusiasm throughout the project for the search for interactional patterns as well as his capacity to spot illogical arguments in my papers. Patricia Mullen provided thoughtful and specific comments on the various drafts of this dissertation and was most generous in her encouragement to specialize in qualitative research.

Intellectual inspiration also came from Pauline Tomlow, my roommate and the initiator of the research project, who was always willing to give her comments and who provided great inspiration for my work by her suggestions on how to consider the data from the perspective of women's studies; from Klasien Horstman with whom the collaboration in teaching and writing on women's studies subjects enlarged and clarified my perceptions and increased my confidence; and from Hanneke Houtkoop whose boundless enthusiasm for my data and suggestions on the use of conversation analysis have been very encouraging. Thank you all.

Various people have been helpful in more practical ways. I am grateful to Maas Jan Heineman for introducing me into the gynaecological field; to Manon van den Boorn, for the many hours she spend typing the tapes of the consultations and interviews; to Bob Wilkinson for his detailed correction of my English, to Ger Houben for his help with editing the dissertation and to Louk Peters and Joop Weijts for checking the final draft for typing errors. My colleagues of the Department of Health Education deserve a special thanks, as they offered me a very pleasant surrounding to conduct a research in.

Finally, I am indebted to all who lent support along the way, my friends, my sister and brother and especially my parents, for words of comfort, distraction and belief in this thesis. 
viii 


\section{Chapter 1}

\section{General overview}

\subsection{Introduction}

The importance of increasing patient participation during the phases of problem definition, diagnosis and advice-giving in medical interviews has been well established. Up to now, however, little is known about how patients exactly participate in medical interviews and what are the precise effects of patients' initiatives on the course of the interaction between practitioners and patients.

This thesis examines the ways in which participants in gynaecological consultations communicate about the questions, understandings and concerns that patients bring to the fore. More specifically, we look at how patients express their needs for information, and how they present their concerns regarding two culturally sensitive issues which play an important role in the gynaecological setting, i.e., malignancy and sexuality. Subsequently, we examine how physicians react to these patient initiatives and what in turn the patient reactions are. In other words, we study interactional patterns following patient initiatives in gynaecological consultations. This research project has the character of a descriptive pilot study. Its main goal is to recognize interactional patterns and to generate hypotheses which can be tested in a more representative sample of gynaecologists and patients.

Audiotapes of 32 gynaecological consultations have been transcribed and analysed using concepts of conversation analysis, a research method which provides a systematic approach to the study of talk in its own right. Our criteria to assess the effectiveness of the interactional patterns that we have observed are based on the theoretical framework underlying the Dutch phenomenon of 'vrouwenhulpverlening': health care which focuses on encouraging women's autonomy by defining, diagnosing and treating complaints from an integral perspective and by reducing the power-imbalance between client and practitioner. 
In this overview, we first argue the necessity of patient participation in medical interviews and we introduce the reader to the problems female patients face with regard to patient participation in medical interviews. After an illustration of some typical aspects of interactions in gynaecological settings, we describe the theoretical perspective and procedures of 'vrouwenbulpverlening' concerning patient involvement in care. Then, the initial research questions are introduced. This is followed by a description of the method of conversation analysis and the sample of physicians, patients and medical exchanges analysed in this thesis. Subsequently, we provide the main results of the three separate studies that have been conducted for this research project. These studies address interactional patterns following: patients' requests for information (reported in chapter 2), patients' presentation of concerns regarding malignancy (chapter 3) and patients' presentation of problems relating to sexuality (chapter 4). Finally, we discuss the results in the light of theory on patient participation in medical interviews and of theory on 'vrouwenbulpverlening', and we provide recommendations for future research and for practice.

\subsection{Patient participation in medical interviews}

Communication between patients and physicians is currently a significant topic in medical training programmes and in research on clinical practice. For a long time, the literature has mainly advocated an adequate transmission of information by physicians (Freemon et al., 1971; Korsch \& Negrete, 1972; Bertakis, 1977; Stiles et al., 1979; Comstock et al., 1982; Ley, 1982; 1983). This was because non-compliance, one of the major problems health care faces, was principally viewed as a failure of the physician to persuade the patient of the benefits of treatment. However, more recently special emphasis has been put on the clinical significance of attending to patients' definitions of their problems, their goals and expectations for outcome, and their requests for information, which may all reflect patients' understandings of their illnesses (Lazare and Eisenthal, 1977; Lipkin et al., 1984; Mishler, 1984; Cassell, 1985a, 1985b; Brody, 1987; Charon, 1986; 1989; Kleinman, 1988). The underlying theoretical perspective is that parients' perceptions of illness, prevention and treatment are primary forces in their behaviour and that patients' perceptions may differ substantially from those of their providers. During medical consultations, negotiation about physicians' and patients' 'explanatory models' (Kleinman, 1980) is necessary in order to provide effective care. 
Viewing patient-provider interaction from this perspective and the programmatic statements which have been derived from it have gained empirical support from correlational studies examining the effects of doctor-patient communication on outcomes, such as patient satisfaction, compliance, reduction of concern and symptom reduction (for excellent reviews see: DiMatteo \& DiNicola, 1982; Pendleton, 1983; Mullen et al., 1985; Meeuwesen, 1988; Hall et al., 1988a, 1988b; Roter et al., 1988; Roter, 1989; Tones et al., 1990; Joos \& Hickam, 1990; Bensing, 1991). A first factor which has been shown to have a positive influence on patient outcomes is the degree of patient exposition, patients' statements about their illnesses in their own words during medical consultations. Stewart (1984) found that patients expressing thoughts, feelings and expectations during consultations were more likely to be satisfied and compliant 10 days later than those who did not or who were not encouraged to do so by their physician. Moreover, patients' concerns about their symptoms decreased more if they had expressed them than if they had not (Hernbest \& Stewart, 1990). Putnam et al. (1985) found that the frequency of patient exposition during the medical history was correlated with patient satisfaction, although not with compliance. In a subsequent study by Orth et al. (1987), patient exposition during the medical history predicted reductions in the blood pressure of hypertensive patients two weeks later, although again not their medication compliance. Winefield \& Murrell (1991) found greater patient satisfaction with consultations where patients had provided more information about their experiences and attitudes, in response to doctor's advice. Frankel \& Beckman (1989) observed a tendency among physicians to interrupt patients after the first stated concern and to start early data gathering and hypothesis testing. This premature interruption of patient concerns was related to non-adherence.

A second factor which encourages the success of the communication process is patient question asking. As Garfinkel (1964) and Cicourel (1964) have pointed out, it is very difficult to communicate without making assumptions about what people know. Therefore, patients who ask questions can save their doctors from the laborious task of guessing what their patients would not understand. Patients who ask more questions appear to be more likely to obtain better information than those who do not ask questions (Svarstad, 1974; Tuckett et al., 1985). Several intervention studies have revealed that patients who are trained to be more assertive in putting questions to the physician have higher appointment-keeping ratios (Roter, 1977) and better functional status and physiologic outcomes, such as blood glucose and blood pressure readings, than those who do not receive this 
training (Greenfield et al., 1985; Greenfield et al., 1988).

Despite these benefits, the literature on patient participation suggests that both patients and physicians display a reticence for active patient involvement in medical interviews. Several experimental studies have shown that patients ask few questions and make few attempts to make explicit their viewpoints (Roter, 1977, 1984; Boreham \& Gibson, 1978; Greenfield et al., 1985; Tabak, 1988; Beisecker \& Beisecker, 1990). Stimson and Webb (1975) conclude in their ethnographic analysis that patients rarely give open expression to feelings of disagreement or dissatisfaction but may mask them behind mumbled comments which are barely audible. Conversation analysis research has demonstrated that patients' infrequent questions to doctors are often marked by speech disturbances, by which patients seem to display a dispreference for self-initiated queries (West, 1984; Frankel, 1990). Some researchers have hypothesized that asking direct questions is too threatening for patients (West, 1984; Greenfield et al., 1985), that patients lack the communicative skills to formulate in a direct way what they want (Hughes, 1982; Tuckett et al., 1985), and that they are rather reluctant to display their medical knowledge, due to a ritual respect towards the doctor (Ten Have, 1991). Physicians, as several observational studies have revealed, do little to encourage patients to present their views and quite often actively inhibit them from doing so or evade responding to what patients say (Korsch et al., 1968; Tuckett et al., 1985). Studies focusing on the structure of discourse have demonstrated how patjents' efforts to introduce their concerns and understandings are typically interrupted or disregarded. Patients' efforts are followed by actions, such as repetitions or reformulations of the original question, which reinstate the physician's agenda (Frankel, 1984; Treichler et al., 1984; West, 1984; Davis, 1988; Clark \& Mishler, 1992). In Mishler's (1984) analysis, physicians use the 'voice of medicine', which expresses the scientific attitude and insists on technical interests, suppressing patients' 'voice of lifeworld', which represents their biographical and real-world concerns.

These findings of patients' restraint and physicians' unwillingness to take into account patients' information and questions reflect a highly documented phenomenon in medical sociology: the power asymmetry between patients as laypersons and physicians as experts. Studies of doctorpatient relationships uniformly describe an asymmetry of knowledge and authority that allows doctors to disseminate medical expertise against and at the expense of lay forms of understanding (see for useful reviews: Mishler, 1984; West, 1984; Anspach, 1988; Davis, 1988; Wolinsky, 1988). This hierarchy of domination and subordination is produced and reproduced by 
both participants of medical interactions: they jointly maintain the 'ceremonial order of the clinic' (cf. Strong, 1979), i.e., they routinely behave according to tacit notions about what behaviours fit and what do not fit with the roles of patient and doctor respectively. Several authors have stressed the constitutive role of power and domination in medical interaction (Hughes, 1982; Ten Have, 1987; Maseide, 1991). They argue that it enables the doctor to act as situationally and institutionally competent. Such competence is often expected and demanded by patients and it is legally and professionally prescribed. According to this viewpoint, the impact of power is effective to the extent that doctor and patient share a system of knowledge and assumptions that facilitates the provision of relatively conflict-free interaction. Other authors, however, have criticized the distorted and undemocratic quality of the interaction resulting from professional power and they have pointed out that it is detrimental to the provision of adequate health care (Cicourel, 1983; Fisher and Todd, 1983; West, 1984; Davis, 1988; Fisher and Groce, 1990).

To conclude, it is now widely agreed that patient involvement in medical interviews is very important with respect to patient satisfaction, patient compliance and patient health outcomes. When patients do not have the opportunity to express fully their concerns, expectations and questions and when their understandings of the cause of their complaints and the benefits and drawbacks of treatment approaches are not taken into account, this may result in fragmented or inadequate diagnosis and in advice that does not 'fit' the particular person. However, despite these advantages of patient involvement in care, the literature has indicated that patients as well as physicians are not very supportive regarding an active patient contribution during medical consultations. In this way, the power imbalance between patients as laypersons and physicians as experts has, at the microlevel of medical discourse, detrimental consequences for the effectiveness of the health care provided.

\subsection{Gender issues in patient participation in medical con- versations}

Several studies have investigated the influence of patient gender on communication in the medical visit. A result which has been frequently found is that female patients ask more questions in general and ask more questions following the doctor's explanation than male patients (Wallen et al., 1979; Pendleton \& Bochner, 1980; Roter, 1991). Another salient finding is 
that women patients' contributions in medical interviews are more often disregarded than those of men. Tuckett et al. (1985) found that women were twice as likely as men to find themselves in a consultation in which their ideas were evaded. West's (1984) analysis indicated a tendency toward more frequent interruption of female patients. Further, Fisher and Groce (1990) showed that doctors rejected the accounts that women patients provided twice as often as men's accounts. Qualitative studies focusing on the communication between male physicians and female patients have found that the concerns women brought to the fore were left unacknowledged (Todd, 1984, 1989; Fisher, 1986; Davis, 1988; Porter 1990) and that physicians were not very supportive regarding women's frequent questionasking, in the sense that medical responses to women who asked questions were very poor and that women who asked many questions were likely to be labelled as 'difficult' or 'neurotic' by physicians (Hart, 1977; Porter \& Macintyre, 1989; Porter, 1990). Davis (1988) showed how the female patients in her sample did not always accept the way in which doctors treated their problems, but engaged in numerous subtle and less subtle power practices in order to exercise some control over how their problems were being defined, diagnosed and treated.

In the samples of the aforementioned studies the majority or all of the physicians were male. Few investigations have varied both patient gender and physician gender. The study by Roter et al. (1991), based on the largest sample of female physicians reported in a communication study, has shown that female physicians conduct longer medical visits and that they talk more, especially during the history part of the visit, than their male colleagues. Same-sex dyads tended to have longer visits than opposite-sex dyads. The longest visits were between female patients and female physicians and the shortest between female patients and male physicians. Compared with male physicians, female physicians engaged in more positive talk, partnership-building, question-asking and information-giving. Further, patients, both women and men, talk more during the medical visit when the physician is a woman and appear to participate more actively in the medical dialogue. They engage the physician more, ask more questions and give more information, both biomedical and psychosocial, when the physician is a woman. Very similar conclusions were drawn by Meeuwesen et al. (1991b) who found that the communication strategies of female physicians are more patient centred and that female patients especially benefit from exchanges with female physicians by longer visits.

How can we explain women patients' more active participation than men's in terms of question-asking during medical interviews? A first 
explanation for this phenomenon stems from women's social position. Women in Western society have been given responsibility for the family's health. It is likely, then, that women both attend to signs and symptoms of illness more readily than men (cf. Gijsbers-van Wijk \& Van Vliet, 1989) and discuss them with other people, especially women, more frequently. They are therefore particularly likely to arrive at the doctor's surgery with well thought-out views on the nature of their problem and its treatment (Tuckett et al., 1985). A second explanation for women patients' more active participation in medical discourse, which does not contradict the first one, draws on sex differences in conversational styles. According to Maltz and Borker (1982), men and women live in different 'sexual subcultures', which are reflected in their language. Boys and girls learn the conversational style of their sexual subculture during youth in same-sex peer groups (cf. Goodwin \& Goodwin, 1987). Women tend to use a more expressive conversational style which focuses on making connections and reinforcing intimacy, whereas men use a more instrumental conversational style to protect their independence and negotiate -or enforce- status (Gilligan, 1982; Tannen, 1990). Thus, it is possible that asking the doctor questions has a different meaning for women and men. A female patient may, unconsciously, consider asking questions as a reinforcement of the bond between her and the doctor, while male patients may interpret asking questions as a behaviour by which one frames oneself as uninformed and inferior in status. This difference in meaning may result in a higher number of questions from female patients.

Why are contributions of female patients more easily disregarded by (male) physicians than those of male patients in medical interviews? A first explanation draws on professional power, which, as we have described, allows doctors to disseminate medical expertise against and at the expense of lay forms of understanding (Mishler, 1984; Cassell, 1985a, 1985b; Kleinman, 1988). This may have negative consequences for female patients in particular, as medical training programmes largely fail to provide knowledge about the influence of women's social position and socialization on the incidence, experience and expression of health problems (cf. Roberts, 1985; Kjervik \& Martinson, 1986; McPherson, 1987; Nicolai, 1992b; Roberts, 1992). Due to this lack of knowledge, physicians may easily label the information women bring to the fore as 'trivial', 'troublesome' and irrelevant for diagnosis and treatment (cf. Stimson, 1976; Roberts, 1985). A second explanation for the greater disregard of women patients' participation is the power imbalance based on gender. In the empirical studies mentioned above, the majority of the physicians were male. The literature 
has shown that the sex difference in conversational styles is also apparent in medical interaction: women patients tend to express their health problems in contextual experiences whereas men tend to report their symptoms (cf. Wodak, 1981; Davis, 1988; Meeuwesen, 1988; Meeuwesen et al., 1991b) and female physicians use a communication style (more expressive, stronger interpersonal orientations) which differs from that of their male colleagues (more reserved, less empathetic). Thus, within the female patient-male physician dyad we may expect a 'clash of conversational styles'. This clash has negative results for women due to the power difference between males and females.

In conclusion, women are more participative than men in medical consultations, probably because of their expertise as caregivers and their more expressive conversational style. However, women patients' contributions are twice as often negated by (male) physicians than those of men. This seems related to structures of domination based on both professional power and gendered power.

\subsection{Characteristics of interaction in gynaecological consultations}

In the Netherlands the gynaecological setting typically involves a female patient and a male physician: of all 732 gynaecologists in the Netherlands in 1989, only 13 percent was female (Sociaal Cultureel Planburo, 1991). Thus, based on the findings of the aforementioned studies, we may expect that interactions in gynaecological settings are particularly prone to discouragement and negation of patients' contributions. Surprisingly, however, few studies have examined the actual interaction in this particular setting. Almost all Dutch research on medical interactions has been conducted in primary care settings (Thomassen, 1986; Ten Have, 1987; Meeuwesen, 1988; Davis, 1988). The few U.S. studies examining gynaecological interviews have concentrated on ways that gynaecologists and their patients reach decisions and how these discourses reflect power asymmetries (Fisher \& Todd, 1983; Fisher, 1986; Todd, 1989).

The gynaecological setting can generally be considered as a rather stressful situation. First, there is evidence that gynaecological consultations invoke patient anxiety. Webb (1986) has shown that women are particularly sensitive about disorders of their reproductive systems. Anxiety levels in a group of women who were referred to a gynaecology clinic were significantly greater than in samples of women of corresponding age-groups who 
were referred to other specialists (Salter, 1985). Several studies have revealed that especially the vaginal examination increases patient anxiety (Meyboomde Jong, 1981; Areskog \& Ruusuvaara, 1983; Joustra \& De Vries, 1983). Aspects that contribute to this anxiety are fear of pain, fear of having deviant genitals, fear of a diagnosis of malignancy, and fear of having to show one's genitals, in an unpowerful position, to a male physician (cf. Van Lunsen, 1986; Kleiverda, 1991). A second aspect which complicates the interaction in the gynaecological setting is the topic of conversation: female reproduction and sexuality (Wijma \& Areskog-Wijma, 1987). Survey research has shown that, especially in male-female configurations, both physicians and patients show diffidence when discussing issues relating to sexuality and lack an adequate language to address these issues (Frenken \& Van Tol, 1987; Frenken et al., 1988). A survey by Haar et al. (1977) among gynaecological patients found that almost half of them expressed discontent with their gynaecologist's understanding of women's psychological and sexual problems. In the surveys by Petravage et al. (1979) and Joustra \& De Vries (1983) $16 \%$ of the women indicated that they did not want to discuss emotional or sexual problems with their gynaecologists. In half of the cases the nature of the topic restrained them from talking about these problems; in the other half restraint was due to the physician's personality and attitudes.

Thus, the typical configuration of the gynaecological consultation, the female patient - male physician dyad, in combination with its medical domain, the pelvic floor, makes it a setting in which structures of domination and subordination based on professional power and gendered power are particularly evident.

\section{5 'Vrouwenhulpverlening'}

'Vrouwenbulpverlening' is a product of the feminist movement which arose in the Western world at the beginning of the seventies. Women accused the existing health care system of not meeting women's needs and of being harmful for women's health and well-being. In the Netherlands, during the late seventies this fundamental critique resulted in the development of all kinds of autonomous health care initiatives, such as women's health centres, women's therapy centres and self-help groups with as binding element a complaint (e.g., post partum depression, breast cancer, gynaecological cancers, eating disorders), problem area (DES, sexual violence) or stage of life (menopause). The perspectives and methods which were 
developed within this new type of health care were termed 'vrouwenbulpverlening'. Since the eighties the Dutch government has required integration of 'vrouwenbulpverlening' in the existing health care system. At this moment, this process has partly taken place, especially within ambulatory mental health care (Nicolai, 1992a). The degree of integration in regular somatic health care is still very low (Adviesgroep Vrouwenhulpverlening, 1991).

Within 'vrouwenhulpverlening' the origin of women's complaints and problems is related to their social position. All women, despite differences in class, age, sexual preference, ethnic background or religion, are confronted by the power difference between the sexes (Nicolai, 1992b). This power difference has a very subtle character which is not so much apparent in behaviour, but in people's perceptions, cognitions and preferences. It has the nature of 'the power of self-evidence' (Komter, 1985). Besides this form of power, we find in relations that the borders of what is acceptable physically and sexually are often crossed, as many women are bartered and/or sexually abused by their partners (Römkens, 1989). Another condition in the lives of women is domestic work. Despite the fact that men increasingly participate in domestic work, the major part is still done by women, even if they have paid jobs (Hochschild, 1990). Domestic work has low social status; it is socially invisible. In a society in which acting in public is considered as an important part of one's identity, women who do no work outside the home are seen as 'only' housewives, with the consequent negative effect on self-esteem. Social disdain, entailing almost a taboo on talking about domestic work, implies that one has to deny a large part of one's life and activities. This will also influence women's self-esteem (Eisner \& Wright, 1986; Brown Trevis, 1988). There is evidence that low self-esteem affects the development of psychosomatic complaints (cf. Cochrane \& Stopes Roe, 1983; Krause, 1984). This may explain why, in the Netherlands, general practitioners diagnose one and a half to three times as many psychosomatic complaints among women as among men (Van der Velden et al., 1991, cited in Meeuwesen et al., 1991a). These complaints include anxiety, acute stress, feelings of depression, headache, insomnia, phobia and hyperventilation. For women who are working outside the home and who have children domestic work is something extra to their normal working hours. Many women in this position complain about tiredness, fatigue or exhaustion (Mcllwaine et al. 1989; Popay, 1992; Nicolai, 1992b). A consequence of women's domestic role is that they are expected to give a constant outpouring of emotional and practical support. They absorb the tensions and problems, and provide support for husband, 
children, grandchildren, elderly relatives, friends and neighbours. As many women live in circumstances in which there is a lack of care for themselves, they may develop physical and emotional stress when the appeal on their resources becomes too high (Gove, 1984).

Besides women's social position, another factor which is related within 'vrouwenbulpverlening' to the origin of complaints is women's socialization. Nicolai (1992b), a Dutch psychiatrist and innovator of mental health care, draws on Kohut's theory of the self $(1974,1977)$, which emphasizes the importance of developing a coherent self (the subjective experience of who one is and how one feels about that) through a continuous process of reflection with others during youth. Kohut sees maintenance of a coherent self as a basic human need. The reflection which girls receive from parents and attendants differs considerably from that of boys. Girls get appreciation for their relational and idealistic capacities, while boys are reinforced for their intelligence, independence and assertiveness (Scanzoni, 1975; Baker Miller, 1976; Flax, 1990). Thus, this reflection is coloured by the appreciation of femininity and masculinity in society. As during women's development, certain characteristics are systematically reflected and others are not, many women develop an 'adapted self' and have to push large parts of their own self (e.g., anger, competition, ambition) away. Nicolai (1992b) states that many problems and complaints of women therefore have to do with an internalization of a socially disdained self, and that those complaints or problems can be considered as strategies to overcome this social lack of reflection mediated by the family in order to reach a coherent self. Of course, women's complaints do not arise only through this context of their social position and socialization, but they are definitely coloured and formed through these conditions.

The dominant criterion of 'vrouwenhulpverlening' to assess the communication in medical interviews is whether it helps women to take more control over their health, as part of taking more control over their lives. This implies that 'vrouwenhulpverlening' promotes the objectives that practitioners:

- take seriously a patient's definition of her problems throughout the process of care;

- respect a patient's lay knowledge, e.g. about potential causes of her complaint or about the type of solutions that are adequate in her situation; - relate, where relevant, a patient's social position and socialization to the diagnosis and treatment of her problems;

- tell a patient in advance what is to be expected in any sort of examination or treatment situation; 
- seek to inform a patient sufficiently to make competent choices about alternative plans for treatment or services (cf. Van Mens-Verhulst, 1988; Egtbers et al., 1991; Nicolai, 1992b).

It is our assumption that the criterion of increased control is not opposed to the criterion of effectiveness, in terms of improved satisfaction, compliance and health status, which, as we have seen, is dominant in most discussions and studies on medical communication. Stated more strongly and concisely, in our opinion, gendered care is effective and to be effective care must be gendered. Therefore, in this research we assess the communication patterns that we observe in terms of two basic criteria of 'vrouwenbulpverlening', that is, whether women's definition of their problem is taken seriously and whether their lay knowledge is respected.

\subsection{Provisional research questions}

The exploration of the literature on patient participation and gender, on the characteristics of gynaecological interaction and on the theory and methods of 'vrouwenhulpverlening' resulted in the following research questions:

How do female patients present their concerns, questions and understandings in gynaecological consultations and how do male gynaecologists react to these initiatives? How would these interactional patterns be evaluated in terms of the perspectives of 'vrouwenbulpverlening'?

\subsection{Methods}

\subsubsection{The approach to data}

The usual methodological approach in studies focusing on patient participation has been to develop physician and patient profiles based on frequencies of behaviour and to correlate these profiles with available information on outcomes of the encounter (Inui \& Carter, 1985; Waitzkin, 1990). Most studies merely count the frequency of utterances reflecting specific content or process rather than analysing the sequence and flow of communication (Joos \& Hickam, 1990). Due to these studies' correlational designs, communication 'gaps' are always defined in terms of a shortage of certain behaviours of the individual participants, for example, the less 
patient exposition, the lower compliance rates. Because these studies have generally ignored the sequential organization of utterances, they do not provide insight into what physician behaviour encourages or impedes patient exposition or into what patient behaviour stimulates or impedes eliciting physicians' attention to their concerns. In sum, very little is said about the various forms of mutual participation that affect the course and direction of care. In this way these studies are of limited use in developing solutions to problems in medical interviews.

In this thesis, we draw partly upon methods from conversation analysis, which provides a systematic approach to the study of talk as a topic in its own right. Conversation analysis is concerned with the social organization of conversational interaction. It takes as its starting point the ethnomethodological principle that social order is not something 'out there', but rather is produced by and embedded in people's conversational practices. The fundamental goal of conversation analysis research is, as Heritage \& Atkinson (1984, p. 1) put it, "the description and explication that ordinary people rely on in participating in intelligible, socially organized interaction. At its most basic, this objective is one of describing the procedures by which conversationalists produce their own behaviour and understand and deal with the behaviour of others. A basic assumption throughout is Garfinkel's (1967, p. 1) proposal that these activities - producing conduct and dealing with it - are accomplished as the accountable products of common sets of procedures". Conversation analysis research, in which rather detailed transcriptions of actual conversations are used as data for analysis, results in the formulation of the interactional procedures that conversational partners rely on when they talk with each other. For example, systematic patterns have been identified in the methods persons employ to allocate speaking turns (Sacks et al., 1974), to agree or disagree with preceding utterances (Pomerantz, 1984), to open conversations (Schegloff, 1979; Ten Have, 1987), to initiate, tell and terminate stories and jokes (Sacks, 1970; Sacks, 1974; Ryave, 1978), to accept or reject proposals (Houtkoop-Steenstra, 1987) and to organize laughter (Jefferson, 1984).

We especially made use of insights from conversation analysis in the studies described in chapter 2 (seeking information) and 4 (talking about sexuality). In these chapters we worked according to a principle of conversation analysis, that is, grounding one's arguments with detailed transcriptions of naturally occurring talk, so that the reader can decide whether to agree or disagree with the arguments. However, in the study described in chapter 3 (expressing concerns) and also in parts of chapter 2, we coded conversational units in categories which were generated during the process 
of analysis. Thus, here the reader cannot exactly retrieve how the coding of the conversational units took place. A limitation of the present research is that the latter type of analysis was conducted by only one researcher. In order to overcome potential idiosyncratic analysis on the part of the researcher, it would have been better to have involved a second person in the process. For a more detailed description of the conversation analysis concepts that were used and the way in which the analyses were executed we refer to the method sections in the following chapters. In chapter 4, for instance, the method of analysis was more precise for analytic reasons.

\subsubsection{Obtaining access}

We started by approaching the chairs of two gynaecological out-patient clinics (of a university and a general hospital). Both clinics decided not to participate, arguing that recording would interrupt the relation of confidence between a patient and her gynaecologist.

After these unsuccessful attempts via formal routes, we tried the informal way. The purpose and procedures were discussed with the husband of one of our colleagues: he was a gynaecologist at a general hospital. He agreed to participate and found one of his colleagues who was also interested. After data-collection had started, this gynaecologist became rather enthusiastic about the project and he recommended some colleagues from other hospitals who might participate. This finally resulted in the participation of two more gynaecologists from a general hospital and one from a university hospital. All three hospitals were in the south of the Netherlands. The medical ethics committees of hospitals granted permission to conduct the study.

\subsubsection{Sample and data collection}

As we were interested, at the start of the project, in changes in communication patterns over time, we decided to record all patient visits concerning the complaint with which a patient first visited the out-patient clinic. All five participating gynaecologists had agreed to record the consultations of three or four patients. After a random 'new' patient had made an appointment by telephone with the secretary, she was called by the investigator, who explained the purpose of the research project (to investigate 'how gynaecologists and patients communicate and what can be improved in this communication') and asked her whether she would allow tape-recording of her consultation. Patients were told that the recordings were anonymous and that all identifying references in the transcripts would be left out. It 
was emphasized that they could at any time exempt themselves from recording and that a decision not to participate would not affect treatment. Further, patients were asked to reserve time for an interview with the investigator directly after each encounter. Of all patients who were approached two refused, one because she did not have time for the interview; the other because she found her complaint too private to be audiotaped.

In total, 32 consultations were recorded in three gynaecological outpatient clinics. Five gynaecologists and 15 patients participated in the study. Table 1.1 presents the distribution of visits among participants and the type of complaint(s) of the patients. The distribution of the consultations over the physicians is based on coincidence. Of each physician, except physician $\mathrm{E}$, three or four 'new' patients were followed. Physician E decided to cease involvement in the project, because he was too busy. Physician B had considerably more follow-up consultations. It is difficult to say whether this is because his patients had different complaints or whether he just asked patients back more frequently.

The patients in this sample ranged in age from 18 to 49 years, with a mean age of 34 years, and belonged to the lower $(n=10)$ and middle $(n=5)$ socio-economic classes. They were all white and lived in the south of the Netherlands. All women were referred to the gynaecological out-patient clinic by their general practitioner. Most of them knew the content of their referral letter. In three consultations the patients were accompanied by their husband. Two patients had known their physician from earlier visits concerning other gynaecological or obstetrical complaints, while the others were meeting the gynaecologist for the first time. The mean time per visit was ten minutes. The participating doctors were all male and ranged in age from 37 to 50 years. They all shared some progressive principles of comprehensive medicine, e.g., the importance of providing clear and extensive medical information to patients in order to reassure them and to let them participate in decision-making. Their agreement to participation in the study might mean that they were especially willing to take a critical look at their own behaviour in consultations with patients. Therefore, they are probably more idealistic and actively concerned about providing optimal health care, at least from a communication standpoint, than the average gynaecologist. Thus, it is clear that the present sample is by no means representative of the gynaecological setting in the Netherlands.

The consultations were taped, without the attendance of the researcher, with a small recorder and a separate microphone. In most cases the conversation during physical examination, which took place in a 
Table 1.1 Distribution of visits among participants and types of complaints.

\begin{tabular}{|c|c|c|c|c|}
\hline physician & patient & complaint(s) & encounters & total \\
\hline \multirow{4}{*}{ A } & 1 & abdominal pain & 1 & \multirow{4}{*}{5} \\
\hline & 2 & not getting pregnant & 1 & \\
\hline & 3 & abdominal pain & 1 & \\
\hline & 4 & abdominal pain, back pain & 2 & \\
\hline \multirow{4}{*}{ B } & 5 & $\begin{array}{l}\text { urinary loss, not getting preg- } \\
\text { nant }\end{array}$ & 4 & \multirow{4}{*}{14} \\
\hline & 6 & $\begin{array}{l}\text { heavy and painful menstru- } \\
\text { ation, fatigue, intermenstrual } \\
\text { blood loss }\end{array}$ & 3 & \\
\hline & 7 & intermenstrual blood loss & 5 & \\
\hline & 8 & abdominal pain & 2 & \\
\hline \multirow{3}{*}{$\mathrm{C}$} & 9 & $\begin{array}{l}\text { abdominal pain, urinary loss, } \\
\text { pain during sexual intercourse }\end{array}$ & 2 & \multirow{3}{*}{6} \\
\hline & 10 & $\begin{array}{l}\text { irregular menstruations, no } \\
\text { feeling for sexual intercourse }\end{array}$ & 2 & \\
\hline & 11 & postmenopausal blood loss & 2 & \\
\hline \multirow{3}{*}{$\mathrm{D}$} & 12 & abdominal pain & 2 & \multirow{3}{*}{6} \\
\hline & 13 & $\begin{array}{l}\text { heavy and painful menstru- } \\
\text { ation, no feeling for sexual } \\
\text { intercourse }\end{array}$ & 2 & \\
\hline & 14 & absence of menstruation & 2 & \\
\hline $\mathrm{E}$ & 15 & abdominal pain & 1 & 1 \\
\hline
\end{tabular}


(partly) separate room, was also recorded. The literature does not indicate much about the effect of the presence of recorders on the course of interviews, probably because, for methodological reasons, this is very difficult to examine. We assume, however, that the influence of the audiorecorder on our interactions was small. A first argument for this assumption is that all patients and physicians indicated, during the subsequent interviews, that they forgot the presence of the audiorecorder after a few minutes. Second, the participants (and the researchers!) did not know what aspects of the communication we were especially interested in, as the research questions were very globally formulated at that phase of the research project. This reduced the risk of socially desirable behaviour. Finally, we think that the organization of a medical interview is a rather difficult endeavour, which leaves little room for the participants to think about the presence of an audiorecorder.

As the data are based solely on a record of the audible events which took place in the consultations, we have only paid attention to verbal communicative acts. Clearly doctors and patients can also share information by means of gestures, posture, eye contact, facial expression and other visible, but not audible signs: the study is unable to shed any light on such exchanges.

\subsubsection{Transcription and translation}

Attention to fine details of conversation requires a detailed transcription of the data. The transcription system used here takes into account hesitations, emphasis and overlapping talk. For analytical reasons the transcriptions in study 3 (chapter 4) are more precise, for example pauses are also transcribed, than those in study 1 and 2 (chapters 2 and 3 ). The transcription symbols are explained in Appendix A.

While the analysis to be presented here is based on Dutch conversations, the data have been translated into English. Translations were made following two criteria. First, the sense of the original text should be clear, and second, the translation should keep as close as possible to the Dutch text. These two criteria are difficult to meet at the same time if the objective is to present an English translation which looks like colloquial English conversation. On several occasions we decided to choose a relatively poor translation in order to retain certain characteristics of the Dutch conversations essential for the analysis.

Analysis was based on the Dutch transcriptions of the recorded medical interviews. Only those excerpts which were selected to be presented in the final text were translated into English. For the original 
Dutch transcriptions of these excerpts, the reader is referred to Appendix $B$. In the transcripts $G$ refers to gynaecologists and $P$ to patients.

\subsubsection{The selection of topics: specifying the research questions}

After each consultation a separate interview was held with both the patient and the gynaecologist. During this interview, the recorded consultation was replayed. Meanwhile, the investigator, who was then hearing the medical exchange for the first time, made notes about salient moments in the interaction. First, patients and physicians were encouraged to express their perceptions and evaluations of the consultations. Then, more specific questions were asked concerning specific instances in the interaction. Our original aim was to use these three sources, the consultation and the participants' separate stories about it, to find out whether potential communication problems in the consultations might be related to a difference in knowledge, expectations or meaning between the doctors and patients. However, in the course of the research process, with conversation analysis becoming increasingly the primary research perspective, we decided not to conduct a systematic analysis of the interview data. Conversation analysis focuses on observable conversational events, and does not include the predispositions or motives that may be in the minds of those involved.

Nevertheless, the interview data had an important function in revealing what the relevant topics in patients' and physicians' experiences were. An interesting observation was that, when the gynaecologists were asked what they found problematic aspects of consultations, they complained that patients disrupted the structure of their protocol by their question-asking. Although they indicated that parients were not to blame for this behaviour, the interviews revealed that this behaviour often made them slightly irritated. Another finding from the interviews was that almost all patients indicated on their own initiative that they had been very anxious before their first appointment with the gynaecologist. They were worried about having a malignancy and they perceived the referral to the gynaecologist by the general practitioner as proof of a serious problem. Finally, a consistently recurring phenomenon in the interviews was that both physicians and patients emphasized the problematic character of discussing sexual problems. These observations guided the choice of aspects of gynaecological interaction on which we focused our analyses, namely:

- the ways in which patients seek for information and how these actions are responded to (study 1);

- the way participants in gynaecological consultations deal with patients' fear that their complaint is caused by cancer (study 2); 
- the ways in which patients and physicians deal with the topic of sexuality (study 3).

Therefore, in the course of the research project, the research questions were specified as follows:

How do female patients in gymaecological consultations present their needs for information, and their concerns regarding malignancy and sexuality, and bow do male gynaecologists react to these patient initiatives? How would these interactional patterns be evaluated in terms of the perspectives of 'vrouwenhulpverlening??

\subsection{Results}

This overview addresses the main results of the three studies conducted; for a detailed presentation of the results the reader is referred to the chapters 2 to 4 .

\subsubsection{Study 1: Seeking information}

The patients in our data generally tried to get information by asking direct questions. Most of these questions were formulated in specific proposal form ("Is constipation a side effect?"). We seldom identified general questions ("What kind of side effects does it bave?"). The patients were especially active in asking questions about treatment, especially about the nature and procedures of a treatment that was advised and about its impact on their lives. Of all 117 direct questions in the data $98(84 \%)$ addressed aspects of treatment. Topics such as causal aspects of complaints, results of examinations and the working of the reproductive organs were less frequently the subject of information-seeking.

Besides these direct questions, we observed indirect verbal behaviours that were meant to gain information. Patients tried to elicit new information, elucidation or confirmation from doctors by means of story-telling finished with a lay conclusion ("... So I thought that these frequent and severe menstrual bleedings might be a result of my working in a mushroom farm "), interrogative utterances which are expressed at prior 'news' given by the physician ("Ob?", "Really?"), motivations to explain why an earlier question had been asked, repetitions of physicians' statements (G: "A Pap-smear is 
not necessary anymore". P: "So a Pap-smear is not necessary anymore?") and tag-questions ("Ob, well then we shouldn't make anything of $i t$, should we?").

Especially causal aspects of complaints, results of examinations and the working of the reproductive organs were often addressed by means of indirect strategies. Of the information-seeking devices regarding the latter issues, $58 \%$ were indirect strategies, whereas only $30 \%$ of the requests for information regarding treatment were indirect.

In general, patients' initiatives were successful in eliciting information from the physicians in the study sample. All direct requests for information were answered and also the subtle, more indirect requests for information generally appeared to be successful in alerting the physician to the need for (more) information or confirmation. Only the indirect requests for information regarding the causes of complaints that were formulated as a story with a conclusion - mostly a lay theory on the cause of the trouble - ran the risk of being unanswered by the physicians. These indirect formulations were easily circumvented because, in contrast to direct questions, they do not create a strong expectation that an answer will follow (Churchill, 1978). Circumvention especially occurred when the patient presented such a lay-theory before the physician had given a diagnosis or after the patient had been told that no gynaecological deviances were found. Patients always reacted to physicians' negation of their lay theories with new indirect efforts to make their point, which were generally negated again.

\subsubsection{Study 2: Expressing concerns regarding malignancy}

The second study demonstrated that the patients in our sample always covertly expressed their concerns about having a malignancy. We observed women alluding to the possibility of having cancer ("I always think that there is something in my belly which is no good"), mentioning a friend or a relative with cancer ("But I must say that I also, in the case of my eldest sister. Well, that remains on my mind. They have everything er removed. Because er of cancer ") and/or negotiating for more drastic medical intervention than the physician had proposed ("But er, to only view what it is (by a laparoscopy) that seems absurd to me. I'm inclined to say: just open it and get it out if there is something which shouldn't be there").

Physicians had three ways of reacting to patients' indirect anxiety expressions. First, their commonest reaction was to provide immediate reassurance, in the form of information-giving, combined with rhetorical strategies such as mitigators (words like 'just', 'quietly' and diminutives), intensifiers ('definitely nothing wrong') and the frequent use of the word 'we' combined with further plans for examination or treatment, referring 
to the joint enterprise between the doctor and the patient ("We must know more about your cervix, especially because it looked so vulnerable. So I think we should do a detailed investigation "). Mostly, the interactional pattern stopped after this reassurance, but in some instances we identified patients providing new indirect anxiety expressions regarding malignancy at a later moment in the same consultation.

Second, a very rare physician reaction in our study sample to patients' indirect anxiety expressions was exploration (e.g., "Are you afraid that something serious is the matter?"). Explorations always resulted in more overt expressions of patients' concerns ("I want to know what it is, so er, that $I$, just that it is not malignant, because that is of course what you are concerned about at first"), which were followed by reassurances, that is, fragments of information-delivery joined with one of the rhetorical strategies described above. Then the interaction switched to another topic.

Finally, a third way of reacting to patients' indirect emotional expressions was negating them. This happened by interrupting patients and producing a counter-question on another topic ( $P$ : "But now I was a little concerned... G: "You said you bad blood loss after sexual intercourse. Did you also bave pain during intercourse?") or by providing a trivializing assessment of the patient's worry (G: "Well, you must not make things so beavy, you must have some fun in life $)^{\prime}$. After a negation, we observed patients returning to their point, again, however, indirectly. These new anxiety expression were once more negated, which again elicited indirect anxiety expressions. In this way an interactional loop was developed which finally ended up with a reassurance from the physician. The physician strategy of negating patients' indirect anxiety-expressions occurred when the patients' concerns were not 'properly' addressed from a medical point of view, as diagnosis had already revealed that 'there was nothing to be concerned about'.

\subsubsection{Study 3: Talking about sexuality}

Both the patients and the physicians in our study sample used specific procedures to introduce and further address subjects relating to sexuality. We identified four major strategies in the talk about this issue: delay, avoidance, depersonalization and tuning.

Both patients and gynaecologists tended to delay discussing issues relating to sexuality. We observed two different forms of delay. First, the topic of sexuality could be delayed. For example, patients introduced sexual problems after their 'reason-for-contact-complaint' had been discussed ( $G$ : "Shall we try those vitamin preparations, let's see bow they work". P: "But maybe it will belp too but er I really don't feel like having sex you know"). 
We also identified patients who delayed the presentation of problems relating to sexual dysfunctioning to follow-up consultations. Physicians sometimes reacted to patients' presentation of sexual problems by delaying them to a subsequent meeting, while indicating that it was necessary to know each other better before being able to engage adequately in 'that kind of topic'. Second, we observed a delay in the delivery of potentially delicate terms concerning sexual practices. Patients used 'expressive caution' through pauses and hesitations, before touching upon potentially delicate topics (P: "And (0.3) you can't stand anything, er (1.2) er no intercourse with your busband "). Likewise, doctors also used 'expressive caution' before touching upon similarly potentially delicate topics relating to the sexual behaviour of a particular patient. However, routine questions or instructions, which had a certain measure of generality were not delayed ("You never bave pain while making love?" and "Mostly you flow a little after a curettage. During that period you mustn't bave intercourse").

Another major strategy that people used when talking about sexuality in the gynaecological consultations was avoidance of delicate terms. We identified three forms of avoidance. First, the participants avoided the use of explicit terms referring to sexual activities (e.g., G: "And what does hurt then, the penetration or the event itself, or afterwards. Do you bave any cramps afterwards?") and to the female reproductive organs (G: "You've got to realize that down there not very much happened due to pregnancy"). Second, both gynaecologists as well as patients omitted delicate terms ("I can tell you that the size [of the vagina] is normal") and, third, they only referred by using pronouns ('it', 'that') to items relating to sexuality, once these had been mentioned.

The interaction between gynaecologist and patient regarding sexuality was also permeated by what we have called depersonalization: speech that loosens the link between the person and her most private actions and bodily aspects. The two principles governing the construction of depersonalized talk were nominalizing (e.g. 'the coming' instead of 'when you're coming') and the substitution of definite articles for personal pronouns before delicate organs ('the breasts' and 'the vagina' instead of 'your breasts' and 'your vagina').

We observed both speakers adopting each other's styles of speaking regarding delicate issues - a phenomenon which we have called 'tuning'. When patients delayed the delivery of more detailed descriptions of pain during sexual intercourse, physicians copied patients' devices in their responses. Patients responded to physicians' neutral, depersonalized terms by avoiding all terms referring to the reproductive organs or sexual activi- 
ties. In that way, the delicacy of the subject of sexuality was jointly produced by both participants of the gynaecological consultations.

\subsection{Discussion and conclusions}

An important finding of this thesis is that the mechanism by which patients seek information is a complex and subtle interactional process. Patients in this study sample, besides asking direct questions, used indirect patient behaviours that were intended to gain information. Moreover, by formulating their direct questions in specific proposal form, patients included their lay knowledge regarding the nature of their problem and its treatment in their questions. These findings suggest that the conception of patients as passive participants of medical interviews, which has been expressed in several experimental studies on patient-involvement (Roter, 1977; Bain, 1979; Greenfield et al., 1985; Tabak, 1988; Beisecker \& Beisecker, 1990), needs to be altered. It seems as if, due to their rigorous coding categories, these studies have overlooked the more subtle strategies patients can make use of to present their lay-knowledge and to request information. The results of this thesis correspond with those of Davis (1988) who found in her study of medical consultations between male physicians and female patients that patients made use of several subtle interactional power practices in trying to achieve their aims and that they constantly showed themselves to be knowledgeable, competent conversational partners in medical interviews.

The patients in our research were more active and direct in seeking information when aspects of treatment were the subject of discussion (especially the nature, the procedure and the practical consequences of treatment), than in the case of aetiological aspects of their complaints. Porter (1990) also found that women in gynaecological settings were more active in questioning procedural aspects of treatments, for example, how long they would be in the hospital or off work or whether they could be done as day patients, than in questioning the diagnosis or asking about treatment alternatives. An explanation for this finding is women's specific social position. In our society women are the people most responsible for the care for household and children. In the same way as women present their problems as part of their everyday life contexts (Wodak, 1981; Davis, 1988; Meeuwesen, 1988), they may also place treatment advice directly into the 'normal appearances' of everyday life. Information about how a treatment, e.g. a laparoscopy or a hysterectomy, will interfere with their social 
and family life, might be more important for women than information on any other topic, as they need it to decide how daily practical tasks can be continued as normally as possible. However, this explanation does not explain patients' relatively inarticulate speech concerning the nature and cause of their complaints. A first explanation for this phenomenon draws on the power imbalance between patients and physicians based on professional and gender inequality. Patients may perceive, unconsciously, that introducing subjects regarding aetiological factors is rather 'unsafe'. In contrast to questions about the nature, procedures and consequences of treatment, questions about the aetiology of the illness directly address the medical domain of knowledge and may challenge the physician's authority (cf. Fisher, 1986; Davis, 1988). Implicit ritual constraints, connected with asymmetrical power relations between medical experts and lays, may discourage patients from using direct formulations to solicit information regarding aetiological aspects of their complaints (cf. Ten Have, 1991). Like other subordinates, patients do not challenge those in authority directly. It is as if they have internalized the implicit rule that "in the medical setting doctors not patients are vested with the institutional authority to make diagnostic decisions" (Fisher \& Groce, 1990, p. 238). We may expect that this is valid for female patients in particular, as women tend to use a conversational style which is focused on making connections (cf. Gilligan, 1982; Maltz \& Borker, 1982; Tannen, 1990). In their communication female patients will therefore concentrate on confirming the competence of the (male) doctor. They unconsciously prefer to avoid using direct questions which may disturb the physician's domain of medical competence. Formulating indirect requests for information may be a solution in these situations.

A second explanation for patients' relatively little and inarticulate speech concerning the nature and cause of their problems is the psychological process of avoidance. Schouten (1982) has pointed out that patients are ambivalent in talking about these issues. On the one hand they wish to go into them because it could reduce their concerns; on the other they tend to repress them, because they are afraid of having their anxious suppositions affirmed. This ambivalence might result in indirect formulations of requests for information.

Our data revealed that patients' requests for information, both the direct and the indirect ones, were generally successful in eliciting (more) information or confirmation from physicians. The observations in this select group of physicians do not support the observation in research on patient participation that physicians mostly actively inhibit patients from 
presenting their views or evade responding to what patients say (Korsch et al., 1968; Tuckett et al., 1985). Nor do the results correspond with findings from studies that specifically focus on female patient-male physician conversations, which have shown that physicians were not very supportive regarding women's question-asking (Wallen et al., 1979; Porter \& Macintyre, 1989; Porter, 1990). Nevertheless, although physicians in this study sample were in general very willing to answer patients' requests for information, their client-directedness was limited. They circumvented patients' indirect requests for information regarding causal aspects of their complaints, especially when patients presented them before the physician had given a diagnosis or after the patient had been told that no gynaecological deviances were found. An explanation for this finding draws on physicians' professional power. Within the medical paradigm, physicians are taught and have internalized a strong responsibility for determining the diagnosis and aetiology of patients' complaints. They are not used to take into account patients' own perceptions of the nature and cause of their complaints (Cassell, 1985a, 1985b; Brody, 1987; Charon, 1986; Kleinman, 1988). Therefore, it is likely that they will perceive the understandings patients bring to the fore as disturbances of the medical frame, especially when they are presented at moments that do not 'fit their agenda'. In agreement with Davis (1988), we observed that patients did not accept these negations, but that they engaged in subtle power practices, such as repeating again and again their understandings about the cause of their illness, in trying to be taken seriously. This may well be the way less powerful persons pursue their case.

The patients in this study sample always presented their fear of having cancer indirectly. By introducing this issue, patients in fact started a discussion about aetiological aspects of their complaints. Therefore, we draw on the same explanations as were used to explain patients' indirect behaviour in seeking information about the nature and cause of their illnesses. First, the indirect presentation of fear of having cancer may be a result of displaying ritual respect regarding the (male) physician, stemming from structures of subordination based on professionalization and gender. After all, expressing concerns about potentially having cancer might suggest that one throws doubt upon the medical team's diagnostic capacities. Second, patients' indirect formulations might be a result of ambivalence whether or not to address the subject, based on fear of hearing unpleasant information.

The physicians' most common reaction to patients' indirect expressions of anxiety was immediately trying to reassure patients by providing 
information. Sometimes, patients' indirect expressions of fear of cancer were even completely ignored. We seldom observed the gynaecologists explore patients' anxiety expressions and therefore overt conversations about patients' fear of cancer hardly occurred. Physicians seemed to restrict reassurance to solving patients' assumed informational needs. Our observation that patients sometimes brought up new indirect anxiety expressions in the same consultation suggests that the physicians made wrong estimations of the actual patient concerns. A first explanation for physicians' limited attention for patients' concerns and their immediate switch to solutions in the form of information-delivery is related to the dominance of the medical paradigm. Many specialists have not been taught the relevance of exploring patients' (and especially women's) concerns and, as a result, do not use the communication format in which a discussion about emotional issues is possible (Lipkin et al., 1984; Cassell, 1985a, 1985b; Brody, 1987; Charon, 1986; 1989; Kleinman, 1988). Peräkylä and Silverman (1991) distinguish two communication formats in provider-client conversations: the interview format and the information-delivery format. In the interview format provider and client are respectively aligned as the questioner and the answerer, in the information-delivery format as the speaker and the recipient. Specialists are trained to use the information-delivery format. This format is far less complicated to handle for the hard-pressed physician than an interview format, as the contribution required from the patient is of a smaller scale and a similar range of issues can be covered within a shorter period of time. A second factor which might have contributed to the limited opportunity the patients in our data were given to talk overtly about their concerns and fears is gendered power. As the literature has revealed women and men tend to use different conversational styles. The expressive, contextual style of female patients will conflict with male physicians' more instrumental style (Roter et al., 1991; Meeuwesen, 1991b). This 'clash of conversational styles' may have negative results for female patients' expressions of anxiety about cancer, due to the power asymmetry between the sexes. Again, however, we found that patients did not accept the negation of their concerns but engaged in covert forms of protest, such as repeating their indirect expressions of anxiety for malignancy. Clearly, patients attempted to establish their authority and interactional rights regarding the way their problems were defined (cf. Davis, 1988).

In our sample of gynaecological consultations, issues relating to sexuality were, in a massively recurrent manner, avoided or approached very carefully. Patients copied physicians' devices and vice versa. Silverman \& Peräkylä (1990) found similar devices in their study on how potentially 
delicate issues in HIV and ADS counselling sessions were communicated. We view these interactional devices as ways of speaking to mark 'precarious' topics in interactions. The phenomenon of 'copying' each other's devices has been explained by Bergmann (forthcoming) and Silverman \& Peräkylä (1990), who have shown that once a topic is marked as delicate, this topic is turned into a matter which is in need of being formulated cautiously and discretely. Based on this reasoning we can conclude that, for the patients as well as for the physicians in our study, discussing women's reproductive organs and their sexual behaviour during gynaecological consultations was a delicate interactional activity. This corresponds with results from survey research in which patients and physicians have emphasized the problematic character of discussing sexuality in clinical discourse (Petravage et al., 1979; Joustra \& De Vries, 1983; Frenken \& Van Tol, 1987; Frenken et al., 1988). A consequence of physicians' neutral and veiled vocabulary regarding sexuality is that it underlines that sexuality is not a legitimate topic for discussion in gynaecological consultations. It may discourage women from describing in more detail their problems relating to sexuality.

The explanation for participants' veiled way of addressing issues relating to sexuality is the cultural taboo which still applies to talking about this issue, especially within male-female configurations (Wijma \& Areskog-Wijma, 1987). However, one would expect that physicians' professional socialization would have decreased their bashfulness to discuss issues relating to sexuality. Our data of this small sample of gynaecological consultations suggest that this is not true; a suggestion corresponding with the complaint regularly appearing in medical journals that gynaecologists lack sufficient training in sexology (Frenken \& Van Tol, 1987; Van Binsbergen, 1988). Whether physician gender also influenced the way sexuality was interactionally dealt with in these consultations is difficult to assess, as we could not trace any literature on gender differences in talking about sex during service-encounters. However, it seems logical to assume that female physicians, due to their familiarity with the female body, may use a vocabulary that allows them to refer more explicitly to women's sexual and reproductive activities.

In most interactional patterns that we observed the two criteria of 'vrouvenbulpverlening' underlying this research, that is, respecting women's lay knowledge and taking seriously their problems, were met. Patients' requests for information, in which they included their lay knowledge, were answered and their concerns regarding malignancy and sexuality mostly received attention. However, four patterns were identified in which these 
criteria of 'vrouwenhulpverlening' did not come out well. This was when physicians:

- disregarded patients' information about the nature and cause of their complaints;

- disregarded patients' concerns about having malignancy;

- switched immediately to information-delivery after patients' presentation of concerns about having cancer;

- used a neutral and veiled vocabulary regarding sexuality.

In these patterns we identified physicians providing 'conversational sanctions' in response to the concerns and knowledge patients raised. In this way physicians cemented their respective positions as (male) expert and (female) layperson. It is clear that these interactional patterns do not support the aim of 'vrouwenbulpverlening', i.e. helping women to take more control over their health, as part of taking more control over their life. Moreover, we may assume from the literature that the way women's concerns and knowledge are dealt with within these patterns may finally result in a decrease in patient satisfaction, compliance and even in health outcomes.

\subsection{Recommendations for future research}

This descriptive pilot study generates several questions which need further investigation. A first recommendation for further research is to conduct a comparable study among a more representative sample of gynaecologists and patients. Such a study can indicate whether the relationship that we observed between the extent of directness of patients' speech and the topic under consideration can be verified. Moreover, it can reveal whether the specific interactional patterns that we identified, in which patients' contributions run the risk of being disregarded, can be generalized. Also the influence of patient characteristics (e.g., age, socio-economic status, region), physician characteristics (age, gender, extent of training in communicative skills) and contextual factors (nature of the complaint, stage of treatment) on the course of interactional patterns needs to be taken into account. Once these interactional processes of patient involvement have been explored more thoroughly, the relationship between the interactional patterns and outcome variables, such as patient satisfaction, compliance and health outcomes could be tested.

Further, in more general medical situations, studies may be recommended in which patient and physician gender are varied. This might provide answers to questions which remained unanswered in this inquiry. 
Is indirectness typical for female patients? Is it typical for female patients to be more active and direct in questioning treatment aspects than in questioning aetiological aspects? Is it typical for women patients to talk in a veiled way about sexuality? Are female physicians more supportive regarding patients who construct their own assumptions about the aetiology of their illnesses than male physicians? Are female physicians more inclined to discuss emotional matters with patients? Is there less hiding of or delay in broaching sexual issues in same-sex consultations than in opposite-sex consultations? Answers to these questions may shed more light on the relation between power based on professionalization and power based on gender.

A final suggestion for further research is to conduct an experimental study among gynaecologists, in which one group who received a training in the principles of 'vrouwentulpverlening', is compared on outcome variables such as patient satisfaction and compliance to a group who did not receive this training. The results of the present thesis can be used for the development of the 'vrouwenhulpverlening' intervention of this experimental study.

\subsection{Recommendations for practice}

Translating the results of this study to practice should be done with caution because our corpus of data does not constitute a representative sample of gynaecologists or patients. Only five male gynaecologists were involved who had an interest in good relationships with patients. All fifteen patients participating belonged to the lower or middle socio-economic classes and lived in the south of the Netherlands. A few patients and physicians knew each other already, while others were meeting for the first time. Thus, generalizations based on our findings cannot be extended to physicians, patients or doctor-patient exchanges at large. Our analysis has demonstrated some of the ways that patients express their concerns or request for information and some of the ways physicians can react to these initiatives; it does not, by any means, encompass all of the ways that patients' initiatives are dealt with in medical encounters in general, or in gynaecology in particular. Nevertheless, we will provide some recommendations for medical practice and health education. These suggestions aim at achieving 'vrourwenbulpverlening', health care in which women's problems, their context and the knowledge women raise are respected.

One set of recommendations concentrate on improving gynaecologists' communicative skills. They could be trained to be alert to 
the indirect ways in which women can package their requests for information regarding the cause of their symptoms and their concerns regarding sensitive issues, such as malignancy and sexuality. Moreover, training programmes could focus on improving gynaecologists' skills in discussing emotional issues, such as anxiety for malignancy, and delicate issues, such as sexuality. Finally, gynaecologists could be trained in gaining more insight into the context of women's lives and in the relation between this context and women's complaints. This would, for example, imply that gynaecologists acquire knowledge and skills regarding specific 'women problems' such as sexual abuse and eating disorders, complaints which are frequently observed among gynaecological patients. This knowledge may prevent the information women, often implicitly, bring up being labelled as 'ballast', and, subsequently, being negated.

Another set of recommendations addresses the empowerment of patients. A salient finding of this thesis is that the more articulate patients are, the more they avoid the risk that their requests for information and their concerns will be circumvented or negated. Especially when aetiological aspects of their symptoms are the subject of discussion, a less reserved expression of the attention or information they wish to receive might facilitate physicians' services. Several intervention studies (Roter, 1977; Greenfield et al., 1985; Tabak, 1988) have suggested that short training sessions before medical interviews or brochures in which patient assertiveness is encouraged, can be successful in achieving the target behaviours. 


\section{Chapter 2}

\section{Seeking information ${ }^{1}$}

\section{Abstract}

The focus of interactional studies on patients' information-seeking behaviour has almost entirely been on direct question-asking. In contrast, this paper offers a systematic analysis of patients' information-seeking actions and physicians' responses. Verbatim transcripts of 32 gynaecological interviews, audiotaped in a natural situation were analysed. Drawing on methods from conversation analysis, it is shown that, besides direct questions, patients have several other ways to obtain (more) information from physicians, such as the production of topicalisers and motivations. Most information-seeking actions concern the nature or procedure of treatment and are formulated in a straightforward way. However, causal aspects of complaints are relatively often addressed via indirect requests for information. Patterns of comparable information-seeking actions and responses reveal that most information-seeking actions elicit adequate responses. Only indirect requests for information run a relatively bigh risk to result in minimal answers, especially when they are produced under specific circumstances. The paper finishes with some recommendations relevant to medical practice.

\subsection{Introduction}

For already more than two decades a more participative model for patients in clinical interaction has been advocated (Meeuwesen et al., 1991b; Bensing, 1991). Broad social factors have contributed to this interest, including higher educational levels, the rise of democratic movements such as the women's health care movement, sophistication about health matters and rising consumerism in numerous spheres of activity (Tabak, 1988). Evidence exists that a more active role of patients during medical exchanges

\footnotetext{
'Accepted for publication in: Qualitative Health Research, 1993, vol. 3.
} 
leads to better understanding of the problem and necessary treatment, often resulting in improved health care. Greenfield et al. (1985) showed that increased patient involvement resulted in fewer limitations imposed by the disease on patients' functional ability. Gynaecological out-patients who used questioning techniques could trigger the provider to list treatment alternatives, thus avoiding a hysterectomy when less invasive procedures were available (Fisher, 1986).

Studies which focus on patients' information-seeking behaviour show that patients, although they have a strong desire for information about their medical conditions (Waitzkin, 1984; Beisecker \& Beisecker, 1990), ask few questions and make few attempts to influence the interaction during the encounter with the doctor (Roter, 1977, 1984; Boreham \& Gibson, 1978; Greenfield et al., 1985; Tabak, 1988; Beisecker \& Beisecker 1990). A meta-analysis of studies on doctor-patient interaction has shown that almost $47 \%$ from patients' utterances belong to the category 'information-giving', while only $6 \%$ can be headed under the category 'information-asking' (Roter et al., 1988). Moreover, most of the few questions patients ask are presented quite hesitatingly and/or are not very successful (West, 1984; Frankel, 1990). Most of these studies operationalize information-seeking as asking direct questions. It may be doubted, however, whether asking questions is the only patient strategy to obtain information. Greenfield et al. (1985) suggest that patients can make use of alternative, more subtle, information-seeking strategies, such as joking about their uncertainties and concerns, or introducing topics attributed to others. Up to now, however, we lack studies which systematically investigate in what ways patients try to obtain information from their physicians. Consequently, we have no insight in the successfulness of different information-seeking actions in alerting physicians to the need for information. This kind of information might offer relevant suggestions for medical practice, for example on how to educate patients to ask 'better' questions.

The main goal of the present study is to examine which informationseeking actions patients use to gain information from their physicians and whether there is a correlation between the form of information-seeking actions and their content. As we are also interested in the effect of patients' information-seeking actions, we investigate the interactional sequences which follow after these actions until the moment that a topic shift takes place. This means that we analyse whether patients' information-seeking actions elicit responses from physicians, how patients react to these (non)responses, how physicians consequently react to these patient reactions, etcetera. This analysis has resulted in the identification of several 
interactional patterns, i.e., sequences of comparable information-seeking actions and responses. We conclude with an examination of the relevance of the analysis within the context of medical practice.

Gynaecological out-patient care was selected as the setting for this study because of its complicatedness from an interactional point of view. Talking about gynaecological complaints has problematic aspects for doctors as well as patients, due to the taboo which still holds on sexuality and reproduction (Petravage et al., 1979; Weiss \& Meadow, 1983; Joustra \& De Vries, 1983; Frenken \& Van Tol, 1987). Moreover, the male providerfemale client dyad, the usual configuration in most gynaecological consultations in the Netherlands, holds the highest risk for communicational problems (Meeuwesen, 1988).

\subsection{Methods}

\subsubsection{Sample and data collection}

Data for this analysis consist of 32 tape-recorded consultations between gynaecologists and women patients. The data were gathered in three gynaecological out-patient clinics in the Netherlands. Five male gynaecologists and 15 patients participated in the study. All consultations by each patient concerning the same complaint have been included in the data. The patients in these encounters range in age from 18 to 49 years, with a mean age of 34 and belong to the lower $(n=10)$ and middle $(n=5)$ socio-economic classes. The gynaecologists range in age from 37 to 50 years old. They all share some progressive principles of comprehensive medicine, for instance, the importance of providing clear and extensive medical information to patients in order to reassure them and to let them participate in decision-making.

The consultations themselves were not standardized according to complaint presented or duration of relationship between the gynaecologist and the patient. However, of the 15 patients involved, only 2 had previously known the physician. With consent of the physicians, the patients and the medical ethics committees of the hospitals involved, consultations were audiotaped, without the attendance of the researcher, and transcribed for later analysis. 


\subsubsection{Operationalizations}

Below we present the definitions and operationalizations of the analytic categories we used for the analysis of the data.

Patients' verbal information-seeking actions are operationalized as utterances which are produced with the intention of being interpreted as 'information-seeking' by the receiver. The goal of information-seeking actions is to obtain an adequate response, i.e. the information needed. The function 'seeking information' has been distinguished into three subfunctions because we expected that the forms of patients' informationseeking actions would differ for each subfunction. These subfunctions are: requests for new information, requests for elucidation and requests for confirmation. In case of a request for new information the patient introduces new subject $\mathrm{x}$ and asks information about it because she does not possess this information or because she only has hypothetical knowledge about $\mathrm{x}$ which she wants to have verified. By a request for elucidation the patient asks more information about subject $\mathrm{x}$, on which some information has already been given during the consultation, either at the patient's request or on the initiative of the physician. In a request for confirmation the patient again asks for information about $\mathrm{x}$, although this subject has already been discussed and the information which the patient desires has already been provided.

An important category of analysis we used during the process of identifying the different forms of patients' information-seeking actions were 'questions'. These are operationalized as sentences with inverted word order, interrogative words and/or interrogative intonation (Churchill, 1978). Following Churchill, we distinguished general questions and specific proposal questions. General questions are those that do not propose an element of the answer-set in the statement of the question ("What kind of side effects does it have?"), while specific proposal questions do propose such an element, for confirmation or disconfirmation ("Is constipation a side effect?"). According to Churchill, using the specific proposal form makes the conversational partner(s) assume that the speaker has some degree of belief or certainty that her proposal is correct. Otherwise, she would have used the general form. An analysis based on this distinction can provide insight into the extent to which patients include their knowledge and conceptions in the formulation of their questions. Of course, determining more subtle information-seeking actions than asking questions is rather an interpretative process. It is often the communicative context which gives important cues as to which actions can be perceived as 'information- 
seeking'. To exclude subjectivity as much as possible our arguments are based on insights from conversation analysis.

In order to determine physicians' responses we used the notion of 'adjacency pair', which has been developed within conversation analysis. An adjacency pair is a "sequence of two utterances which are adjacent, produced by different speakers, ordered as a first part and a second part and typed, so that a first part requires a particular second part" (Schegloff \& Sacks, 1973, p. 291). According to this principle patients create, by producing an information-seeking action (first pair part), the expectation that an answer containing the desired information (second pair part) will follow. If physicians' answers to a patient's information-seeking utterance do not contain the information asked for, we called it a 'minimal answer'. Disconfirmations without corrections in case of (partly) incorrect specific proposals are also defined as minimal answers, because in our culture it is expected that the speaker should supply the missing piece of information. Otherwise the hearer will not hear what she presumably wants to know (Churchill, 1978).

\subsection{Results}

We now describe, for each subfunction, the different forms of patients' information-seeking actions and physicians' responses that we identified in the conversations we observed.

\subsubsection{Requests for new information}

The usual way to request new information is asking direct questions:

1 G: Do you have any more questions?

2 P: Well er, not at this moment actually. Oh yes, when the bowel motion and urine start again, is that painful?

3 G: No that's not so bad.

4 P: Yes?

5 G: People in hospitals often have some difficulties with er bowel motion (continues elucidation). 
In line 2 the patient introduces a request for information on a new subject, that is, the effect of a hysterectomy on bowel motion and urine. The form of this information-seeking action is a question, because it has inversion and interrogative intonation. The question is stated in specific proposal form. The response of the physician shows that he has interpreted the woman's utterance as a question. He answers by providing a disconfirmation of the woman's proposal (line 3).

1 G: You are not discharged if you're not fit yet.

2 P: er, is it (a hysterectomy) done through the belly or through the vagina?

3 G: Well, examination during the curettage has shown how far the uterus is inclined towards prolapse. And actually the inclination is sufficient to enable an operation on you through the vagina.

4 P: Oh alright.

Here the patient produces a specific proposal question on a new topic. She includes two answer alternatives in her proposal. The physician interprets this utterance as an information-seeking action, as shown in his response in which he mentions and gives reasons for the correct alternative.

1 G: (...) But that's a very nice brochure giving the answers to your questions.

2 P: Mmmm

3 G: OK?

4 P: OK yeah. And er, when will that (a laparoscopy) be done?

5 G: Well, we're going to make an appointment for that (gynaecologist writes). Have you still got some holidays coming?

Here the patient asks a general question about a topic which has not been discussed yet, namely the planning of a laparoscopy (line 4). As the physician's answer demonstrates, he has perceived the utterance as an information-seeking action. 
The general questions patients ask have restricted response possibilities: most of them are 'when' questions. 'Why' and 'what' questions are seldom asked.

In the conversations we observed patients also making use of a more indirect way to seek new information. This takes place by producing one or more declarations, followed by a conclusion. This conclusion often contains specific conceptions, which the patient wants the gynaecologist to reflect upon. The following excerpt is an example of this indirect way of requesting for new information:

(4)

1 G: It (=a contrast photo of the uterus and the ovaries) didn't inconvenience you?

2 P: No, only here you know. Constantly here. Whether that's those strings, I don't know.

3 G: Yes.

4 P: And here

5 G: That can of course still [be

$6 \mathrm{P}: \quad$ [that's still all a consequence

7 G: Because you pull the uterus a little, so that instrument is placed upon the uterus (continues information-giving).

This excerpt can be analysed as follows:

Form Function Response

2 P: declaration + request for new conclusion information

3 G: 'yes'

minimal answer

$4 \mathrm{P}$ : declaration continues request

5 G:

$7 \mathrm{G}:$

information

information

We defined the patient's actions in line 2 and 4 as seeking information for two reasons. First, she formulates the first part of a contrast pair "Whether that are those strings, I don't know" in which the unexpressed question "What do you, as expert, think?" can be heard. Second, she starts continuing her request after the gynaecologist's minimal answer in line 3. This response shows that the physician has not yet interpreted the patients' 
utterances as seeking information. It is in line 5 that he starts to treat them as a request for information. In his answer he explains the cause of the pain which the patient has felt.

\subsubsection{Requests for elucidation}

When information has been discussed, either on the patient's initiative or on the initiative of the physician, patients can indicate that they want to have more and/or clearer information. These requests for elucidation can have different forms. The forms we identified in the data are questions, topicalisers and motivations. Questions are the most usual form to request for elucidation:

1 G: When you find during the curettage that it's a very irregular uterus, but that there are no strange things be[hind

2 P: [Can you see that during a curettage?

3 G: Yes, during a curettage you can feel how the uterus is. Whether (continues elucidation)

The patient in the previous excerpt asks for more information about the nature of a curettage (line 2). In order to get this information she uses a specific proposal question, which is interpreted as a request for information, as appears from the gynaecologist's answer. He confirms the proposal made by the patient and adds more elucidation.

Another way in which patients can request for elucidation is using 'topicalisers', mostly in third turn positions. These are interrogative utterances such as "Oh?", "Really?" and "Yes?" , which are expressed with rising intonation at prior 'news' which the conversation partner has given (Jefferson, 1978). Houtkoop-Steenstra (1987) argues that the first speaker who asks a question can demonstrate in the third turn position whether the response has been satisfying. By producing a topicaliser the truth of the answer is implicitly challenged. An example:

1 P: Does getting fibroids have something to do with getting children?

2 G: No. 
3 P: Nothing?

4 G: No, no in fact, women who were never pregnant, er nuns for instance, they er may have really large fibroids.

5 P: Really?

6 G: Yes, so er, no that doesn't have anything to do with having children. Probably getting children protects a little against getting fibroids. So er, these things are totally independent of each other. But er, one in five women has a uterus with fibroids. So it is somethingwhich occurs so often that you might say, well, if you aren't greatly inconvenienced by it, then you should not worry about it.

Analysis of this excerpt shows the following result:
Form
Function
Response

1 P: question request for new information

2 G: minimal answer

3 P: topicaliser request for elucidation

4 G:

5 P: topicaliser request for elucidation

6 G:

elucidation

continues elucidation

In this excerpt the gynaecologist at first provides a minimal answer: he disconfirms the woman's specific proposal without correcting it (line 2). In cases where specific proposals are partly or wholly incorrect, it is expected that the speaker should supply the missing piece of information, because otherwise the hearer will not hear what she presumably wants to know (Churchill, 1978). The topicalisers which the woman consequently produces, show that the interactional rule is violated for her at that point. They stimulate the physician to provide further elucidation about the relationship between having children and getting fibroids. We often find topicalisers when patients have asked incorrect specific proposals, which are 
only disconfirmed by the physician, while no correct version has been given. Then topicalisers can still provoke the desired elucidation.

Sometimes patients motivate their questions after the physician has answered them. The patient in the next excerpt had a colposcopy during which some deviant tissue of the cervix was taken away. Now she has to wait for three months in order to have a reliable new Pap-smear. At the end of the consultation she asks:

(7)

1 P: Suppose that the Pap-smear after three months is $\mathrm{OK}$

2 G: Yes

3 P: Will I still be treated here then?

4 G: Yes, we think that when a Pap-smear has been deviant, you must have a correct Pap-smear here at least twice, before you go back to the routine of once a year.

5 P: $\mathrm{Mmmm}$

6 G: And eventually at your GP's, but if you wish you've every reason to say that you'll come here for that Pap-smear.

7 P: Because my GP doesn't do it once a year. He thinks that once in three years is enough.

8 G: Yes but now something has happened, which is a reason to do it more frequently (continues elucidation).

Analysis:
Form
Function
Response

3 P: question

request for new information

4 G:

information

5 P: continuer request for elucidation

6 G: elucidation

7 P: motivation request for

8 G: elucidation 
In line 7 the patient gives the reason for her specific proposal question, delivered in line 3 . She wonders whether she can continue receiving cervical checks at the gynaecological out-patient clinic, because she expects that her general practitioner will only make a Pap-smear once in three years. The physician interprets her motivation, as his response shows, as a request for elucidation. Also in other conversations where patients motivate their questions, gynaecologists expand their elucidations after these motivations. Whether patients produce these motivations with the intention to receive more elucidation is not clear. It is also possible that they produce them in order to finish the sequence on a certain topic.

\subsubsection{Requests for confirmation}

Relatively often patients express requests for confirmation. They may do this to check whether they have correctly understood the information they have had from the physician and/or to show the physician that they have understood what he has told them. In the conversations we analysed, requests for confirmation have the following forms: a repetition of the previous utterance of the physician, a conclusion based on the information provided by the physician or a question in conclusion form or tag-question. Sometimes a request for confirmation and its response serve to finish a sequence about a certain topic:

(8)

1 G: That we were not examining you (during a colposcopy) at the right moment of your menstrual cycle, that's no problem. I could still see it clear[ly.

2 P: could still see it [clearly?

[So you

3 G: [Yes, as far as that concerned it's OK that it's happened (topic shift)

This previous excerpt shows that the sequence stops after the patient's request for confirmation, which is a repetition of the physician's previous utterance, and the confirmation provided by the physician. The request for confirmation is expressed to introduce the closure of the sequence. Quite often, however, a request for confirmation is followed by a request for elucidation or by another request for confirmation. This might suggest that the first request for confirmation is meant as a request for elucidation. The following excerpt comes from the consultation of a woman who had a 
hysterectomy and returns with complaints of abdominal pain. During the vaginal examination she asks:

(9)

1 P: Will a Pap-smear be taken doctor?

2 G: That's not necessary anymore

3 P: Oh isn't that necessary anymore?

4 G: No, that's not necessary anymore

5 P: Oh?

6 G: No in fact that will never be necessary anymore (topic shift)

Analysis of this excerpt:
Form
Function
Response

1 P: question

request for new information

2 G: minimal answer

3 P: repetition

request for physician's confirmation

4 G: utterance

5 P: topicaliser request for elucidation

$6 \mathrm{G}$ :

confirmation

elucidation

Although the patient's repetition of the previous utterance from the physician (line 3 ) is formally a request for confirmation, it might be meant as a request for elucidation, given her utterance in line 5 . Here she produces a topicaliser which is perceived as a request for elucidation by the physician. In line 6 he provides, though rather restrictively, further elucidation.

The following excerpt is an example with two requests for confirmation, taken from the final part of a consultation:

1 G: When you think I forgot to tell you something else or something else, just write it down and then I'll 
hear it in five weeks' time.

2 P: Yes only that er I've pain (during sexual intercourse; this has been discussed earlier in the consultation), but yes you say that everything looks [fine

3 G: yes looks fine.

[Yes, yes fine

4 P: Oh, well then we shouldn't make anything of it, should we?

5 G: No (finishes consultation)

Analysis:
Form
Function
Response

$2 \mathrm{P}$ : conclusion request for confirmation

$3 \mathrm{G}$ :

4 P: tag-question request for confirmation

confirmation

5 G:

confirmation

Both the first request for confirmation (line 2), which is a conclusion based on the information provided by the physician, and the second one (line 4), a tag-question, are interpreted as requests for confirmation, as shown by the physician's responses. Although the sequence is finished after the last request for confirmation, we wonder whether these requests for confirmation might not have been meant as requests for more elucidation. This is derived from the fact that the patient re-introduces the subject of pain during intercourse at the end of the consultation, although it has already been discussed before. It might be possible that repeating requests for confirmation regarding a certain issue in a latter part of the conversation is a subtle patient effort to get more elucidation.

\subsubsection{Relation between form and content}

In order to determine whether a relationship exists between form and content of patients' information-seeking actions, we conducted a content analysis. We found that information-seeking actions concerned the following seven subjects: nature of treatment (what medical interventions imply 
Table 2.1 Relation between form and content of patients' informationseeking actions.

\begin{tabular}{|c|c|c|c|c|c|c|}
\hline \multirow[b]{2}{*}{ Content } & \multicolumn{5}{|c|}{ Form } & \multirow[b]{2}{*}{ Total } \\
\hline & $\begin{array}{l}\text { Specific } \\
\text { proposal } \\
\text { questions }\end{array}$ & $\begin{array}{l}\text { General } \\
\text { questions }\end{array}$ & $\begin{array}{l}\text { Declaration(s) } \\
+ \text { condusion }\end{array}$ & $\begin{array}{l}\text {-Topicalizers } \\
\text {-Motivations }\end{array}$ & $\begin{array}{l}\text {-Reperitions } \\
\text {-Tag-questions } \\
\text {-Conclusions }\end{array}$ & \\
\hline $\begin{array}{l}\text { Nature of } \\
\text { treatment }\end{array}$ & 32 & 1 & 4 & 7 & 4 & 48 \\
\hline $\begin{array}{l}\text { Procedural } \\
\text { aspects }\end{array}$ & 32 & 7 & & 5 & 11 & 55 \\
\hline $\begin{array}{l}\text { Practical } \\
\text { aspects }\end{array}$ & 12 & 2 & & 5 & 3 & 22 \\
\hline $\begin{array}{l}\text { (Side) } \\
\text { effects }\end{array}$ & 12 & & 2 & 6 & 1 & 21 \\
\hline $\begin{array}{l}\text { Cause of } \\
\text { complaint }\end{array}$ & 10 & 1 & 10 & 5 & 6 & 32 \\
\hline $\begin{array}{l}\text { Results of } \\
\text { exams }\end{array}$ & 5 & 1 & & 2 & 2 & 10 \\
\hline $\begin{array}{l}\text { Appearance } \\
\text { of repr. org. }\end{array}$ & 2 & & & & 1 & 3 \\
\hline Total & $105^{*}$ & $12^{* *}$ & 16 & 30 & 28 & 191 \\
\hline
\end{tabular}

* From these 105 specific proposal questions 39 are expressed as requests for new information and 66 as requests for elucidation.

** From these 12 general questions 9 are requests for new information and 3 are requests for elucidation.

and how they are conducted), procedural aspects of treatment (planning and duration), practical aspects of treatment (consequences for daily activities), effects and side-effects, cause of complaint, results of examinations, and appearance of the female reproductive functions. Table 2.1 shows the relation between form and content of patients' information- 
seeking actions. One third of all patients' information-seeking actions in the observed excerpts are specific proposal questions concerning the nature of treatment and procedural aspects of treatment. Although most other subjects are remarkably less often addressed, patients still generally use the specific proposal form to ask for information. An exception is informationseeking actions regarding causal aspects of complaints: patients relatively often seek information about this issue via indirect requests for new information. The finding that patients make use of this rather complicated way of getting information about causal aspects suggests that it is difficult for patients to raise this issue. The few general questions patients ask mostly concern procedural aspects of treatments. This is because patients often ask when a certain treatment will be planned. The table further shows that requests for elucidation in the form of topicalisers and motivations are quite evenly spread over the different subjects. Requests for confirmation are mostly produced when procedural aspects of treatment or causal aspects of complaints are the topic of discussion. This might suggest that especially regarding these subjects patients have a need for checking information that they have previously received.

\subsubsection{Interactional patterns}

Comparable sequences of patients' information-seeking actions and physicians' responses, interactional patterns, could be identified within the different conversations. All patterns which were identified more than four times, occurred across all physicians. This did not accord for physician number $E$ (see table 1.1, chapter 1), because we only observed one consultation of this gynaecologist. The interactional patterns start either at the patient's initiative or at that of the physician. Figure 2.1 illustrates these patterns. The patterns in this figure start either with a direct request for new information or with a request for elucidation or confirmation relating to information given previously by the physician. In the latter two cases the patterns start under the broken line in figure 2.1.

Direct requests for new information always elicit answers from gynaecologists in our data. Sometimes the sequence ends after this answer; at other times patients produce one or more requests for elucidation in order to receive more or clearer information on the topic of discussion. After the gynaecologist has provided this elucidation the sequence usually ends. In only two cases do patients continue the sequence by expressing a request for confirmation. Patients can also provide requests for confirmation after the physician's answer to their direct request for new informa- 


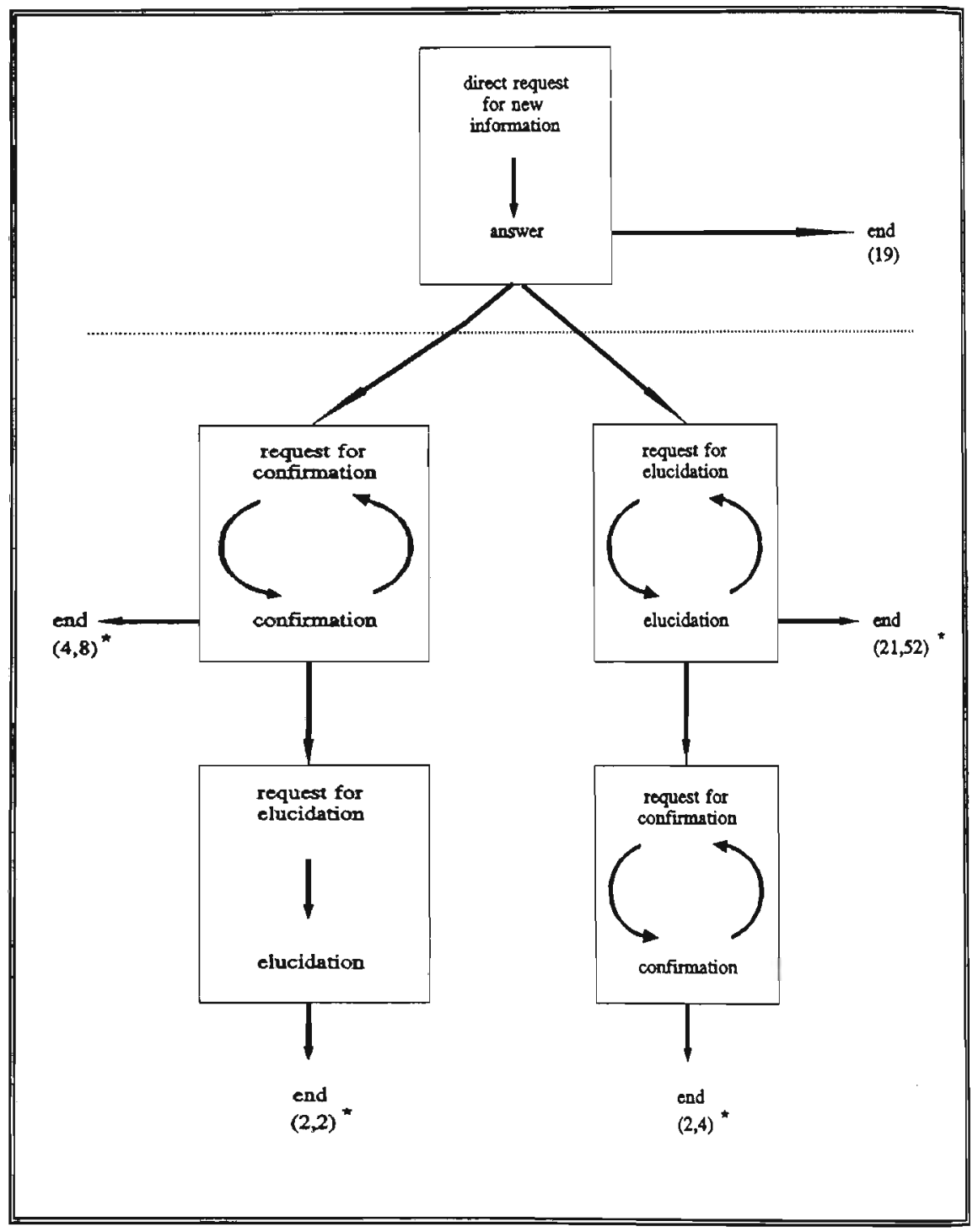

Figure 2.1 Patterns starting with direct requests for new information, requests for elucidation and requests for confirmation.

* The first number refers to the sequence starting with a direct request for new information. The second number refers to the sequences which begin under the broken line, thus either with a request for elucidation or with a request for confirmation. 
tion. These requests for confirmation are always followed by a confirmation. Then the sequence is finished or the patient goes on to produce a request for elucidation which elicits an elucidation from the physician. This finding suggests that requests for confirmation may not just be intended to elicit confirmation that previous information has been understood correctly. It is possible that requesting for confirmation is an implicit way to show a desire for more elucidation about a certain issue. If the latter option is valid, requesting for confirmation is not very effective, because the conversational partner generally just answers this request by providing a confirmation, which finishes the sequence.

When information is provided at the physician's initiative, patients can ask for more information by making a request for elucidation or for a repetition of the response by making a request for confirmation. The course of the sequences is comparable with those which begin with a patient's request for new information. As figure 2.1 reveals, the majority of sequences follow the pattern which start with a request for elucidation after the physician has provided information on his own initiative and end when the elucidation asked for has been given.

Figure 2.2 shows the patterns starting with indirect requests for new information. When patients ask for new information indirectly, which mostly occurs when causal aspects are the topic of discussion, their requests are usually answered. Then the sequence ends or patients can ask for some more information by a request for elucidation, which usually results in an elucidation from the gynaecologist. Sometimes, however, indirect requests for information receive minimal answers or non-answer. In these cases the gynaecologist denies the patient's conclusion regarding the cause of her complaint without indicating what else might have caused it. This results in an interactional loop consisting of indirect requests for new information and minimal or non-answers. When the sequence is finished the patient still has not got an adequate answer to her indirect request for new information. This loop-pattern only occurs when causal aspects of complaints are the topic of discussion. The indirect requests for information on the topic of 'cause' which do not result in loops, are all expressed after a clear diagnosis has been made and has resulted in a treatment proposal. However, in the case of the loops, patients express their indirect requests for information either before the diagnosis of the complaint is clear or when no gynaecological deviances have been found and no further treatment is offered. Thus, it is possible that physicians in the loop-sequence experience patients' indirect requests for new information as interruptions of their medical agendas. 


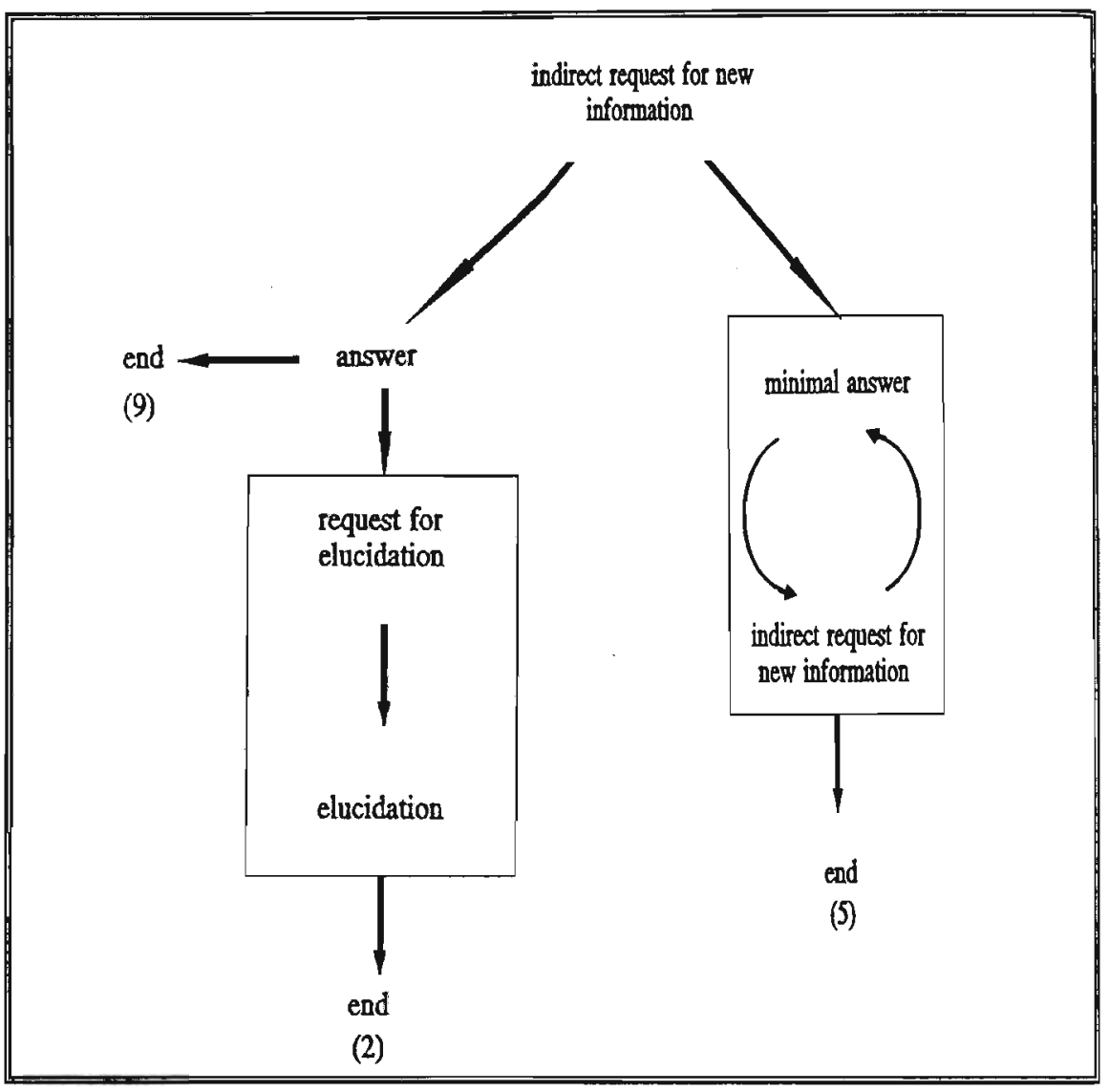

Figure 2.2 Patterns starting with indirect requests for new information.

Because the loop-pattern is the most complicated and problematic pattern within our data, we will illustrate it with an example. The next excerpt comes from a woman's second gynaecological consultation. Two months earlier she had visited the gynaecological out-patient clinic because of severe abdominal pain. Her general practitioner thought that she had an enlarged uterus. After that first consultation, it was decided to make a sonogram in order to get a better view of the uterus. During this second visit the gynaecologist explains that, though the patient's uterus is a little larger than average for her age, this can never be the cause of her abdominal pain. The woman then tells the gynaecologist that she also had cystiris recently. She 
wonders whether this might have a relationship with the enlarged uterus. This assumption is denied by the physician. Then the patient continues:

1 P: Yes er my intestines don't function very well either. I've already had that for so[me time. So I think that er

2 G: [Yes

$3 \mathrm{P}$ : because I really have many complaints in my belly

4 G: Yeah

5 P: And I think that [it perhaps must have something to do with

6 G: [It's no again, in any case I don't think it's from that either.

7 P: It's not something to do with the uterus?

8 G: You can exclude that it's something caused by the uterus, that er uterus is definitely not really abnormal.

9 P: Well I had this month I had now not yet half a month, I had my menstruation er Wednesday, Saturday, fourteen days ago, but last week I had such, oh those breasts, besides I still have that now. It's terrible but that is, I sometimes think, is normal I think.

$10 \mathrm{G}$ : Yes, with [the (unintelligible) yes and with the hormones.

$11 \mathrm{P}: \quad$ [Maybe when you're getting older, that it has something to do with the hormones.

12 G: Yes.

$13 \mathrm{P}$ : Er well er I [can't stand it any longer

$14 \mathrm{G}$ : $\quad[\mathrm{Mmm}$

15 P: it it's [really

$16 \mathrm{G}: \quad \quad$ Mmm, yes, yes.

17 P: And I've had that a few times now but that may have something to do, maybe yes, then I think that it may have something to do with age perhaps.

$18 \mathrm{G}$ : Yes, that's possible, that the ovulation doesn't come quite regularly. That may happen little by little you know. OK Mrs. B, so, as for us, gynaecologically 
$19 \mathrm{P}:$

you know er [everything is

[Yes but that man (who made the sonogram), he really thought, he said I think something is wro[ng he said

$20 \mathrm{G}$ : [Yes.

$21 \mathrm{P}$ : so I expec[ted that er

22 G: [No that's not true. We don't have to do any[thing to it

23 P: [I've already had that complaint for [years and still now in fact.

24 G: with regard to that you can be totally at ease.

[Yes, yes, no

25 P: Alright

$26 \mathrm{G}$ : Alright.

This fragment can be analysed as follows:

Form

Function

Response

1 P: declaration starts request for new information I

2 G: 'yes'

3 P: declaration continues request

4 G: 'yes'

5 P: conclusion makes explicit request

6 G:

7 P: sp-question request for elucidation

8 G:

9 P: declarations starts request + conclusion for new information II

$10 \mathrm{G}$ :

$11 \mathrm{P}$ : conclusion continues request

12 G: 'yes'

$13 \mathrm{P}$ : declaration continues request continuer

continuer

minimal answer

elucidation

confirmation

continuer 
$14 \mathrm{G:}$ ' 'mmm'

$15 \mathrm{P}$ : declaration continues request

$16 \mathrm{G}$ : 'mmm, yes, yes'

17 P: declaration makes explicit + conclusion request

$18 \mathrm{G}:$

$19 \mathrm{P}$ : declaration starts request for new information III

$21 \mathrm{P}$ : conclusion explicits request

$22 \mathrm{G}:$

$23 \mathrm{P}$ : declaration continues request

$24 \mathrm{G}$ : continuer

continuer

information

minimal answer

minimal answer

The patient in the previous excerpt offers three indirect requests for new information. In the first two she presents 'candidate diagnoses' (Houtkoop, 1986). First, she tries to find out whether the troubles with her intestines might be related to her enlarged uterus (lines $1,3,5$ ). We defined these utterances as 'information-seeking' because, from the conclusion "I think that..", the unexpressed question "what do you think?" can be distilled. This utterance is treated by the physician as an information-seeking action in line 6. He disconfirms her candidate diagnosis, but omits to adjust an alternative elucidation for her abdominal pain, which made us define it as a minimal answer.

In line 9 the patient produces a second indirect request for new information, which has the same structure as the first one. Notice that the declarations preceding the conclusion contain 'qualifiers', which underline the seriousness of her complaint, such as "oh those breasts" and "it's terrible". The physician's response (line 10) demonstrates that he has perceived the utterances as 'information-seeking': he confirms the patient's assumption that the pain in her breasts is normal and explains that this may have a relationship with the hormones. However, the woman does not fully accept this answer. She continues her request by repeating a more explicit conclusion in which she relates age and hormones (line 11) and by producing more qualifying declarations ("I can't stand it any longer" and "It's really") followed by a new conclusion with the same content (line 17). The gynaecologist's continuers show that he does not interpret the patient's utterances as a request for information until line 18 . His response is a confirmation of the woman's assumption plus a short elucidation. 
When the physician starts finishing the consultation (OK Mrs. B..., line 18), he is interrupted by the patient, who produces a third indirect request for new information. This time she does not produce a candidate diagnosis in her declarations and conclusion ("So I expected that uh..."), but she introduces another expert, the person who made the sonogram, to emphasize that something must be the matter with her uterus. The physician's disconfirmative response (line 22) shows that he has perceived this utterance as an information-seeking action. Again, however, he does not provide any alternative elucidations for her complaints. The patient does not accept his answer and continues her request for new information by offering another declaration with qualifiers ("I've already had that complaint for years", line 23). After another minimal answer, a disconfirmation without an alternative, the consultation is ended.

\subsection{Discussion}

The present study has revealed that patients have different ways to make requests for new information, for elucidation and for confirmation. Requests for new information mostly take place via asking direct questions, most of which are specific proposals, i.e., yes/no questions or questions indicating alternatives. General questions are asked very infrequently. However, patients can also request for new information in a more indirect way, by means of a declaration about things that happened before. When the physician does not react or only provides a minimal response, another declaration, often accompanied by qualifiers, follows. In this way a 'story' is created. Finally, the patient presents a conclusion in which words such as "So I thought that" are included, by which she implicitly asks "What do you think?". The requests for elucidation in the conversations we analysed have the following forms: a question, a topicaliser or a motivation of a question asked previously. Finally, we identified three different forms of requests for confirmation: a repetition of the previous utterance of the physician, a conclusion based on the information provided by the physician or a conclusion in question-form or tag-question.

A comparison of form and content of parients' information-seeking actions has shown that a very large part of these actions consist of specific proposal questions concerning the nature or procedure of treatments. Similarly, regarding other subjects patients mostly formulate their information-seeking actions in specific proposal form. However, this does not hold 
for the subject 'cause of complaint'. This subject is relatively often addressed via indirect requests for new information. We find requests for elucidation almost equally spread over all subjects patients ask information about. Requests for confirmation especially concern procedural aspects of treatment or causal aspects of complaints.

Several patterns of comparable sequences of patients' informationseeking actions and physicians' responses could be identified. Most sequences pass off smoothly: physicians interpret the different informationseeking actions from patients as 'information-seeking' and provide the type of answer that the patients ask for. In this data, only indirect requests carry the risk of eliciting minimal answers, i.e. answers that do not contain the information the patient desires. Then, interactional loops of indirect requests for information and non-answers occur. This pattern has been identified especially in circumstances when no medical diagnosis had yet been made or when physicians had told patients that no gynaecological deviances had been found, while omitting to inform them about potential other causes of their symptoms. The fact that this finding was identified across all physicians suggests that the form of the information-seeking device and the circumstances under which it is produced, rather than the physician's personal communication style, influence the type of answer that it receives. Patients rather often produce requests for confirmation after physicians' elucidations, probably to check whether they have correctly understood the physician. After these have been confirmed by the physician, patients sometimes express a request for elucidation. This might suggest that the actual function of a request for confirmation is to get more elucidation.

By concentrating on more information-seeking actions than only simply direct questions, we were able to show that patients have different ways of affecting the actual course of talk during medical conversations and that they can influence the nature and amount of information they receive. The large number of specific proposal questions demonstrates that patients have specific conceptions, for instance about how investigations and treatments are conducted, which they include in the formulation of their questions (cf. Helman, 1990, Kleinman, 1981, 1988). In this way they display their knowledge, while placing the gynaecologist in the position to determine whether this knowledge is right. Thus, asking questions in specific proposal form might be a strategy for patients to present themselves as competent consumers (cf. Davis, 1988; Fisher and Groce, 1990).

Although the analysis suggests that rising consumerism has indeed affected patients' information-seeking behaviour, it also reveals that this 
consumerism has its limits. As long as it concerns factual information, especially about the nature and procedural aspects of treatment, patients do not have any difficulty in producing requests for new information or for elucidation. However, the lack of general questions (why?, what?), the small number of questions on results of examinations and on the appearance and working of the female reproductive functions and the indirect and laborious way in which patients frame requests for information about causal aspects of complaints, indicate that introducing more fundamental issues is rather complicated for patients. These findings correspond with Porter's (1990), who found in her research on professional-client relationships in women's reproductive health care that patients never questioned the diagnosis or asked about treatment alternatives. The study of Verdenius-Jansen (1991) on information-seeking behaviour of women visiting radiologists also shows that requests for information regarding causes of complaints are brought to the fore in a very laborious way. It is possible that patients do not feel the need for information about these more fundamental subjects. Krol (1979) claims, for instance, that patients often come to see their doctor, not primarily because they are interested in the cause of their medical problems, but in order to have certain causes excluded. A more plausible explanation may be that patients perceive, though not consciously, introducing more fundamental subjects as rather 'unsafe'. Ten Have (1991) states that patients are rather reserved about displaying medical knowledge due to a ritual respect towards the physician. Perhaps patients experience subjects such as the cause of complaints and results of examinations as pre-eminently belonging to the physician's domain of knowledge and have internalized the implicit rule that "in the medical setting doctors not patients are vested with the institutional authority to make diagnostic decisions" (Fisher and Groce, 1990, p. 238). In short, implicit ritual constraints, connected with the lay-expert difference, seem to impede a clear expression of patients' requests for information regarding more fundamental issues.

Our analysis reveals that physicians' client-directedness is also limited. Although the physicians are in general very willing to answer patients' requests for information, they do not like (further) talking about causal aspects when the diagnosis is still unclear or when they have not found any gynaecological deviances. It is as if there is an unwritten rule influencing the communication during these gynaecological consultations: patients do not successfully attempt to take the role of the doctor and construct their own assumptions about the cause of their complaints at moments that do not fit physicians' medical agendas. 
The findings of the present study suggest some recommendations for medical practice and health education. Interventions for physicians and patients which focus on getting a better understanding of organizational aspects of medical communication, i.e., its patterns and structures, might improve the communication of information. We suggest that training programs for medical specialists should attempt to make them more aware of patients' indirect efforts to request for new information and of the subtle means by which they can ask for (more) elucidation, such as the use of topicalisers, motivations and, sometimes, requests for confirmation. Moreover, physicians should learn how to avoid entering the ineffective and time-consuming interactional loop of indirect requests for information and minimal answers. This is possible when they take seriously patients' efforts to obtain clarity as to what might have caused their complaints, both in situations when their requests do not exactly 'fit' the medical agenda and when no medical deviances have been found. In the first situation, they can simply explain to patients that their question will be addressed in a later phase of the consultation. In the last situation, it is important for doctors to keep the patient's initial problem in mind: for patients the diagnosis 'no medical deviance' does not mean that their problems are over! Cicourel (1981) stated that little has been done about making patients more aware of how to talk with their physicians, what questions to ask and how to insist on explanations that can be understood. This study suggests that an intervention focused on patients might be rather effective to improve information-exchange. For instance, patients can be stimulated to ask direct questions and to avoid the use of indirect requests for information. Especially when diagnostic aspects are the topic of discussion, a less reserved expression of the information they wish to receive might facilitate physicians' services. 


\title{
Chapter 3
}

\section{Expressing concerns about malignancy}

\author{
Abstract
}

This study describes bow patients express their anxiety during gynaecological consultations and how gynaecologists react to these anxiety expressions. Data for the interactional analysis consisted of 32 audiotaped gynaecological consultations, which were transcribed literally. The results revealed that patients generally present their fear in very covert ways, e.g. by implicit allusions to the possibility of baving malignancies or by pressure for more drastic medical intervention. Doctors bad three types of reactions to patients' anxiety: they explored it, they started to reassure immediately or they negated the anxiety expressions of patients. Together these anxiety presentations and reactions form three interactional 'scenarios', which are illustrated by representative examples. Each observed consultation appeared to contain one of these three scenarios. The findings suggest that communication about emotions takes place within a limited set of specific interactional patterns. The paper finishes with an examination of the relevance of the findings for medical practice.

\subsection{Introduction}

Anxiety is a well-known phenomenon within health care, affecting virtually everyone at some stage in their lives, especially during illness. Literature has shown that patient anxiety has negative consequences. Anxious people for instance have a higher medical consumption (Van der Ploeg, 1980). In case of malignancies, people wait longer before consulting a doctor when they are more anxious (Van Dam, 1974). Moreover, anxious people have

'Published as: Weijts, W., Widdershoven, G. \& Kok, G. (1991). Anxiety-scenarios in communication during gynaecological consultations. Patient Education and Counseling, 18, 149 163. 
difficulties in remembering the medical information they are provided (Maes, 1983).

Consequently, within health education research, the importance of providing patient education to reduce patient anxiety has been well estab. lished. Information about the nature, cause, treatment possibilities and prognosis, has proved to result in a reduction of patients' anxiety and fear. Information is also one of the best treatments for the stress attendant on facing a difficult medical procedure (Johnson \& Leventhal, 1974; Fuller et al., 1978; Shipley et al., 1978; DiMatteo \& DiNicola, 1982). Exchanges in which hospitalized patients can express their emotions have shown to result in a reduction of anxiety and a shorter hospital stay (Skipper \& Leonard, 1965; Waitzkin \& Stoeckle, 1972; Bergsma \& Rullman-Schadee, 1975;

Devine \& Cook, 1983; Visser, 1987).

These health education studies have clearly demonstrated the negative consequences of patient anxiety and the relevance of patient education to reduce this anxiety. However, these are all experimental studies in which several effects of a specific intervention, such as the level of anxiety, were compared between an experimental group and a control group. Until now few attention has been paid to interactional patterns during communication about anxiety in actual medical consultations. Anxiety is, evidently, not only something originating within the patient in response to symptoms or the diagnosis, but it is also an effect of the interaction with the physician. Moreover, patient education is neither just a matter of 'giving the facts', nor is it an isolated act of the physician. How information is provided depends on the reactions of the patient. Thus, anxiety and patient education should be treated as interactional processes, rather than as states or qualities of individuals.

The goal of the present study was to gain a better understanding of the way bow patients express anxiety and how physicians react to patients' anxiety in gynaecological consultations. This setting was chosen as object of research because several surveys have demonstrated that talking about gynaecological complaints has problematic aspects for doctors as well as patients, due to the taboo which is still resting on sexuality and reproduction (Petravage et al., 1979; Weis \& Meadow, 1983 Joustra \& De Vries, 1983; Frenken \& Van Tol, 1987). Moreover, half of the patients visiting a gynaecological out-patient clinic is anxious, especially for the gynaecological examination, the diagnosis and the unfamiliarity with the situation (Joustra \& De Vries, 1983). It has also been proved that the dyad male providerfemale client, which is the common setting in most gynaecological consulta- 
tions, bears the highest risk for communicational problems (Meeuwesen, 1988).

In their experimental studies on 'emotional scenarios', Gergen and Gergen (1988) showed that interactions around emotions have specific patterns. They investigated three emotions, anger, jealousy and depression, and demonstrated that the interactions around these emotions have standard sequences. For example, an expression of anger is followed by questioning the reason. After the explanation for anger is given, three major options were identified: remorse ("I am very sorry I hurt your feelings"), reframing ("I only did it because I thought it would be helpful to you") and anger ("Don't you think you are overreacting a bit? It's not such a big deal"). These responses, in turn, generate additional responses on the part of the expressor of the anger. In their experiments Gergen en Gergen also observed that endings for emotional scenarios almost invariably included the expression of happy sentiments. They concluded: "No cases were discovered in which a negative emotional state (e.g. anger, jealousy, depression) served as the proper ending of a scenario. When lived narratives involve emotional expressions, it appeared that they are very likely to be stories with happy endings". What the Gergens wanted to demonstrate is that, while there is latitude in the range of possible scenarios, there are highly reliable patterns within a specific culture. From a traditional psychological viewpoint, emotions are studied by focusing on the actions of single performers. According to the Gergens, however, to be intelligible, the emotional action must be a constituent of a recognizable narrative. There is good reason, then, to view emotional performances as constituents of larger or more extended patterns of interaction.

In this paper we apply the notion of emotional scenarios to a 'new' emotion 'in vivo', namely anxiety in gynaecological consultations. After a description of the research methods and the characteristics of the respondents, we discuss how patients express their anxiety during gynaecological consultations. This is followed by a description of the gynaecologists' reactions to these anxiety expressions. Next, we present these expressions and reactions in interaction. This results in three anxiety scenarios, which are illustrated by three cases. In the discussion section we relate these findings to Gergen and Gergen's work on emotional scenarios. We conclude with an examination of the relevance of the scenarios within the context of medical practice. 


\subsection{Methods}

The data for this study were gathered in three gynaecological out-patient clinics of general hospitals in the Netherlands. Five gynaecologists participat ted in the study. Thirty-two consultations were recorded on audiotape, involving fifteen patients with gynaecological complaints. The consultations themselves are actual patient visits to gynaecologists, so they are not standardized according to length or presenting complaint. The recordings comprised all consultations by each patient concerning one and the same complaint. The researcher did not attend the consultations. Immediately after each consultation separate interviews were held with both the gynaecologist and the patient in which they were encouraged to express their perceptions and evaluations of the consultations. All the material was obtained on the basis of informed consent with the understanding that the identity of doctors and patients would never be revealed. The medical ethical committees of the three hospitals provided their approval for conducting the research.

The consultations and interviews were transcribed verbatim. Coding and analysis was based on ethnographic methods (Glaser \& Strauss, 1967; Hammersley \& Atkinson, 1983). We began our analysis by examining the transcripts to locate all 'anxiety' instances, that is instances in which words like 'fear' or 'anxious' were mentioned or where other signals (e.g. auditive non-verbal signifiers) gave us the impression that anxiety was communicated. We then examined the interactional context of these anxiety expressions to further determine how anxiety was expressed and how it was reacted upon. The analysis in this paper focuses on the verbatim consultations. The presented extracts are relatively literal translations from the original Dutch transcripts. The information gathered from the interviews with gynaecologists and patients served only as contextual information, which made possible the following description of respondents' characteristics.

\subsection{Characteristics of the respondents}

The fifteen participating patients ranged in age from 18 to 49 years, with a mean age of 34 years. They belonged to the lower $(n=10)$ and middle $(\mathrm{n}=5)$ socio-economic classes. They presented different types of complaints to their gynaecologists, such as abdominal pain, back pain, irregular menstrual periods, involuntary urinary loss, pain during intercourse, 
vaginal secretion, and fatigue. In some cases, women experienced a combination of these complaints. A characteristic of these problems is that they are symptomatic and highly visible to the patient. As described in the interviews with the women, their complaints often caused considerable inconvenience, which imposed constraints upon their social lives. Some of them indicated, for instance, that they repeatedly had to rise during the night due to severe bleedings or that their abdominal pain prevented them from undertaking activities with others or made them sulky.

The gynaecologist was not the first doctor the patients consulted for their complaints. As is usual in the Dutch health care system, women saw their general practitioner (GP) in advance. Thus, their medical career with regard to this complaint had started three or even more weeks before the gynaecological consultation. The GPs referred these patients to the gynaecologist and made a provisional diagnosis. Most of the women knew the content of their referral letter. Two of them already knew the gynaecologist from prior visits. In their accounts during the interview with the researcher, almost all women who consulted the gynaecologists stressed the anxiety they felt during the period between visiting the GP and the outpatient clinic. The referral itself signalled to them that there was really something seriously wrong: "You are not referred to a gynaecologist without reason. When a GP can bandle it bimself, then be will do so".

All patients, except those who came for incontinence or infertility, expressed during the interview their fear that their complaints might turn out to be, as they call it, 'something else'. This anxiety about malignancy in an early stage of the women's medical career was apparent in almost all patients who suffered from bleeding following intercourse, irregular or severe menstrual bleedings or lower abdominal pain.

The five doctors participating in this study were all male and ranged in age from 37 to 50 years old. They shared some progressive principles of comprehensive medicine. During the interview, they stressed, for example, the importance of providing clear and extensive medical information to patients, in order to let them participate in decision-making and to reassure them. Reassurance of patients was a theme that was repeatedly mentioned, because, as one of these physicians said, "it's the largest part of our job during consultations". They pointed out how difficult it sometimes is to reassure patients 'by words'. Some of them admitted that they sometimes conducted medical investigations, such as sonograms, only to calm their patients. 


\subsection{Results}

\subsubsection{Patients' expressions of anxiety}

During the consultations patients never mentioned directly the things they feared. Only when doctors asked if there was something which concerned them, did they talk about their concerns in an overt way. In overt anxiety expressions, words as 'sorrow', 'anxiety' and 'concern' are used and the topic of anxiety is mentioned. For example: "I want to know what it is, so $e r$, that $I$, just that it is not malignant, because that is of course what you are concerned about at first". In this utterance the subject of anxiety is overtly indicated. The meaning of the utterance is clear: the woman wants to know whether her complaints have a relationship with malignancy. Usually, however, patients presented their anxiety in a more covert way. Three types of covert presentation of anxiety during consultations were identified.

Firstly, anxiety appeared from patients' implicit allusions to the possibility of having a malignancy. One patient, for instance, repeated several times during the consultation that it was as if 'something was in her belly that is not right'. Another patient, who had a hysterectomy two years before because of endometriosis and now feels similar abdominal pain, asked the gynaecologist anxiously: "this isn't right, is it doctor? You took everytbing out, didn't you?"

Secondly, anxiety became apparent in patients' pressure for quick and often drastic medical intervention. Women sometimes tried to persuade their doctors to conduct more precipitous medical interventions than the doctors had proposed. This involved considerable argumentation and repetition of arguments, as in the following example which took place after the physician's proposal to conduct a laparoscopy (an investigation of the inside of the belly with a kind of scope) in order to investigate what caused her complaints: "But er, to only view what it is (by a laparoscopy), that seems absurd to me. I' $m$ inclined to say, well, just open it and get it out if there is something which shouldn't be there. (...) I don't feel the need to know whether it's this or that. And what if it is malignant, then it has to be removed anybow. And if it is benign, well, then it can stay. Only if it causes inconven. ience does it bave to be removed. Then I would say: do it immediately". This woman brings to the fore several arguments against 'only viewing' and in favour of 'getting it out immediately'.

Thirdly, anxiety for malignancy was identified in the introduction of relatives or friends who (had) had cancer. Here is an example of a patient who is afraid of having cancer because it is a common disease within her 
family: "But I must say that I also,... in the case of my eldest sister... Well, that remains on my mind. They have everything er removed. Because er of cancer. And that bothers me also a little bit er...".

\subsubsection{Physicians' reactions to patient anxiety}

Three different types of physician reactions were identified: exploration, reassurance and negation.

The gynaecologists either started to explore possible concerns of their patients or they reacted with an explorative question to covert anxiety expressions. When they initiated an exploration themselves they asked about anxiety via closed questions: "Were you afraid to come?". Open ended questions were much less frequently asked. When the gynaecologists started to explore after covert anxiety expressions of their patients, they used several exploration methods such as giving (emotional) reflections, posing open-ended questions, mirroring and providing 'listening signals' ("yes", "uhm") to stimulate patients to express themselves.

The most common reaction of these physicians to patient anxiety was providing reassurance. Several reassurance strategies were identified. Although they were often intertwined during the consultations, we will describe them separately. The first reassurance strategy was providing medical information. Efforts to reassure by giving information were apparently present during and after medical examination and after the provision of less favourable test results. Information also had the function of reassurance in the case of patients' misconceptions about diseases. Several women in the sample, for instance, strongly believed that benign tumors would become malignant after some time. This misconception would usually be corrected by the gynaecologist. Another, more rhetorical, reassurance strategy of physicians was creating an atmosphere of 'joint action' with the patient, focused on solving her problems. 'This was accomplished by demonstrating willingness to investigate concisely and as soon as possible the causes of the patient's complaint(s). By summing up the different medical techniques available for identification of the problem behind the symptoms and by the frequent use of 'we', the patient is convinced that her problems are being dealt with actively. An example: "We must know more about your cervix, especially because it looked so vulnerable. So I think we should do a detailed investigation". In contrast to Silverman (1987), who viewed the 'we'-voice in medical consultations as the voice of the medical team, in our data 'we' seemed to refer to the joint enterprise of the doctor and the patient. This strategy often occurred in combination with the provision of information, when less favourable 
results have appeared from examinations. Finally, another rhetorical reassurance strategy was demonstrating the innocence of complaints, investigations or treatments. To reach this effect, words like 'quietly', 'innocent' and 'just' were used and the painlessness and short duration of investigations were emphasized. This strategy was often encountered when the gynaecologists revealed a less severe problem than the GP had diagnosed. Then the patient had to be convinced that things were not as alarming as her GP had suggested.

Like physicians' explorations, reassurances differed considerably in quality. We doubted whether some of them, which were definitely meant as efforts to calm patients, were successful in achieving this effect. This can be illustrated by the following extract of a consultation in which the gynaecologist and the patient meet each other for the second time. During the first consultation some medical investigations have been carried out. Now the woman comes to hear the results of these investigations. The doctor initiates the exchange as follows:

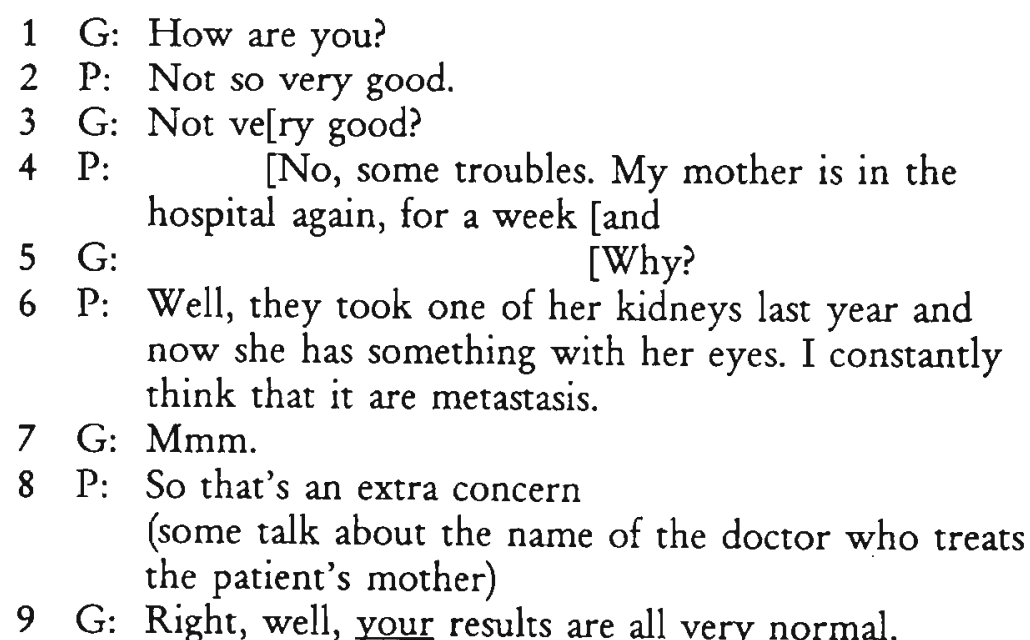

In this extract the physician tries to comfort the patient, emphasizing that at least in her own case no deviancies have been found. Although this information is provided as reassurance it is not provided 'on topic'.

Finally, covert anxiety expressions might be followed by a negation on the doctor's side. This was accomplished by interrupting the patient's anxiety expression with a new medical question: 
(2)

1 P: But now I was a little con[cerned

2 G: [You said you had blood loss after sexual intercourse. Did you also have pain during intercourse?

Another negation strategy was trivializing, as happens in the following excerpt in which the patient tries to express her anxiety about having a cervical smear taken:

(3)

1 P: Oh, not that horror again!

2 G: No, it is nothing, and certainly not for someone who has had children.

Here the gynaecologist trivializes the woman's expression of anxiety, indicating that she need not to be afraid about the pelvic examination, because she is already acquainted with that situation.

\subsubsection{Scenarios in talking about anxiety}

Up to now we have seen how patients in our study express their concerns and how doctors react in handling this anxiety. Now, we will discuss the sequences of these presentations and reactions during medical interaction. The analysis of the consultations from an interactional perspective revealed different patterns in 'anxiety-talk' during consultations between doctors and patients. Following Gergen and Gergen (1988), we will call these patterns 'scenarios'. Three scenarios were identified: an explorationscenario, a scenario of direct reassurance and a negation-scenario. Each consultation contained just one scenario. The following three cases illustrate the range of anxiety scenarios in the sample and were selected as representative of the observed gynaecological consultations.

\section{Exploration scenario}

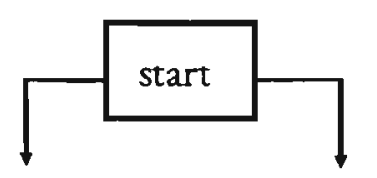

covert anxiety $\longrightarrow$ exploration

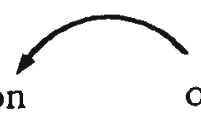

expression

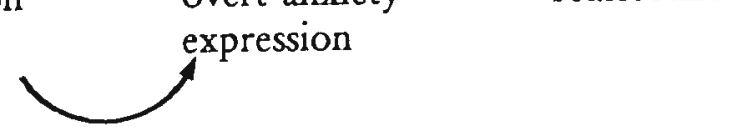


This scenario is started either by a patient's covert anxiety expression or by the doctor's exploration, which always results in an overt anxiety expression from the patient. The overt anxiety expression may be followed by a new exploration, which then again leads to a new overt anxiety expression. The scenario finishes with a reassurance. We will describe an example that starts with an exploration.

The woman in this excerpt is 40 years old. For seven years she has suffered from severe abdominal pain during menstrual periods. The last few months the pain has intensified and her GP referred her to a gynaecologist, indicating that she might have endometriosis. After investigating the medical history the gynaecologist asks her:

1 G: Are you afraid that something serious is the matter?

2 P: No.

3 G: What is the reason you are here? Do you want to have it investigated?

4 P: Yes, I've had these problems for such a long time and the situation is getting worse and worse. And it's not nice for my family too that I get so moody.

5 G: $\mathrm{Mmm}$.

6 P: In fact it really makes me irritable.

7 G: $\mathrm{Mmm}$.

8 P: Before, after and during the menstruation. Yes, almost two and a half weeks in all: that's just too much for my family.

9 G: So, you have the feeling "I want rid of it", isn't it?

$10 \mathrm{P}$ : Well, I wa[nt

$11 \mathrm{G}$ : [I want to know what it is.

$12 \mathrm{P}$ : I want to know what it is. Yes, just that it is nothing malignant because that is what you think of first of course.

13 G: That's right.

14 P: But er just what causes the pain and if it can be treated somehow, with tablets or so.

After this the woman expresses her preference not to have tablets. She decides that tablets are not a good solution in her case. Then the gynaecologist continues: 
$15 \mathrm{G}$ : Well, we are going to examine you calmly. And then we'll see whether further examination is necessary. Most things are innocent. Then you just have to know what the matter is. Then at least you can explain it. However, not everything can be treated.

16 P: Yeah, I know.

$17 \mathrm{G}$ : Real magical methods do not exist. Often complaints are inconvenient but innocent.

After the physical examination the doctor provides his findings:

$18 \mathrm{G}$ : Something strange which you would have to be frightened about

$19 \mathrm{P}$ : isn't there

$20 \mathrm{G}$ : is absolutely improbable. What I have found was a uterus of normal size, definitely no fibroid tumors.

Then, the possible causes of her complaint are discussed: constipation and endometriosis. With regard to the endometriosis two treatment possibilities are offered: pill use or a laparoscopy. The woman prefers the latter option. After a discussion about some technical details, an appointment is made for the laparoscopy.

At the beginning of this excerpt the gynaecologist starts exploring the patient's anxiety by posing a closed question, which is answered in the negative (1-2). By means of open-ended questions, listening signals (" $\mathrm{Mmm}$ ") and a reflection, the gynaecologist continues his exploration successfully (311). Now the woman expresses overtly her concern about having a malignancy and her further questions and preferences (12-14). She wants to know the cause of her complaints and a possible treatment. After this exploration the doctor uses the reassurance strategy of 'joint action': "we are going to examine you calmly" (15). At the same time he also tries to achieve a reassuring effect by emphasizing the innocence of most complaints and assuring that further investigation will provide more clarity (15-17). Later on in the consultation, after the examination, reassurance is provided by giving information about the results of the pelvic examination (18-20). The physician emphasizes the innocence of his findings by using words like 'extremely improbable', 'normal', 'definitely no fibroid tumors', which serve to underline that nothing alarming has been found. Here the scenario ends. Then the phase of discussing treatment possibilities can be started. 
Scenario of direct reassurance

covert anxiety expression

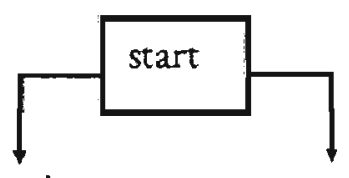

reassurance

This scenario either starts with a patient's covert anxiety expression or by the doctor's anticipating reassurance. The latter option occurs most frequently in the data, especially when findings of investigations are explained. A covert anxiety expression is directly followed by a reassurance, which finishes the talk on that topic. Sometimes the scenario starts again with a new covert anxiety expression on a different topic later on in the consultation.

The following excerpt is part of the first consultation of a 34 year old woman, who had several complaints such as heavy and painful menstrual periods, abdominal pain and fatigue. The GP referred her to the gynaecologist because, based on a sonogram made by the radiologist, he had diagnosed an enlarged uterus possibly with a fibroid. Talking about the enlarged uterus during the history part of the consultation, the patient says:

1 P: Yes, it's as if there is something er yes something that is not right.

2 G: Yes, yes, something is moving there. Did you put on weight?

3 P: Yes, I myself think so. I always have that before menstruation, then er then I have then I am at least two kilos heavier.

4 G: Yes, that is often a hormonal question. You can imagine, shortly before menstruation, there are some changes in hormones. And that feeling is caused because you tend to retain moisture then. And when your menstruation starts, these hormones change a little again and this results in the loss of a lot of extra water. So, a lot of people have that puffed up feeling. That doesn't have anything to do with a fibroid. 
During the physical examination the gynaecologist does not find anything abnormal although he expected, based on the information of the GP, to find an enlarged uterus:

5 G: Well, it's striking that by internal examination the size of the uterus isn't bad at all, I might say. I can feel it very well in this way. I think we should make a sonogram ourselves because I can't conclude here that there clearly is a fibroid.

6 P: Yes, but something must cause the troubles anyhow? (nervously)

7 G: Oh, it's definitely caused by the uterus. But sometimes you can say: this seems to be a large fibroid tumor and for such problems there is a direct solution. But sometimes something else is the matter. The internal examination doesn't provide the explanation for the complaints. So you mustn't say that there is a large uterus with large fibroid tumors. I would like to repeat the sonogram here, so that we can see ourselves what it looks like and what its exact size is. And we should also do a blood count, because the fatigue and all other complaints are related to the blood flow.

Then, appointments about further treatment are discussed. A curettage will be planned after the sonogram has clarified the cause of the complaints. The first utterances by this woman $(1,3)$ show that she relates a 'full feeling' and an increase in weight during menstruation to having a fibroid tumor. Here she makes covert anxiety expressions by gently alluding to possible (malignant) growths. The gynaecologist reacts by providing medical information about the reasons for gaining weight just before menstruation (4). In this way he tries to reassure the patient that this is not an indication of the presence of a fibroid tumor. When the examination does not reveal any abnormalities, the patient says somewhat desperately that something must cause the pain (6). Here she alludes in a covert way to the possibility of growths in the uterus. And, again, the doctor's reaction is to fill his patient's knowledge gap by telling her that it is not always that simple to find the cause of a certain complaint (7). Here he also uses the reassurance strategy of 'joint action' by indicating his plan of action for a more thorough investigation and by using the 'we-format' as proof to the 
patient that her complaints will be investigated precisely. This, evidently, opens the way for making appointments about treatment.

\section{Negation scenario}

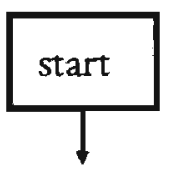

covert anxiety expression
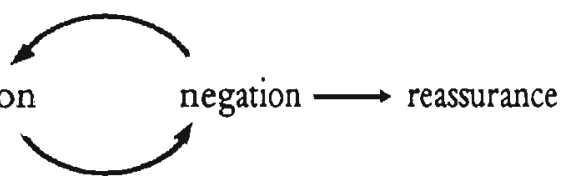

In this scenario, which occurred in our data less frequently than the other two scenarios, the patient initiates the scenario with a covert anxiety expression. This is followed by a negation by the physician. The scenario is often repeated several times during the consultation, until the physician provides a reassurance.

The next excerpt comes from the first consultation of a 34-year old woman who was referred to the gynaecological out-patient clinic with two problems: abdominal pain and unvoluntary urinay loss. Her GP had stated that these complaints were caused by a light prolapse of the vaginal wall. The patient has just answered a lot of medical questions. Directly after the physical examination she starts talking on her own initiative:

1 P: But I must say that I also, in the case of my eldest sister. Well, that remains on my mind.

2 G: What was her name?

3 P: K.M. You know, you treated her too. She was also in this hospital. My eldest sister.

4 G: What was her complaint because I don't remember that very well.

5 P: They have everything er

6 G: removed.

7 P: removed. Because of cancer.

8 G: Now, I remember, yes.

9 P: And that bothers me too er

$10 \mathrm{G}$ : But isn't she doing well then? 
$11 \mathrm{P}$ : Yes, but sometimes when I have a lot of p[ain

$12 \mathrm{G}$ : yes, yes, yes (indifferently)

$[\mathrm{Oh}$, yes,

13 P: Yes, with me it's alright. But she's the eldest and I'm the youngest and my father had it too, er lung cancer and er well, you start thinking about that.

14 G: Well, do you remember whether the GP made a Pap-smear?

15 P: Yes, but I don't know when exactly he made a Papsmear. Because I prefer to have it twice a year instead of once.

16 G: Well, that does not make sense. Look, if you do it twice, then you only have a would-be security, that does not prove anything. When the result is normal then it does not make any difference at all.

17 P: No, but just for myself, you know.

$18 \mathrm{G}$ : For yourself (irritated), but normally once in two years is enough, you know. Otherwise you're fooling your[self.

$19 \mathrm{P}: \quad$ That it becomes a kind of phobia?

$20 \mathrm{G}$ : Well, you must not make things so heavy, you must have some fun in [life.

$21 \mathrm{P:}$ [Yeah, oh but I have [enough fun, but

$22 \mathrm{G}$ :

what is your age?

[Yes, yes,

23 P: 34.

After this excerpt the doctor starts providing medical information about the complaints, especially about the causes for incontinence. The abdominal pain is referred to very briefly :

$24 \mathrm{G}$ : Abdominal pain is related to sorrow. If you say my eldest sister etcetera, I am concerned that the same thing will happen to me, that results in abdominal pain.

$25 \mathrm{P}$ : Yes, that has a psychological base.

$26 \mathrm{G}$ : Well, that is the same for men with gastric ulcers. Often it is not caused by food but by stress. Abdo- 
minal pain too is definitely related to the fact that you have been operated on your belly. The adhesions cause abdominal pain. Moreover, it is related to your belly, which hangs heavily over the pubic bone.

Then the physician gives some practical suggestions and starts making treatment appointments.

After history and physical examination this patient expresses in a covert way her anxiety. She is especially afraid because cancer is a wellknown disease within her family: her father and her eldest sister had malignancies. Therefore she associates her abdominal pain with malignancy (1-11). Only after the woman's considerable explanation does the doctor begin to understand this. He does not consider it a very legitimate concern and, consequently, negates it completely by interrupting: "oh, yes, yes, yes, yes, yes" (12). The patient, however, does not give up demonstrating that she is really worried. Again she makes an effort to introduce the familiar question (13). The gynaecologist negates this again by interrupting the patient with a medical question, namely when the GP made a cervical smear for the last time (14). He has picked up her anxiety for malignancy but instead of exploring it, he immediately places it in his own medical frame: conducting a cervical smear can reveal cervical dysplasias. Once again the patient introduces a covert anxiety expression by explaining that she prefers to have a Pap-smear twice a year instead of once (15). This is an example of a request for more medical intervention than is necessary from a medical point of view. The gynaecologist explains that this is not necessary at all. However, this information is not picked up by the patient because she still has not had the opportunity to talk about her fears. Once more she tries to convince him of her concerns, indicating that having frequent cervical smears gives her some reassurance (17). This is followed by a disqualification (18-21) and a negation (23). Later on in the consultation the gynaecologist tries to reassure her by providing medical information about the possible causes of her complaints. He explains for example that her abdominal pain is probably related to psychological problems and a prior operation (24-26). 


\subsection{Discussion}

In the context of the medical consultation, as the data illustrated, emotional expressions such as anxiety are not presented very directly. Patients indicate their concerns, especially about having malignancies, 'between the lines'. These covert anxiety expressions were identified in patients' allusions to having malignant growths, their pressure for more rigorous medical interventions and their auditive non-verbal anxiety-markers. The expressions were followed by three sorts of action by the doctors: exploration, reassurance and negation. These types of physician action provided the names for three different scenarios. The exploration scenario and the scenario of direct reassurance generally occurred more often than the negation scenario.

The exploration-scenario was the only scenario in which the question of cause was posed. The gynaecologists either started directly by asking whether and why a patient was anxious or they did this after a covert anxiety expression of the patient. In both cases the doctor's query prompted an overt anxiety expression: a narrative that rendered the patient's emotions intelligible. It simultaneously informed the doctor of the action that was subsequently necessary: a reassurance.

In the scenario of direct reassurance physicians provided reassurances after a patient's covert anxiety expression, or, more frequently, they anticipated patient anxiety and started directly with reassurances. The provision of medical information was an important reassurance strategy, which was often combined with two rhetorical strategies. The first is creating a feeling of 'joint-action', which means a combination of using the 'we' format and summing up the treatment plan, indicating that medical steps are going to be taken jointly. This strategy is especially conducted in less optimistic circumstances, e.g. when undesirable information has been provided. The second rhetorical strategy of reassurance is the use of linguistic markers of 'innocence'. It is often used when the diagnosis of the gynaecologist is less serious than the diagnosis of the GP. This suggests that the patient's previous treatment history offers an important context for the interactional work during a certain consultation. This accords with earlier studies on out-patient encounters, which have revealed how consultations vary according to their place in a patient's career (West, 1976; Strong, 1979). One might expect that reassurance offered directly after a covert anxiety expression, without first exploring the career, would probably lead to new anxiety expressions because the reassurance might be provided on the wrong topic. However, this appeared not to be the case. After reassur- 
ance, the discussion on that topic stopped. It was remarkable that patients accepted the reassurances provided, even if these were not related to the concerns as formulated in their anxiety expression. This phenomenon might be an indication of the interactional power of physicians over patients. Sometimes patients came back with new covert anxiety expressions later on in the consultation, but these were based on other subjects. Nevertheless, this may well be the way a less powerful person pursues her case (cf. Davis, 1988).

In the negation-scenario doctors negate patients' covert anxiety expressions by interrupting them with a medical question or by trivializing the anxiety. As we have seen in the data, doctors negate patients in order to stay on the medical frame. However, patients in this scenario do not stop talking on the subject of anxiety. On the contrary, they introduce new covert anxiety expressions, which sometimes are negated again, and so on. Thus, this scenario costs both the physician and the patient the most interactional 'work' and it is, due to its cyclical character, typically longer in duration. However, like the other scenarios, it ends when the gynaecologist offers reassurance.

This last scenario fits in Mishler's discourse analysis of medical encounters (Mishler, 1984). Mishler builds on the work of Silverman and Torode (1980) in identifying two 'voices' in medical consultations: the 'voice of the lifeworld' and the 'voice of medicine', which interrupt one another. The voice of the lifeworld is the expressive mode of the patient (for most of the time). The voice of medicine is couched in terms of decontextualized and impersonal medical phenomena. In the exploration and reassurance scenarios the two different 'voices' interrupt each other less frequently than in the negation scenario.

In their experiments, Gergen and Gergen (1988) found that each emotion (anger, depression and happiness) engendered only a single form of reply: an inquiry into cause. As they pointed out: "in terms of narrative the emotional expression is without sense or definition until it has placed within a narrative context - that is, supplied with antecedents". However, our data are not consistent with this observation, because they show that the question of cause was only posed in the exploration scenario. It is remarkable that gynaecologists often started very quickly providing reassurance. One explanation for this phenomenon is that gynaecologists assume they already know what the patient is worried about. They probably base this knowledge on the context of the actual consultation or on their experience with other patients. A second explanation is that the gynaecologists consider reassurance as something to be reached by provision of 
information and nor by legitimation to let patients tell their concerns. A final explanation for the fact that gynaecologists often start to reassure immediately is that, in contrast to the experimental situation in the study of the Gergens, emotional expressions in an actual clinical setting are so covert that they do not evidently result in questions about cause.

The observation of Gergen and Gergen that emotional scenarios almost invariably end optimisticly can also be concluded from our data. Gynaecologists, the last speakers in all three scenarios, did their best to end a scenario as positively as possible by providing reassurances. Especially in those cases in which gynaecologists disclosed a less favourable diagnosis, they immediately tried to reduce the impact of their words by using the 'joint-action' strategy. Discussion shifted away from the diagnosis to what type of medical interventions might take place in the particular case. This finding is consistent with Taylor's (1988) finding that surgeons, after having told women that they have breast cancer, quickly start to carry out efforts to soften the blow. Although a reassurance cannot be defined as a happy sentiment, it is at least a rather optimistic form in a medical setting.

The three scenarios seem partly physician dependent. The exploration and reassurance scenarios were found in the consultations of all four gynaecologists, while the negation scenario could only be identified in the consultations of two of the physicians. It was established, however, that, once a scenario was used, the sequence of the interaction was always identical. Furthermore, although the content of the different steps in the three scenarios was partly dependent on personal and contextual factors, again and again the sequences appeared to be the same. Clearly, these three anxiety scenarios are highly reliable within the context of the gynaecological interactions that we studied. Because of the small amount of data, it was not possible to find out under which conditions which scenario was chosen by patients and gynaecologists.

A final question that has to be answered is why patients present their anxiety in such a covert way. Schouten (1982) offers an explanation for this finding in his guidelines for the information-exchange between physician and patient. He points out that patients are ambivalent in talking about anxiety: on the one hand they wish to go into the problems that are related to their anxiety, on the other hand they tend to repress them, perhaps because they are afraid to have their anxious suppositions affirmed. This ambivalence might result into a covert way of expressing anxiety. Schouten (1982) and De Jongh (1987) hypothesize that patients have to be invited to talk, otherwise it is almost impossible for them to clarify such complicated 
feelings as anxiety and fear. This is confirmed in the present study: when doctors explored, patients always expressed their anxiety overtly. Another explanation for patients' covert anxiety expressions might be that these subtle forms of emotional expressions are more frequently used by women than by men. This hypothesis needs to be investigated in further research.

\subsection{Conclusion}

In this paper a preliminary attempt is made to apply Gergen and Gergen's work on emotional scenarios to an 'in vivo' situation, namely the communication about patients' anxiety for malignancy in gynaecological consultations. Our analysis of medical interactions revealed that patients have different ways of presenting anxiety and gynaecologists have different types of reactions to patients' anxiety. Three scenarios in communication about anxiety could be identified: an exploration scenario, a scenario of direct reassurance and a negation scenario. The scenarios suggest that dealing with emotions has a narrative basis and that the narratives involved require interdependency of action for their execution. This indicates that the strategy of providing more medical information to patients in order to reduce their anxiety, is too general. Provision of information is not just a matter of providing facts. Information is reassuring only when it is accompanied by rhetorical strategies. The provision of information has to take place within the framework of a scenario. Not every scenario is appropriate for an effective exchange of information. In the negation scenario, for example, accurate information does not reach patients.

Although all scenarios observed here end with reassurances, these reassurances do not seem to be equally effective. Those reassurances that are provided without any form of exploration, as in the scenario of direct reassurance and in the negation-scenario, bear a higher risk of inadequate interpretations of the patient's concerns. Doctors who engaged in the negation-scenario did not reach the time-saving effect they might have expected from negating patients' 'stories'. On the contrary, due to the interactive loop, the negation scenario requires more interactional work and has a longer duration than the other two scenarios. The exploration scenario is the only scenario in which patients are able to provide a complete and open narrative on the causes of their concerns.

Since the data of this study were not generated by random sampling techniques and since the amount of data is rather small, it would be 
inappropriate to generalize from these results to medical consultations at large. However, it is difficult to close this paper without commenting very tentatively on the implications of the findings for medical practice. We will list the most important recommendations for patient education which may be implied from this study.

As the present study revealed, an overt presentation of anxiety increases the opportunity that these concerns will be explored by physicians. Therefore, patients should be encouraged, e.g. by mass media, to express their concerns more overtly during medical consultations. The gynaecologists in this study tended to engage quickly in providing reassurances, without having explored precisely the actual concerns of their patients. This bears the risk that reassurance is provided 'on the wrong topic'. Thus, we would suggest gynaecologists and other medical practitioners to pay more attention to the exploration of patients' concerns. The present study offers several interactional means which are effective in encouraging patients to talk, such as posing open-ended questions ("Tell me more about the way this symptom worries you" (or words to that effect) (Sapira, 1972) and paraphrasing patients' terms. Finally, if gynaecologists want to avoid entering the ineffective interactional loop of covert anxiety expressions and negations, they should become more aware of patient behaviour which may mark anxiety, that is, allusions to malignant growths, pressure for rigorous medical intervention and speech-disturbances, and should perceive this behaviour as an indication that (further) exploration is necessary. 


\title{
Chapter 4
}

\section{Speaking about sexuality}

\author{
Abstract
}

Although survey research bas shown that both parties in medical consultations have difficulties with discussing issues relating to sexuality, little is known about how talk about sexuality is actually organized in medical consultations. This paper drawes upon conversation analysis to examine 32 gynaecological consultations involving 5 male doctors and 15 female patients. In these encounters we observed both patients and physicians using specific procedures to introduce and maintain topics relating to sexuality. Participants marked potentially delicate matters by 'expressive caution', i.e., interactional strategies such as delay, avoidance and depersonalization. This expressive caution was cooperatively accomplished between the participants. However, the doctors in these data had the power to determine the appropriate vocabulary to address and discuss women's reproductive organs and their sexual behaviour. Finally, we consider the consequences of the observed interactional strategies for gynaecological practice, concluding that the 'caution' strategies surrounding sexual topics reinforce stereotypes of female sexuality and prevent sexuality from becoming a legitimate and discussable subject in the medical encounter.

\subsection{Introduction}

Socio-cultural changes such as sexual liberalization and women's emancipation have led to a more open attitude towards (female) sexuality and the perception of sexuality as important to general well-being. This has resulted in heightened consciousness of sexual problems. Van Hall (1982) and

'Published as: Weijts, W., Houtkoop, H. \& Mullen, P. (1993). Talking delicacy: speaking about sexuality during gynaecological consultations. Sociology of Health and Illness, 15, 259-278. 
Ketting (1984) state that, due to these changes, women increasingly expect gynaecologists to attend to the psychosexual aspects of their gynaecological complaints. The gynaecologist sees on average 10 patients per week who consult him or her because of some kind of sexual dysfunction, or because of a gynaecological problem with a sexual dysfunction as a secondary symptom (Frick-Bruder, 1983; Frenken \& Van Tol, 1987). Dissatisfaction about sexual functioning is often underlying somatic complaints, such as recidive vaginal infections, chronic abdominal pain, urinary symptoms and pain during intercourse (Stanley \& Ramage, 1984; Van Binsbergen, 1988). Studies have shown that women with gynaecological complaints more often have a history of sexual abuse than women in age-related population samples (Ribberink \& Slurink, 1988; Drayer, 1990). These findings indicate that gynaecologists have an important role in clarifying and diagnosing problems relating to sexuality (Frenken \& Van Tol, 1987).

Although taboos regarding sexuality have eased considerably, discussing sexuality in clinical discourse still seems a difficult and embarrassing endeavour for physicians and patients (Hawton \& Oppenheimer, 1987; Wijma \& Areskog-Wijma, 1987). During gynaecological interviews we can observe both participants emphasizing the delicate nature of this issue. For example:

G: And about that - yes the sexual happening, being sulky, the fact that you don't feel like having it, I always find it very difficult to discuss that during a first meeting. It's difficult, anyhow, you know.

(2)
P: Because it is - well, not annoying to talk about it, but you can't talk about it with other people, because you just don't talk about that, you know.
$\mathrm{G}$ : It's still under taboo, isn't it?

The results of several surveys also emphasize the problematic character of talking about sexuality in clinical discourse. A representative study among Dutch gynaecologists has shown, for example, that more than half of them consider their communicative skills insufficient to talk about sexual problems and that one-fifth report feeling uncertain when patients tell them aspects of their sex life (Frenken \& Van Tol, 1987). Forty percent of a representative sample of Dutch general practitioners find it difficult to 
discuss sexual problems in detail with their patients and one in every five GPs reports lacking an appropriate language to talk normally about sexual issues. Moreover, GPs indicate that patients generally delay asking for help for sexual problems, and $75 \%$ identify a strong resistance among their patients to discussing their sexual behaviour and experience (Frenken et al., 1988). Finally, almost $20 \%$ of patients visiting a gynaecological out-patient clinic indicate that they would never discuss emotional or sexual problems with their physicians (Joustra \& De Vries, 1983; Petravage et al., 1979).

These surveys provide useful insights in patients' and physicians' perceptions of communication about sexuality during medical interviews. However, up to now, we lack knowledge of how patients and physicians actually talk to one another about such a non-routine issue as sexuality. Do they make use of specific devices when addressing this issue? And, if so, is there a difference between patients' and physicians' sexual vocabularies? Who initiates the use of a certain device and is it adopted by the other participant in the course of the interaction? In this paper, drawing on methods from conversation analysis, we examine, the interactional organization of talk about sexuality in gynaecological consultations with male physicians and female patients. We will argue that, although there are clearly cultural norms which identify delicate issues, the identification and treatment of delicacy is also a local matter, which is interactionally organized (cf. Silverman \& Peräkylä, 1990; Silverman, forthcoming). Or, as Bergmann (forthcoming) has nicely put it: "By describing something with caution and discretion this 'something' is turned into a matter which is in need of being formulated cautiously and discreetly".

After having demonstrated some typical ways of speaking about sexuality in the sample of gynaecological consultations that we observed, we argue that some of these discursive practices in clinical discourse may reinforce cultural stereotypes regarding (female) sexuality and may impede a sound conversation about sexuality and reproduction.

\subsection{Data collection and sample}

This paper is based on an analysis of 32 tape-recorded gynaecological consultations which were gathered in three gynaecological out-patient clinics in the Netherlands. Five gynaecologists and 15 patients participated in the study. The recordings comprised all successive consultations by each patient concerning the same complaint. The consultations were not standardized according to complaint presented or duration of relationship 
between the gynaecologist and the patient. However, of the 15 patients involved, only two had previously known the physician.

With consent of the physicians, the patients and the medical ethics committees of the hospitals involved, consultations were audiotaped, without the attendance of the researchers, and transcribed for later analysis. The transcriptions which are used in this paper are relatively literal translations from the Dutch transcripts. As all patients and physicians indicated that they forgot the presence of the audiorecorder after a few minutes, we may assume that its presence did not highly influence the course of the interactions. Immediately after each consultation separate interviews were held with both the gynaecologist and the patient in which they were encouraged to express their perception and evaluation of the consultation. However, because, during data collection, we had not envisaged focusing on 'talking about sexuality', this topic was not addressed as elaborately as it could have been. Therefore, the interview data in this article has only limited use.

The patients ranged from 18 to 49 years old, with a mean age of 34 , and belonged to the lower $(n=10)$ and middle $(n=5)$ socio-economic classes. The gynaecologists were all male and ranged from 37 to 50 years old. Their agreement to participate in the study suggests that they were especially willing to take a critical look at their own behaviour in consultations with patients. Therefore, they were probably more idealistic and actively concerned about providing optimal health care, at least from a communications standpoint, for their patients than the average gynaecologist.

\subsection{Procedure of analysis}

The findings reported in this paper did not emerge from any initial plan to study characteristic features in communication about sexuality. The data set has already formed the basis of two other analyses (Weijts et al., 1991; Weijts et al., forthcoming). From our first glance at the transcripts, however, we were rather surprised that several patients participating in the study presented problems with sexuality after having brought to the fore other gynaecological complaints. Moreover, as soon as sexual issues were discussed the language of the speakers seemed to change drastically. It was these observations that inspired us to conduct a more comprehensive analysis into 'delicate talk'.

Our analysis started by selecting all excerpts in which aspects relating 
to sexuality were the topic of conversation. Drawing on methods from conversation analysis, each of these excerpts was examined in detail for typical ways of speaking. The central goal of conversation analysis research is the description of the rules that ordinary people use and rely on in participating in intelligible social interaction. At its most basic, this objective is one of describing the procedures by which conversationalists produce their own behaviour and understand and deal with the behaviour of others. At a fundamental level lies Garfinkel's (1967) assumption that these activities - producing conduct and understanding and dealing with it - are accomplished as the accountable products of common sets of procedures (Atkinson \& Heritage, 1984).

Having identified a certain procedure in an excerpt, we checked whether it also occurred in other excerpts concerning sexuality. If this was the case, we investigated the incidence of the device during talk about other, less delicate, topics. If it was seldom observed in these other excerpts we decided that it might be a typical way of 'making delicate talk'.

\subsection{Results}

\subsubsection{Delay}

Our first observation was that both the patients and the gynaecologists in our data had a tendency to delay discussing issues relating to sexuality. Two different forms of delay are observed. First, the topic of sexuality can be delayed, either till the end of a consultation or even till a subsequent consultation. Second, we have observed a delay in using words concerning sexuality.

\section{Delay of sex-as-a-topic}

Patients can delay matters relating to sexuality by introducing them only when their 'reason-for-contact-complaint' has been addressed and when the consultation is about to end. This is illustrated in excerpt 3, which follows after the physician has informed the patient about two treatment options for premenstrual tension: hormones or vitamin preparations. His suggestion is to try the vitamin preparations first, to which the patient agrees. Then the physician concludes: 
(3)

1 G: Shall we try those vitamin preparations, let's see

2 how they work and yes (1.0)

3 P: But maybe it will help too, but e::r (0.9) I rea:lly

4 don't feel like having sex, you know.

$5 \quad(0.8)$

6 Absolutely not.

By repeating the treatment proposal (line 1) the gynaecologist proffers a 'possible pre-closing', an action to initiate the closing section (Schegloff \& Sacks, 1973; Houtkoop-Steenstra, 1987). However, before the physician gets the chance to move towards further closing of the conversation, the patient cuts off the sequence with a new and unrelated topic, i.e., not feeling like having sex (lines 3 and 4). Notice how she tries to make an apparently logical link between the former topic and her sexual problem ("but maybe it will help too..."). In our data sexual problems are almost the only, complaints which are presented late in the conversation. In general, women with more than one complaint or request normally present them all at the beginning of the encounter. An exception is the late presentation of a request for cosmetic surgery on the belly by a woman whose initial complaint was abdominal pain. In the interview right after the consultation, the woman said that requesting a correction of her appearance was very embarrassing for her. Apparently, delaying the presentation of complaints or requests is a patient strategy, albeit unconscious, to deal with delicate issues. Despite their delayed presentations, these problems receive physicians' attention in our data.

We have also observed physicians delaying talking about sexual problems. One patient, for example, who introduces sexual problems during a first meeting, is told that her problems will be dealt with in the next consultation (see excerpt 1). The reason the physician gives for this is that they first need to know each other better. However, in this woman's second and last consultation, we observe that the issue does not recur anymore. During the interviews all physicians indicate that they prefer to delay talking in detail about sexual problems to a later consultation. They emphasize the importance of constructing a relationship built on trust with a patient, before being able to engage effectively on this topic.

\section{Delay in using delicate terms}

Patients can delay using delicate terms by refraining from answering potentially delicate questions regarding sexuality during history-taking. An 
example: in the sequence before excerpt 4, which takes place during history-taking, the gynaecologist has asked the patient whether she has problems with her bowel movement. After the woman's negative answer, he summarizes and introduces a new subject:

(4)

$1 \mathrm{G}$ : So the movements are OK (0.8) and with sexual

2 contact you don't have any problems?

$3 \quad(0.4)$

4 P: Yes.

5 G: Which?

6 P: Always had that, you know.

When the physician asks the leading question "And with sexual contact you don't have any problems?" (line 1-2), he displays that he expects a 'no'answer (Sacks, 1987). The conversation, however, has not provided any indication for the physician to make such an assumption. Furthermore, as the patient shows in her answer ("Yes"), she does have problems. By saying "yes", the woman chooses the shortest possible answer. However, according to the Dutch pragmatic-linguistic rules, a single "yes" is inappropriate as a disconfirmation. She should have said "Yes, I do" ("Jawel" instead of "Ja"). Silverman (forthcoming) states that by producing a minimal amount of potentially delicate items at a first turn after a question, the speaker leaves it up to the recipient to decide whether to treat it as a gloss which needs unpackaging, e.g. via a probe or a demand for specification. Such requests provide a favourable environment for disciosing items marked as delicate because such items can now be produced as demanded by physicians rather than as volunteered by patients. However, in excerpt 4, it does not seem to work out this way. After the physician's attempt to encourage the woman to specify her sexual problems (line 5), she further delays giving details. Whereas the doctor asks for a specification of the sexual problems, the patient's reply is about the time she has had them (line 6).

Although we have not systematically studied the phenomenon, the use of leading questions to conduct the anamnesis in these data is striking. In the fragments presented in this paper, it is a feature of fragment 4 "And with sexual contact you don't have any problems?", fragment 5 "You don't use the pill?" and "Just being a little careful?", fragment 9, lines 1-2, fragment 12 lines 21,27 and 33, and fragment 16. And in none of these cases does the preceding conversation give reason for making the assumptions that are contained in the questions. 
Based on the work by Sacks (1987) and Pomerantz (1984), it may be hypothesized that formulating questions in this way may constitute an interactional problem, and maybe a medical problem as well. Sacks and Pomerantz have shown that conversationalists tend to give answers that are in agreement with the answer that is presupposed by the question. When the answer is not in agreement, it tends to be structured differently if compared to agreeing answers. Disagreeing answers are often prefaced by delays, such as pauses or fillers ("well"), or they are prefaced by 'agreementtokens'. An example:

$\begin{array}{rll}1 & \text { G: } & \text { You don't use the pill? } \\ 2 & \text { P: } & \text { No } \\ 3 & \text { G: } & \text { How is contraception managed then? } \\ 4 & & \text { Do you use condoms [or } \\ 5 & \text { P: } & \text { [No, no just e::r }(0.5) \text { we } \\ 6 & & \text { don't use [anything. } \\ 7 & \text { G: } & \text { [Just being a little careful? } \\ 8 & \text { P: } & \text { Well, well, [we have one child and a second one } \\ 9 & \text { G: } & \text { [Or not being careful? } \\ 10 & \text { P: } & \text { would be welcome, you know. }\end{array}$

In this fragment the doctor clearly assumes that the patient uses some form of contraception (line 3). When the woman answers that she and her partner do not use anything (line 5-6), a disagreement, she does not contradict the assumption that she would want to prevent becoming pregnant. And the doctor then assumes that they use the 'contraceptive' of 'just being a little careful' (line 7). Note that this is the third time he makes the wrong assumption. It is only then that the patient contradicts the assumption, and she does so in a rather implicit way. It is not that she not uses any form of contraception; on the contrary, she does not want to prevent pregnancy: "Well, well,... a child would be welcome, you know".

By formulating their questions in this way, physicians display ideas of 'normality', that is, what they see as the normal situation or the normal thing to do. When these ideas are contrary to women's situation or behaviour, this may make it difficult for patients to disagree with the physician's question, especially when the question concerns a 'delicate' topic.

Another way of delaying the delivery of potentially delicate words is producing hesitations and pauses in the context of these terms. Silverman 
and Peräkylä (1990) observed that both counsellors and clients in HIV/AIDS counselling interviews delay the production of terms, such as 'condom', 'ADS', 'intercourse', by preceding them with perturbations. They identify a perturbation by the presence of any disturbed speech in a turn at talk. The disturbance may be a pause, a hesitation, a change of intonation or a self-repair (which occurs when the speaker corrects her utterance). Although perturbations can have several functions, e.g. topic or speaker change is often associated with a pause, Silverman and Peräkylä termed it a pre-delicate perturbation "when the only sequential or interactional explanation for a perturbation is the delicacy of the item that follows it" ( $p$. 297). According to these authors, by producing pre-delicate perturbations speakers mark the delicacy of a subject in that specific situation.

Excerpt 6 takes place at the very beginning of a consultation. Notice how the patient describes her first problem, irregular menstruations, very fluently, while she produces hesitations and pauses (lines 13 and 14) before finally presenting her second and 'main problem': being sulky and not feeling like having sex.

(6)

$1 \mathrm{G}$ : What has happened during these two years?

$2 \mathrm{P}$ : $E r$, it has started with the complete absence of the

3 menstruation. So (0.6) for about three months I

4 didn't have it at all. And then I went to the GP

5 because I didn't know what was wrong. Well, he

6 said I think you are at the change of life. And he

7 prescribed tablets to start it again. It was those red

8 tablets. And (0.6) well, they made it start again. But

9 it is very irregular. Sometimes even every fortnight.

10 Because I had it at the beginning of June and last

11 Friday I had it again. And it's just a little bit, but

12 personally, I find the main problem that I am e:r

13 tremendously sulky. And (0.3) you can't stand

14 anything, e::r (1.2) er no intercourse with your

15 husband. So for two years no intercourse.

16 G: $\mathrm{Mmmm}$

Note also that the patient in this excerpt begins her account (lines 11-15) by attending to her dispositions ('tremendously sulky', 'can't stand anything'). Presumably such dispositions are less problematically reportable 
than sexual behaviour. Thus, the woman not only delays an account of sexual behaviour but first makes it accountable.

Sometimes, patients' pauses or hesitations before potentially delicate terms result in a completion of the turn by the gynaecologist. Excerpt 7 , for example, occurs at the end of an infertility consultation during which the physician has explained to the woman that her husband has to bring sperm to the out-patient clinic in order to have it examined. When the physician asks her at the end of the interview whether she has any more questions, she answers:

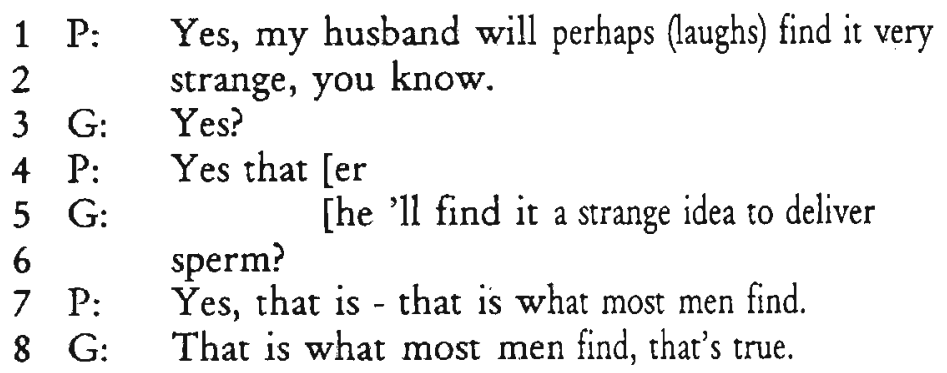

In line 1 the patient avoids explicitly mentioning the subject of the delivery of sperm. In this way she marks the delicacy of this topic. After the physician's continuer ("yes?"), the woman starts elucidating her point (line 4). When she produces a hesitation, the physician completes her sentence, while producing himself the potentially 'delicate' issue (line 5). The same phenomenon can be noticed in excerpt 5 , where in line 7 the physician completes the patient's sentence after her hesitation and pause. The phenomenon, physicians completing sentences in which patients produce hesitations, can be considered as a collaborative production from both participants. Patients probably hesitate before embarrassing terms in order to leave it to the physician to determine the current terms in this context. In fact, it seems to work out this way, because physicians take over the turn and produce the delicate terms. Their behaviour may be motivated by concerns with 'face' (cf. Goffman, 1967). In their role as professional, physicians may feel responsible, though unconsciously, to avoid facethreatening activities for their patients, such as the production of delicate terms. Although producing perturbations is a common phenomenon in normal speech, we can observe, among patients, a much higher quantity of hesitations and pauses in the context of potentially delicate issues. Also the 
completion of turns by physicians can be seen more frequently in such contexts.

We also observed physicians delaying the delivery of potentially 'delicate' topics:

(8)

1 G: E::r I'd like to mention that er (1.5) there is one

2 thing which is very uncertain about operating on a

3 uterus and that is how sex works out afterwards.

4 There are er women who er (0.9) find that after an

5 operation, the removal of the uterus, that making

6 love is much more pleasant. Apparently (0.6) not

7 being anxious about flow plays a role, that you (0.4)

8 er (0.7) maybe don't have pain anymore during

9 intercourse. It could have those kinds of reasons. So

10 they are very satisfied. There are women also who

11 say well (0.4) I miss something (0.8) now (0.4) with

12 coming especially. That er there are women who

13 say, afterwards I notice since my uterus has been

14 taken out that er (1.3) that coming is less (1.1)

15 intense, to put it that way.

This excerpt contains information about the effect of a hysterectomy on sexual feelings. Note the hesitation, pause and repair before 'coming' in line 14 and the pause before the sexually associated 'intense', also in line 14. Moreover, in line 10 the physician delays the presentation of the negative consequences of a hysterectomy by first mentioning women's positive experiences. This finding is consistent with those of Silverman (forthcoming) who also found that 'bad news' sequences are routinely preceded by 'good news'.

We have found that physicians systematically produce hesitations and pauses only when they talk about psychological or relational aspects of sex or when sexual actions are discussed. Routine questions regarding sexuality (e.g., "You never have pain during making love"?) or instructions which have a certain measure of generality and do not specifically concern the person addressed (e.g., "Mostly you flow a little after a curettage. That's quite normal. During that period you mustn't have intercourse "), are seldomly preceded by perturbations. Apparently, there are no universal delicate issues: what is delicate is always a local matter (cf. Silverman, forthcoming). 


\subsubsection{Avoidance}

A second major strategy that people use when talking about sexuality in the gynaecological consultations that we observed, is avoiding delicate terms relating to sexuality. The ways of speaking which characterize this phenomenon of avoidance are using vague terms, omitting delicate terms, and using pronouns.

\section{Using vague terms}

In talking about sexuality we find physicians using very vague terms, including euphemistic terms, such as 'down there', referring to the vagina and 'to go to the meadow' (in Dutch: 'de wei ingaan'), referring to a period of trying to get pregnant after several infertility tests have been carried out. Another example of vague terminology can be seen in excerpt 10 in which the physician asks whether the patient, an 18-year woman suffering from abdominal pain, has experienced sexual abuse:

(9)

1 G: And nothing has ever happened (0.7)

2 with examination or

$3 \quad(1.4)$

4 G: problems at home

$5 \quad(0.7)$

6 brothers or

$7 \quad(0.7)$

8 P: No.

9 G: Never no.

10 P: I was er (0.3), let's see, when I was at the GP's, I

11 got er for the first [time er a gynaecological exam-

12 ination.

13 G: [That the examination was con-

14 ducted. OK (continues)

The physician formulates his leading question in rather vague terms: only after the word 'brothers' (line 6) does the association with sexual abuse become apparent. 'Nothing happened with examination' and 'problems at home' are much more general descriptions. In lines 3, 5, and 7 the physician uses what Sacks in his unpublished lecture notes calls 'interruption invitation devices' (Houtkoop-Steenstra, 1987). After 'examination', 'problems at home' and 'brothers', he pauses each time, by which he invites the patient to take over the turn. As long as she does not provide 
an answer, she indicates that the turn is not complete enough for response (Schegloff, 1980, p. 150). In this way she 'forces' the gynaecologist to become more specific. Thus, by means of the interruption invitation device, the physician manages to provide only that amount of information necessary to communicate the delicate issue. The interview with the patient directly after the consultation showed that she had understood that the physician was referring to sexual abuse.

\section{Omitting delicate terms}

Besides vagueness, avoidance of delicate terms can also involve the total omission of delicate terms:

(10)

$1 \mathrm{P}:$ Well, because I $(0.8)$ regularly experience

2 pain [omission]

$3 \quad(1.0)$

4 G: $\mathrm{Mmm}, \mathrm{mmm}$

5 P: I don't feel the need for it. Because it isn't healthy

6 once in three, four months [omission], is it?

The patient in excerpt 10 does not indicate when she experiences pain and what is not healthy to do only once in three or four months. In the course of that same consultation, after the gynaecological examination has taken place, the omitting of delicate terms is continued by the gynaecologist:

(11)

1 G: And the third is, say, is the sexual contact.

$2 \quad(1.8)$

3 That was already before pregnancy. Yes, I - having -

4 having examined you, I can tell you that the size

5 [omission] is normal, so not that one would say

6 [omission] is too small - is too small or too narrow

7 or there are special ribs in it as a result of which it

8 [omission] hurts etcetera. But I really can imagine

9 that it causes some complaints.

Here the physician omits indicating what has a normal size (line 5), what is not too small and too narrow (line 6) and what hurts (line 8). 


\section{Using pronouns}

During conversations about sexuality, physicians and patients frequently refer to issues in terms of demonstrative pronouns and adverbs once they have been introduced. Consider excerpt 12, in which the physician returns to the patient's problem with 'sexual contact' and starts exploring it. As excerpt 4 showed, this problem was discovered during history-taking. In order to understand excerpt 12, the reader should know that this woman has had two Caesarian sections some years ago:

(12)

1 G: So what's the problem with sexual contact?

$2 \quad(1.0)$

3 Is it [that

4 P: $\quad$ [Well it isn't pleasant, it hurts also.

$5 \quad(1.0)$

6 G: Always?

7 P: Well mostly it does

$8 \quad(1.7)$

9 G: And what [does

10 P: [a:nd I'm also a little scared

11 to e::r yes

12 G: Mmmm and what hurts then, the penetration or

13 the event itself or afterwards

$14 \quad(0.8)$

15 do you have any cramps afterwards for example

$16 \quad(1.0)$

17 [or

18 P: [yes there are very severe shootings you know.

19 G: But it's during the sexual contact that it hurts? =

$20 \mathrm{P}: \quad=$ Yes.

21 G: And you already had that before you got pregnant?

22 P: $\mathrm{Mmmm}$

$23 \quad$ (4.6)

24 I think I wasn't born quite right down

25 there (laughs shyly).

26 (3.0)

27 G: But you don't say (.) it got - it got - it got

28 worse since pregnancy?

$29 \quad(1.2)$ 
30

31

32

33

34

35

36

37

38

39

40

41

42

43

44

45

46

$47 \mathrm{P}$ : Because it's not healthy once in three, four months,

48

Because (.) of course (0.7), you've got to realize that quite well, that down there (0.8) not very much happened due to the pregnancy. You've never (1.3) delivered normally, have you? =

P: = It hasn't been damaged, has it?

G: No that remained the same, to put it cautiously. So (.) I can very well imagine that if you had problems with that before, that those problems still exist now, But (.) you should think over with your husband whether it's a er technical problem, that it's a little narrow, or that it is very tough or stiff or whether the problem is more that $(0.6)$ you don't feel like having it, or that you say, [well

P: [Well, because I (0.8) regularly experience pain, (1.0) I don't feel the need for it.

G: $\mathrm{M}: \mathrm{mm}, \mathrm{M}: \mathrm{mm}$. is it?

After the physician has produced the term 'sexual contact', both the physician and the patient refer to it further by using demonstrative pronouns and adverbs: 'it' (line 4), 'afterwards' (lines 13 and 15), 'with that' (line 37) and 'it' (lines 42 and 45). In the same way the issue 'pain during sexual contact' (ine 19) is not repeated, but referred to by pro-forms ('that', line 21; 'down there', line 24 and 'it', line 27). After the physician's introduction of the euphemism 'down there', this item is further addressed by 'it' (line 34), 'that' (line 35) and 'it' (line 40).

Although pronominalizing is a normal procedure, we have observed it much more frequently in talk about sexuality than about any other subject. Pronominalizing becomes problematic when it is not clear anymore from the context what nouns the pronominal expressions refer to. The large number of demonstrative pronouns and adverbs in excerpt 12 do not cause problems with understanding. However, in order to identify the referents correctly, the speakers need to conduct quite a lot of inferential work, especially because some pronouns refer to nouns which have been mentioned much earlier, for example, 'with that' in line 37 and 'it' in line 40 refer to the term 'sexual contact' in line 1. Moreover, sometimes pronouns even refer to something which has not been mentioned at all, e.g. 
in "that it's a little narrow" and "it's very tough or stiff" (line 40). It is because of the context and because of our everyday knowledge of the world, including the female body, that we are able to infer that the physician is referring to the vagina here.

\subsubsection{Depersonalization}

A third major strategy which characterizes talk about sexuality in our data is, what we would like to call, depersonalization. This strategy includes ways of speaking which loosen the link between the person and her most private actions and bodily aspects. Two devices have been observed regarding this phenomenon: nominalizing, i.e. forming nouns from verbs, adjectives, etc., and using definite articles instead of possessives.

\section{Nominalizing}

Physicians in our data regularly change verbs into nouns, especially when asking questions during history-taking (e.g., "Any problems with defecation", "Urination goes well?", "You never have pain during making love?"). This is probably because it is the fastest way to get through a series of, often protocollized, questions. However, in our sample it is only in talk about sexuality that we observe a general tendency to nominalise. For example:

G: $M m m$ and what hurts then, the penetration or the event itself or afterwards, (0.8) do you have any cramps afterwards for example (1.0) or

G: There are women also who say well $(0.4)$ I miss
something $(0.8)$ now $(0.4)$ with coming especially.

In excerpt 13 the physician nominalizes 'when you're penetrated' and 'when you're having intercourse' in the more general 'the penetration' and 'the event itself respectively. Excerpt 14 contains the gerund 'coming' instead of 'when you're coming'. By using the nominalizing form one can avoid mentioning the actor. This offers the opportunity to talk in a more abstract, depersonalized and thus more discrete way about the private and delicate aspects of the patient's life. 


\section{Using definite articles}

When physicians mention parts of the patient's body, they mostly precede these terms with possessive adjectives. For example, they talk about 'your kidneys', 'your belly', 'your cervix', 'your ovaries"' and 'your muscles'. However, in our data, two parts of the body are never preceded by possessives, i.e, the vagina and the breasts (see also, Emerson, 1972):

\section{G: Do you ever use a tamp in the vagina?}

\section{G: You don't have any secretion from the breasts?}

Patients also normally use possessive adjectives when talking about parts of their body and physiological processes: 'my back', 'my leg', 'my belly', 'my menstruation'. We have observed that the patients in our sample never produce the word vagina, neither do they use any other word to indicate this part of the body. Moreover, the only part of the body which patients never qualify by possessive adjectives are the breasts. For instance:

P: What I did notice, when I used the pill I didn't have any pain in the breasts before I got periods and now I do have each time.

The replacement of possessives by definite articles is a form of 'agent reduction'. It is a way to push the person performing the action into the background. Similarly to nominalizing, this may also be a technique to talk in a discrete way about delicate issues.

\subsubsection{Tuning}

An important observation in our data is that physicians, during interview episodes, tend to adopt patients' styles of speaking regarding sexuality. In excerpt 12 , for example, the physician starts talking with a respectful distance, using many pronouns, after the woman has avoided becoming concrete about her pain during sexual contact. Moreover, he adopts the patients' omissions (excerpts 10 and 11) over time. We have also observed physicians repeating patients' terms, as is illustrated in the following excerpt: 
1 P: But personally I - I find it so strange (1.6) e:r that

2 for two years I haven't had e::r well a feeling for

3 intercourse or so

4 G: But the feeling for intercourse, that that has gone or

5 has changed, has of course a relation with er your

6 age (continues)

Patients, however, do not take over physicians' terms regarding sexuality, even though physicians offer them a rather neutral vocabulary. They just avoid using potentially delicate terms referring to the reproductive organs (except 'uterus') or sexual activities in their answers to physicians' questions. Consider, for example, excerpt 12 in which the physician speaks about the vagina in terms of 'down there' and the patient consequently refers to the vagina by 'it'. It seems as if the patients prefer the physicians to do the 'explicit' mentioning of the delicate terms, so they, the patients, can use these terms in more 'indirect' ways.

\subsection{Discussion and conclusion}

According to Bergmann (forthcoming), "Sociologically viewed, there is not first an embarassing, delicate, morally dubious event or improper behaviour about which people then speak with caution and discretion; instead, the delicate and notorious character of an event is constituted by the very act of talking about it cautiously and discretely".

In our sample of gynaecological consultations, we have seen that issues relating to sexuality are, in a massively recurrent manner, avoided or approached very carefully. The participants in the gynaecological consultations introduce and address such 'delicate' matters by what Silverman (forthcoming) calls 'expressive caution', represented by delay, avoidance and depersonalization. We have also identified that, by copying each other's interactional devices of 'expressive caution' (tuning), the conversationalists jointly accomplish the delicacy of the topic under discussion. The different devices categorized under these strategies are summarized in table 4.1: 
Table 4.1 Strategies and devices in speech about sexuality.

\begin{tabular}{|c|c|c|}
\hline major strategy & device & performer(s) \\
\hline delay & $\begin{array}{l}\text { - delaying sex-as-a-topic } \\
\text { - refraining from answering } \\
\text { questions } \\
\text { - producing pertubations in } \\
\text { the context of delicate } \\
\text { terms }\end{array}$ & $\begin{array}{l}\text { patient / physician } \\
\text { patient } \\
\text { patient / physician }\end{array}$ \\
\hline avoidance & $\begin{array}{l}\text { - using vague terms } \\
\text { - omitting delicate terms } \\
\text { - using pronouns }\end{array}$ & $\begin{array}{l}\text { physician } \\
\text { patient / physician } \\
\text { patient / physician }\end{array}$ \\
\hline depersonalization & $\begin{array}{l}\text { - nominalizing } \\
\text { - using definite articles }\end{array}$ & $\begin{array}{l}\text { physician } \\
\text { patient / physician }\end{array}$ \\
\hline tuning & $\begin{array}{l}\text { - adopting patients' use of } \\
\text { pronouns and their } \\
\text { omission of delicate terms } \\
\text { - repeating patients' terms } \\
\text { - omitting physicians' } \\
\text { references }\end{array}$ & $\begin{array}{l}\text { physician } \\
\text { physician } \\
\text { patient }\end{array}$ \\
\hline
\end{tabular}

Although we have described the different devices separately, in reality they are often used simultaneously. The physician in excerpt 8 , for instance, delays talking about 'sex after a hysterectomy' by mentioning the negative consequences only late in the turn, but he also contributes to depersonalization by turning verbs into nouns.

This analysis shows that in these gynaecological consultations the physicians have (and are also given) the power to determine what is the appropriate vocabulary to address and discuss women's reproductive organs and their sexual behaviour. Their way of speaking may have several problematic implications for the care women receive. First, the discursive practices that are identified may reproduce and produce cultural stereotypes regarding (female) sexuality. For example, the analysis has revealed that certain gender-specific words like 'vagina' and 'orgasm' are regularly 
omitted from conversations or are referred to very vaguely. In fact, we observed a common avoidance of explicit terminology in staff-patient contacts. Such signifiers are problematic because they reinforce the stereotype that female sexuality is something 'dark and mysterious'. They may prevent that women become less alienated from their bodies and more familiar with at least the functional aspects of their sexuality and reproductive capacities. Another example of discourse that may reinforce stereotypes are the leading questions that the physicians generally use when addressing issues relating to sexuality (e.g., "With sexual contact you don't have any, problems?", "You don't use the pill?"). These questions display physicians' 'ideas of normality' regarding sexual behaviour. For example, they reveal the assumption that people have sex regularly and that they use contraception, preferably birth control pills.

A second problem connected with the way discussions about sexuality are interactionally organized in the consultations that we observed, is that women's problems with sexual dysfunctioning run the risk of remaining unaddressed or only partly addressed, because of physicians' and patients' tendency to delay discussing these issues. The communication format which is usually adopted at the start of a specialist consultation is, what Peräkylä and Silverman (1991) termed, an interview format, a communication format in which the physician and the patient are aligned as questioner and answerer respectively. Unless the physician asks a question about sexual functioning, it is difficult for the patient to introduce sex as a topic for discussion. This would require a 'departure from the ordinary communication format'. 'Therefore, a recommendation for practice could be to ask questions about sexual functioning early in the consultation, within the interview format used during history-taking. After all, within this format the question into sexuality is 'noticeably absent' (Sacks, 1987) and in this way, the topic is defined as 'irrelevant' to the consultation. Furthermore, physicians' neutral and veiled vocabulary emphasizes that sexual problems are a delicate topic of discussion in the gynaecological setting and that physicians prefer not to go into it. We have seen that physicians' neutral vocabulary regarding sexuality is not adopted by patients. It is possible that this neutral vocabulary implicitly discourages patients from talking in more detail about their sexual problems. In other words, there is no atmosphere in which the patient can feel as comfortable as possible talking about her sexuality. Therefore, gynaecologists could be trained to incorporate experience with a vocabulary that allows them to refer sexual and reproductive activities with less of the cultural mystique which reproduces stereotypes regarding (female) sexuality and which prevents that sex 
becomes a legitimate and discussable subject within gynaecological practice.

An important subject requiring more insight is the discursive practices around the topic of sexuality in consultations between female gynaecologists and female patients. Roter et al. (1991) have suggested that patients talk substantially more and that there may be less avoidance of or delay in broaching psychosocial concerns when patients are with female physicians. It is possible that, within a female context, patients and doctors have a completely different mode of dealing with female sexuality. 


\section{References}

Adviesgroep Vrouwenhulpverlening (1991). Vrouwenbulpverlening in de somatische zorg. Rijswijk: Ministerie van Welzijn, Volksgezondheid en Cultuur.

Anspach, R.R. (1988). Notes on the sociology of medical discourse: the language of case presentation. Journal of Health and Social Behaviour, 29, 357-375.

Areskog, B. \& Ruusuvaara, L. (1983). The first gynaecological examination. Journal of Psychosomatic Obstetrics and Gynaecology, 2, 200-201.

Atkinson, J.M. \& Heritage, J. (Eds.) (1984). Structures of social action: studies in conversation analysis. Cambridge: Cambridge University Press.

Bain, D.J.G. (1979). The content of physician/patient communication in family practice. Journal of Family Practice, 8, 745-753.

Baker Miller, J. (1976). Towards a new psychology of women. London: Pelican Press.

Beisecker, A.E. \& Beisecker, T.D. (1990). Patient information-seeking behaviors when communicating with doctors. Medical Care, 28, 19-28.

Bensing, J.M. (1991). Doctor-patient communication and the quality of care. An observation study into affective and instrumental bebavior in general practice. Dissertation. Rotterdam: Erasmus University.

Bergmann, J.R. (forthcoming). Veiled morality: notes on discretion in psychiatry. In P. Drew \& J. Heritage (Eds.), Talk at work: Social interaction in institutional settings. Cambridge: Cambridge University Press.

Bergsma, J. \& Rullman-Schadee, G. (1975). Een bijdrage van de psychologie aan het ziekenhuisklimaat. Utrecht: Nationaal Ziekenhuis Instituut.

Bertakis, K. D. (1977). The communication of information from physician to patient: A method for increasing patient retention and satisfaction. Journal of Family Practice, 5, 217-223.

Boreham, P. \& Gibson, D. (1978). The informative process in private medical consultations: a preliminary investigation. Social Science and Medicine, 12, 409-416.

Brody, H. (1987). Stories of sickness. New Haven: Yale.

Brown Trevis, C. (1988). Women and bealth psychology: Biomedical issues. Hillsdale: Lawrence Erlbaum Associates.

Cassell, E. (1985a). Talking with patients, Vol.1: The theory of doctor-patient communication. Cambridge: MIT.

Cassell, E. (1985b). Talking with patients, Vol.2: Clinical Technique. Cambridge: MIT. 
Charon, R. (1989). Doctor-patient/reader-writer: learning to find the text. Soundings, 72, 1101-1106.

Churchill, L. (1978). Questioning strategies in sociolinguistics. Rowley, Mass.: Newbury House.

Cicourel, A.V. (1964). Method and measurement in sociology. New York: Free Press.

Cicourel, A.V. (1981). Language and meaning. In C.A. Ferguson \& S. Brice Heath (Eds.), Language in the USA (pp. 407-429). Cambridge: Cambridge University Press.

Cicourel, A.V. (1983). Hearing is not believing: Language and the structure of belief in medical communication. In S. Fisher \& D. Todd (Eds.), The social organization of doctor-patient communication (pp. 221-239).

Washington D.C.: Center of Applied Linguistics Press.

Clark, J.A. \& Mishler, E.G. (1992). Attending to patients' stories: refraiming the clinical task. Sociology of Health and Illness, 14, 344-372.

Cochrane, R. \& Stopes Roe, M. (1983). Women, marriage, employment and mental health. British Journal of Psychiatry, 11, 373-381.

Comstock, L.M., Hooper, E.H., Goodwin, J.M. \& Goodwin, J.S. (1982).

Physician behaviors that correlate with patient satisfaction. Joumal of Medical Education, 57, 105-112.

Davis, K. (1988). Power under the microscope. Toward a grounded theory of gender relations in medical encounters. Dordrecht: Foris Publications.

De Jongh, T.G.M. (1987). Ongerustheid, een eerstelijns ziekte. Medisch Contact, 26, 828-830

Devine, E.C. \& Cook, T.D. (1983). A meta-analytic analysis of effects of psycho-educational interventions on length of post-surgical hospital stay. Nursing Research, 32, 267-274.

DiMatteo, M.R. \& DiNicola, D.D. (1982). Achieving patient compliance.

New York: Pergamon Press.

Drayer, N. (1990). Seksuele traumatisering in de jeugd. Gevolgen op lange termijn van seksueel misbruik van meisjes door verwanten. Amsterdam: SUA.

Eisner, M. \& Wright, M. (1986). A feminist approach to general practice. In C. Webb (Ed.), Feminist practice in women's health care (pp. 113145). Chicester: Wiley.

Egtbers, J., Van der Marel, K., Rijkschroeff, R. \& Soetenhorst-de Savornin Lohman, J. (1991). De integratie van vrouwenbulpverlening in het algemene psychiatrische ziekenbuis. Utrecht: Nationaal Ziekenhuis Instituut. 
Emerson, J.P. (1972). Behavior in private places: sustaining definitions of reality in gynecological examinations. In H.P. Dreitzel (Ed.) Recent sociology (vol. 2): Patterns of communicative behavior (pp. 74-96). New York: McMillan.

Fisher, S. (1986). In the patient's best interest. Women and the politics of medical decisions. New Brunswick: Rutgers University Press.

Fisher, S. \& Groce, S. B. (1990). Accounting practices in medical interviews. Language in Society, 19, 225-250.

Fisher, S. \& Todd, A.D. (1983). Friendly persuasion: Negotiating decisions to use oral contraceptives. In S. Fisher \& A.D. Todd (Eds.), The social organization of doctor-patient communication (pp. 3-25). Washington D.C.: Center of Applied Linguistics Press.

Flax, J. (1990). Remembering the selves: Is the repressed gendered? Michigan Quarterly Reviere, 29, 93-110.

Frankel, R.M. (1984). From sentence to sequence: Understanding the medical encounter through micro-interactional analysis. Discourse Processes, 7, 135-170.

Frankel, R.M. (1990). Talking in interviews: A dispreference for patientinitiated questions in physician-patient encounters. In G. Psathas \& $\mathrm{R}$. Frankel (Eds.), Interactional competence (pp. 231-262). Washington: University Press of America.

Frankel, R. \& Beckman, H. (1989). Evaluating the patient's primary problem(s). In M. Stewart \& D. Roter (Eds.), Communicating with medical patients (pp. 86-98). Newbury Park: Sage.

Freemon, B., Negrete, V.F., Davis, M. \& Korsch, B.M. (1971). Gaps in doctor-patient communication: Doctor-patient interaction analysis. Pediatric Research, 5, 298-311.

Frenken, J., Rodenburg, K. \& Van Stolk, B. (1988). Huisartsen belpen bij seksuele moeilijkheden. Deventer: Van Loghum Slaterus.

Frenken, J. \& Van Tol, P. (1987). Seksuele problemen in de gynaecologenpraktijk. Medisch Contact, 42, 150-154.

Frick-Bruder, V. (1983). Female sexuality. In L. Dennerstein \& G.D. Burrows (Eds.), Handbook of psychosomatic obstetrics and gynaecology. Amsterdam: Elsevier Biomedical Press.

Fuller, S.S., Endress, M.P. \& Johnson, J.E. (1978). The effects of cognitive and behavioral control on coping with an aversive health examination. Journal of Human Stress, 4, 18-25.

Garfinkel, H. (1964). Studies in the routine grounds of everyday activities. Social Problems, 11, 225-250. 
Garfinkel, H. (1967). Studies in ethnomethodology. Englewood Cliffs Prentice Hall.

Gergen, K.J. \& Gergen, M.M. (1988). Narrative and the self as relationship. In L. Berkowitz (Ed.), Advances in experimental social psychology. Social psychological studies of the self: perspectives and programs (vol. 21, pp. 17-56). London: Academic Press.

Gijsbers-van Wijk, C.M.T. \& Van Vliet, P.P. (1989). Het zieke geslacht. Over sekseverschillen in morbiditeit, medische consumptie en de rapportage van lichamelijke symptomen. Gedrag en Gezondheid, 2, 59 68.

Gilligan, C. (1982). In a different voice. Psychological theory and women's development. Cambridge: Harvard University Press.

Glaser, B.G. \& Strauss, A.L. (1967). The discovery of grounded theory. Chicago: Aldine.

Goffman, E. (1967) Interaction ritual. Essays on face to face behavior. New York: Anchor Books.

Goodwin, M.H. \& Goodwin, C. (1987). Children's arguing. In S.U. Philips, S. Steele \& C. Tanz (Eds.), Language, gender and sex in comparative perspective (pp. 200-248). Cambridge: Cambridge University Press.

Gove, W.R. (1984). Gender differences in mental and physical illness: the effects of fixed roles and nurturant roles. Social Science and Medicine, 19, 77-84.

Greenfield, S., Kaplan, S. \& Ware, J.E. (1985). Expanding patient involvement in care. Annals of Internal Medicine, 102, 520-528.

Greenfield, S., Kaplan, S.H. \& Ware, J.E. (1988). Patient participation in medical care: effects on blood sugar and quality of life in diabetes. Journal of General Internal Medicine, 3, 448-457.

Haar, E., Halitsky, V. \& Stricker, G. (1977). Patients' attitudes toward gynecologic examination and to gynecologists. Medical Care, 15, 787795.

Hall, J.A. \& Dornan, M.C. (1988). What patients like about their medical care and how often they are asked: A meta-analysis of the satisfaction literature. Social Science and Medicine, 27, 935-939.

Hall, J.A., Roter, D.L. \& Katz, N.R. (1988). Meta-analysis of correlates of patient-provider behavior in medical encounters. Medical Care, 26, 657-675.

Hammersley, M. \& Atkinson, P (1983). Ethnography: principles of practice. London: Tavistock. 
Hart, N. (1977). Parenthood and patienthood: a dialectical autobiography. In A. Davis \& G. Horobin (Eds.), Medical encounters: the experience of illness and treatment (pp. 98-114). London: Groom Helm.

Hawton, K. \& Oppenheimer, C. (1987). Sexual problems. In A. McPherson (Ed.), Women's problems in general practice (pp. 247-284). Oxford: Oxford University Press.

Helman, C. (1990). Culture, bealth and illness. An introduction for bealth professionals. Bristol: Wright.

Heritage, J. (1984). A change-of-state token and aspects of its sequential placement. In J. M. Atkinson \& J. C. Heritage (Eds.), Structures of social action: Studies in conversation analysis. Cambridge: Cambridge University Press.

Heritage, J. \& Atkinson, J.M. (1984). Introduction. In J.M. Atkinson \& J. Heritage. Structures of social action. Studies in conversation analysis (pp. 1-15). Cambridge: Cambridge University Press.

Hernbest, R. \& Stewart, M.A. (1990). Patient-centeredness in the consultation 2: Does it really make a difference? Family Practice, 7, 28-33.

Hochschild, A. (1990). De late dienst: werkende ouders en de thuisrevolutie. Houten: De Haan.

Houtkoop, H. (1986). Summarizing in doctor-patient interaction. In E. Ensink, A. van Essen \& T. van der Geest (Eds.), Discourse analysis and public life: the political interview and doctor-patient conversation. Dordrecht: Foris Publications

Houtkoop-Steenstra, H. (1987). Establishing agreement. An analysis of proposal-acceptance sequences. Dissertation. Amsterdam: University of Amsterdam.

Hughes, D. (1982). Control in the medical consultation. Organizing talk in a situation where co-participants have different competence. Sociology, 16, 359-376.

Inui, T.S. \& Carter, W.B. (1985). Problems and prospects for health services research on provider-patient communication. Medical Care, 23, 521-538.

Jefferson, G. (1978). Sequential aspects of storytelling in conversation. In J. Schenkein (Ed.), Studies in the organization of conversational interaction (pp. 219-248). New York: Academic Press.

Jefferson, G. (1984). On the organization of laughter in talk about troubles. In J.M. Atkinson \& J. Heritage (Eds.), Structures of social action: studies in conversation analysis (pp. 346-369). Cambridge: Cambridge University Press. 
Johnson, J.E. \& Leventhal, H. (1974). Effects of accurate expectations and behavioral instructions on reactions during a noxious medical examination. Journal of Personality and Social Psychology, S, 710-718.

Joos, S.K. \& Hickam, D.H. (1990). How health professionals influence health behavior: Patient-provider interaction and health care outcomes. In K. Glanz, F.M. Lewis \& B.K. Rimer (Eds.), Health behavior and health education. Theory, research and practice. San Francisco: Jossey-Bass.

Joustra, A. \& De Vries, J. (1983). Poliklinische blik; ervaringen van vrouwen op een gynaecologische polikliniek. Unpublished manuscript. Groningen: University of Groningen.

Ketting, E. (1984). Gynaecology - duty or service? Journal of Psychosomatic Obstetrics and Gynaecology. 3, 107-114.

Kjervik, D.K. \& Martinson, I.M. (1986). Women in bealth and illness. Life experiences and crises. Philadelphia: W.B. Saunders Company.

Kleinman, A. (1980). Patients and healers in the context of culture: An exploration of the borderland between anthropology, medicine, and psychiatry. Berkeley: University of California Press.

Kleinman, A. (1981). The meaning context of illness and care: Reflections on a central theme in the anthropology of medicine. In E. Mendelsohn \& Y. Elhana (Eds.), Sciences and cultures. Sociology of the sciences, (vol 5, pp. 145-176). Dordrechr: D. Reidel Publishing Company.

Kleinman, A. (1988). The illness narratives. Suffering, healing and the buman condition. New York: Basic Books.

Kleiverda, G. (1991). Gezocht: gynaecoloog (v). Zijn vrouwen beter af met een vrouwelijke gynaecoloog? Opzij, 4, 68-70.

Kohut, H. (1974). The analysis of the self. New York: International Universities Press.

Kohut, H. (1977). The restoration of the self. New York: International Universities Press.

Komter, A. (1985). De macht van de vanzelfsprekendheid. Relaties tussen vrouwen en mannen. 's-Gravenhage: VUGA.

Korsch, B.M., Gozzi, E.K. \& Francis, V. (1968). Gaps in doctor-patient communication I. Doctor-patient interaction and patient satisfaction. Pediatrics, 42, 855-871.

Korsch, B.M. \& Negrete, V.F. (1972). Doctor-patient communication. Scientific American, 227, 66-74.

Krause, N. (1984). Employment outside the home and women's psychological well-being. Social Psychiatry, 1, 41-48. 
Krol, L. J. (1979). Ongerustheid en causa incognita. Nederlands Tijdschrift. woor Geneeskunde, 123, 865-868.

Lazare, A. \& Eisenthal, S. (1977). Patient requests in a walk-in clinic. Joumal of Nervous and Mental Disease, 165, 330-340.

Ley, P. (1982). Giving information to patients. In J.R. Eiser (Ed.), Social prychology and behavioral science (pp. 339-372). Chicester: Wiley.

Ley, P. (1983). Patients' understanding and recall in clinical communication failure. In D. Pendleton \& J. Hasler (Eds.), Doctor-patient communication (pp. 89-107). London: Academic Press

Lipkin, M., Quill, T.E. \& Napodano, R.J. (1984). The medical interview: A core curriculum for residencies in internal medicine. Annals of Internal Medicine, 100, 277-284.

Maes, S. (1983). In gesprek met de patient. Nijmegen: Dekker \& Van de Vegt.

Maltz, D.N. \& Borker, R.A. (1982). A cultural approach to male-female miscommunication. In J.J. Gumperz (Ed.), Language and social identity (pp. 196-216). Cambridge: Cambridge University Press.

Maseide, P. (1991). Possibly abusive, often benign, and always necessary. On power and domination in medical practice. Sociology of Health and Illness, 13, 545-561.

Mcllwaine, G., Rosenberg, K. \& Rooney, I. (1989). The health of mid-life inner-city women. Journal of Psychosomatic Obstetrics and Gynaecology, 10, suppl. 1, 102-109.

McPherson, A. (1987). Why women's health? In A. McPherson (Ed.), Women's problems in general practice (pp. 1-13). Oxford: Oxford University Press.

Meeuwesen, L. (1988). Spreekuur of zwïguur. Somatische fixatie en sekseasymmetrie tijdens het medisch consult. Dissertation. Nijmegen: University of Nijmegen.

Meeuwesen, L., Ruiter, M., Esterbeek van Eerten, J. \& Brinkgreve, C. (1991a). Vrouwen en gezondheid. Een overzicht van onderzoek naar gezondheidsklachten van vrouwen, 1970-1990. Den Haag: STEO.

Meeuwesen, L., Schaap, C. \& Van der Staak, C. (1991b). Verbal analysis of doctor-patient communication. Social Science and Medicine, 32, 11431150.

Meyboom-De Jong, B. (1981). Hoe ervaren vrouwen het vaginaal onderzoek. Medisch Contact, 36, 1577-1578.

Mishler, E.G. (1984). The discourse of medicine: dialectics of medical interviews. Norwood: Ablex Publishing Corporation. 
Mullen, P.D., Green, L.W. \& Persinger, G. (1985). Clinical trials of patient education for chronic conditions: a comparative meta-analysis of intervention types. Preventive Medicine, 14, 753-781.

Nicolai, N. (1992a). De hordenloop door de instituties. Een analyse van struikelblokken. Vrouw en Gezondheidszorg, 2, 3-6.

Nicolai, N. (1992b). Vrouwenbulpverlening en psychiatrie. Amsterdam: SUA. Orth, J.E., Stiles, W.B., Scherwitz, C., Henrikus, D. \& Vallbona, C. (1987). Patient exposition and provider explanation in routine interviews and hypertensive patients' blood pressure control. Health Psychology, 6, $29-42$.

Pendleton, D. (1983). Doctor-patient communication: a review. In D. Pendleton \& J. Hasler (Eds.), Doctor-patient communication (pp. 5-53). London: Academic Press.

Pendleton, D.A. \& Bochner, S. (1980). The communication of medical information in general practice consultations as a function of patients' social class. Social Science and Medicine, 14, 669-673.

Peräkylä, A. \& Silverman, D. (1991). Reinterpreting speech-exchange systems: communication formats in AIDS counselling. Sociology, 25, 627. 651.

Petravage, J.B., Reynolds, L.J., Gardner, H.J. \& Reading, J.C. (1979). Attitudes of women toward gynecologic examination, Journal of Family Practice, 9, 1039-1045.

Pomerantz, A.M. (1984). Agreeing and disagreeing with assessments: some features of preferred/dispreferred turnshapes. In J.M. Atkinson \& J. Heritage (Eds.), Structures of social action: studies in conversation analysis (pp. 57-101). Cambridge: Cambridge University Press

Popay, J. (1992). 'My health is all right, but I'm just tired all the time'. Women's experience of ill health. In H. Roberts (ed.), Women's bealth matters (pp. 99-120). London: Routledge.

Porter, M. (1990). Professional-client relationships and women's reproductive health care. In S. Cunningham-Burley \& N.P. McKeganey (Eds.), Readings in medical sociology (pp. 182-210). London: Routledge.

Porter, M. \& Macintyre, S. (1989). Psychosocial effectiveness of antenatal and postnatal care. In S. Robinson \& A. Thomason (Eds.), Research in midwifery/childbirth care (vol.1). London: Croom Helm.

Putnam, S.M., Stiles, W.B., Jacob, M.C. \& James, S.A. (1985). Patient exposition and physician explanation in initial medical interviews and outcomes of clinic visits. Medical Care, 23, 74-83.

Roberts, H. (1985). The patient patients. Women and their doctors. London: Pandora Press. 
Roberts, H. (1992). Introduction: women's health matters. In H. Roberts (Ed.), Women's bealth matters (pp. 1-10). London: Routledge.

Römkens, R. (1989). Geweld tegen vrouwen in beteroseksuele relaties. Een landelijk onderzoek naar de omvang, de aard, de gevolgen en de achtergronden. Amsterdam: Universiteit van Amsterdam.

Roter, D.L. (1977). Patient participation in the patient-provider interaction: The effects of patient question-asking on the quality of interaction, satisfaction and compliance. Health Education Monographs, 5, 281-330.

Roter, D.L. (1984). Patient question asking in physician-patient interaction. Health Psychology, 3, 395-409.

Roter, D. (1989). Which facets of communication have strong effects on outcome - a meta-analysis. In M. Stewart \& D. Roter (Eds.), Communicating with medical patients (pp. 183-196). Newbury park: Sage.

Roter, D.L. (1991). The influence of patient characteristics on communication between the doctor and the patient. Huisarts en Wetenschap, 34, 295-301.

Roter, D., Hall, J. \& Katz, N. (1988). Patient-physician communication. A descriptive summary of the literature. Patient Education and Counseling, 12, 99-119.

Roter, D., Lipkin, M. \& Korsgaard, A. (1991). Sex differences in patients' and physicians' communication during primary care medical visits. Medical Care, 29, 1083-1093.

Ryave, A.L. (1978). On the achievement of a series of stories. In J. Schenkein (Ed.), Studies in the organization of conversational interaction (pp. 113-132). New York: Academic Press.

Sacks, H. (1970). Facets of the organization of story-telling in conversation. Paper presented at the VIth World Congress of Sociology, Varna, Bulgaria.

Sacks, H. (1974). An analysis of the course of a joke's telling in conversation. In J. Sherzer \& R. Bauman (Eds.), Explorations in the ethnography of speaking. London: Cambridge University Press.

Sacks, H. (1987). On the preference for agreement and contiguity in conversation. In: G. Button. \& J.R.E. Lee (Eds.), Talk and social organization (pp. 54-69). Cleveland: Multilingual Matters.

Sacks, H., Schegloff, E. \& Jefferson, G. (1974). A simplest systematics for the analysis of turn-taking in conversations. Language, 50, 696-735.

Salter, J.R. (1985). Gynaecological symptoms and psychological distress in potential hysterectomy patients. Journal of Psychosomatic Research, 29, 155-159. 
Sapira, J.D. (1972). Reassurance therapy: what to say to symptomatic patients with benign diseases. Annals of Internal Medicine, 77, 603-604. Scanzoni, J.H. (1975). Sex roles, life styles and child bearing. New York: The Free Press.

Schegloff, E.A. (1972). Notes on conversational practice: Formulating place. In D. Sudnow (Ed.), Studies in social interaction (pp. 75-119). New York: Free Press.

Schegloff, E.A. (1979). Identification and recognition in telephone conversation openings. In G. Psathas (Ed.), Everyday language: Studies in ethnomethodology (pp.23-78). New York: Irvington.

Schegloff, E. (1980). Preliminaries to preliminaries: "Can I ask you a question?". Sociological Inquiry, 50, 104-153.

Schegloff, E. \& Sacks, H. (1973). Opening up closings. Semiotica, 8, 289327.

Schouten, J.A.M. (1982). Anamnese en advies: nieuwe richtlijnen voor de informatie-uitwisseling tussen arts en patient. Alphen a/d Rijn: Stafleu.

Shipley, R.H., Butt, J.H., Horwitz, B. \& Farby, J.E. (1978). Preparation for a stressful medical procedure: effect of amount of stimulus pre-exposure and coping style. Journal of Counseling and Clinical Psychology, 3, 499-507.

Silverman, D. (1987). Communication and medical practice. Social relations in the clinic. London: Sage.

Silverman (forthcoming). Describing sexual activities in HIV counselling: the co-operative management of delicacy.

Silverman, D. \& Peräkylä, A. (1990). AIDS counselling: the interactional organisation of talk about 'delicate' issues. Sociology of Health and Illness, 12, 293-318.

Silverman, D \& Torode, B (1980). The material world: some theories of language and its limits. London: Routledge and Kegan Paul.

Skipper, J.K. \& Leonard, R.C. (1965). Social interaction and patient care. Philadelphia: Lippincot.

Sociaal Cultureel Planburo (1991). Sociale atlas van de vrouw. Den Haag: VUGA.

Stanley, E.M.G. \& Ramage, M.P. (1984). Sexual problems and urological symptoms. In S.L. Stanton (Ed.), Clinical Gynaecological Urology (pp. 398-405). Toronto: Mosby.

Stewart, M.A. (1984). What is a successful doctor-patient interview? A study of interactions and outcomes. Social Science and Medicine, 19, 167-175. 
Stiles, W.B., Putnam, S.M., Wolf, M.H. \& Sherman, A.J. (1979). Interaction exchange structure and patient satisfaction with medical interviews. Medical Care, 17, 667-681.

Stimson, G. (1976). General practitioners: trouble and types of patients. In M. Stacey (Ed.), The sociology of the NHS. Sociological Review Monograph, 22, Keele: University of Keele.

Stimson, G.V. \& Webb, B. (1975). Going to see the doctor: The consultation process in general practice. London: Routledge and Kegan Paul.

Strong, P. (1979). The ceremonial order of the clinic: Parents, doctors and medical bureaucracies. London: Routledge and Kegan Paul.

Svarstad, B. (1974). The doctor-patient encounter. An observational study of communication and outcome. Dissertation. Madison: University of Winconsin.

Tabak, E.R. (1988). Encouraging patient question-asking: A clinical trial. Patient Education and Counseling, 12, 37-49.

Tannen, D. (1990). You just don't understand. Women and men in conversation. New York: Ballantine Books.

Taylor, K.M. (1988). Physicians and the disclosure of undesirable information. In M. Lock \& D. Gordon (Eds.), Biomedicine examined (pp. 441463). Dordrecht: Kluwer Academic Publishers.

Ten Have, P. (1987). Sequenties en formuleringen. Aspecten van de interactionele organisatie van huisarts-spreekuur gesprekken. Dissertation. Amsterdam: University of Amsterdam.

Ten Have, P. (1991). Vorm en inhoud van spreekuurgesprekken. Huisarts en Wetenschap, 34, 330-333.

Thomassen, J.F.M. (1986). Consult analyse. Communicatieve en kwalitatieve aspecten van bulpverlenen in de buisartspraktijk. Dissertation. Amsterdam: VU Uitgeverij.

Todd, A.D. (1984). The prescription of contraception: negotiations between doctors and patients. Discourse Processes, 7, 171-200.

Todd, A.D. (1989). Intimate adversaries. Cultural conflict between doctors and women patients. Philadelphia: University of Philadelphia Press.

Tones, K., Tilford, S. \& Robinson, Y. (1990). Healtb education. Effectiveness and efficiency. London: Chapman \& Hall.

Treichler, P., Frankel, R., Kramarae, C, Zoppi, C. \& Beckman, H. (1984). Problems and problems: power relationships in a medical encounter. In C. Kramarae (Ed.), Language and power (pp. 62-88). Beverly Hills: Sage. 
Tuckett, D., Boulton, M., Olson, C. \& Williams, A. (1985). Meetings between experts. An approach to sharing ideas in medical consultations. London: Tavistock.

Van Binsbergen, C.J.M. (1988). Opvattingen over seksualiteit en de invloed hiervan op gynaecologisch handelen. Nederlands Tijdschrift voor Obstetrie en Gynaecologie, 101, 45-49.

Van Dam, F.S.A.M. (1974). De psycho-sociale zorg voor patiënten met borstkanker. In W.H.G. Wolters (Ed.), Ontwikkelingen van psychosociale zorg in ziekenhuizen. Baarn: Bosch en Keuning.

Van der Ploeg, H.M. (1980). Persoonlijkheid en medische consumptie. Lisse:

Swets en Zeitlinger.

Van Hall, E. (1982). Androgyny: a model for improving gynaecologistpatient interaction. Journal of Psychosomatic Obstetrics and Gynaecolo. gy, 1, 87-90.

Van Lunsen, H.W. (1986). Wie is er bang voor het gynaecologisch onderzoek? Het gynaecologisch onderzoek; een kritisch moment voor patiēnten, studenten en docenten. Dissertation. Groningen: University of Groningen.

Van Mens-Verhulst, J. (1988). Modelontwikkeling voor vrouw-en-bulpverlening. Op weg naar het land symmetria. Dissertation. Utrecht: University of Utrecht.

Verdenius-Jansen, W. (1991). Dokter, mag ik u iets vragen? Een onderzoek naar het verbaal informatiezoekend bandelen van de patiënt. Unpublished manuscript. Utrecht: University of Utrecht.

Visser, A.Ph (1987). Angst en voorlichting bij ziekenhuispatienten. In A.Ph. Visser \& W.F.M. De Haes (Eds.), Angst en gezondheidsvoorlichting en -opvoeding. Amsterdam: VU Uitgeverij.

Waitzkin, H. (1984). Doctor-patient communication. Journal of the American Medical Association, 252, 2441-2445.

Waitzkin, H. (1990). On studying the discourse of medical encounters. A critique of quantitative and qualitative methods and a proposal for reasonable compromise. Medical Care, 28, 473-488.

Waitzkin, M. \& Stoeckle, J. (1972). The communication of information about illness: Clinical, sociological and methodological considerations. Advanced Psychosomatic Medicine, 8, 180-215.

Wallen, J., Waitzkin, H., \& Stoeckle, J.D. (1979). Physician stereotypes about female health and illness: A study of patient's sex and the informative process during medical interviews. Women and Health, 4, 135-146. 
Webb, C. (1986). Women as gynaecology patients and nurses. In C. Webb (Ed.), Feminist practice in women's bealth care (pp. 93-112). Chicester: Wiley.

Weijts, W., Widdershoven, G. \& Kok, G. (1991). Anxiety-scenarios in gynecological consultations, Patient Education and Counseling, 18, 149-163.

Weijts, W., Widdershoven, G., Kok, G. \& Tomlow, P. (forthcoming). Patients' information-seeking actions and physicians' responses in gynecological consultations.

Weiss, L. \& Meadow, R. (1983). The young woman and the gynecologist: women's attitudes toward current gynecological procedures. In L. Dennerstein \& M. De Semarkens (Eds.), The yound woman: Psychosomatic aspects of obstetrics and gynecology (pp. 348-355). Amsterdam: Excerpta Medica, International Congress Series.

West, C. (1984). Routine complications. Troubles with talk between doctors and patients. Bloomington: Indiana University Press.

West, P. (1976). The physician and the management of childhood epilepsy. In M. Wadsworth \& D. Robinson (Eds.), Studies in everyday medical life (pp 13-31). London: Martin Robertson.

Wijma, K. \& Areskog-Wijma, B. (1987). Women's experiences of their genitals as an important aspect of their meetings with gynaecologists. Journal of Psychosomatic Obstetrics and Gynaecology, 6, 133-141.

Winefield, H.R. \& Murrell, T.G.C. (1991). Speech patterns and satisfaction in diagnostic and prescriptive stages of general practice consultations. British Journal of Medical Psychology, 64, 103-115.

Wodak, R. (1981). Women relate, men report: sex differences in language behavior in a therapeutic group. Journal of Pragmatics, 5, 261-285. Wolinsky, F.D. (1988). The sociology of health. Principles, practioners and issues. Belmont: Wadsworth. 


\section{Summary}

This thesis contains a descriptive pilot-study which examines how patients during gynaecological consultations express their needs for information, and how they present their concerns regarding two culturally sensitive issues which play an important role in the gynaecological setting, i.e., malignancy and sexuality. Subsequently, we examine how physicians react to these patient initiatives and what in turn the subsequent patient reactions are.

Chapter 1 provides a general overview of the dissertation. After presenting the general subject of this thesis, it starts with a review of the literature on patient participation in medical interactions. Results of correlational studies have revealed the importance of patient involvement in medical interviews with respect to patient satisfaction, compliance and health outcomes. However, despite these benefits, we know from observational studies that patients as well as physicians are not very supportive regarding an active patient contribution during medical consultations. We view this finding as a reflection of the working of professional power in doctor-patient relationships: the asymmerry of knowledge and authority allows doctors to disseminate medical expertise against and at the expense of lay forms of understanding and this seems to be accepted by patients as part of the 'ceremonial order' of the clinic.

Studies on gender issues in patient participation have indicated that women are more participative than men in medical consultations. They ask more questions and present their complaints in greater detail. An explanation for this phenomenon is the difference in social position between the sexes. Due to their role as caregivers, women may have more expertise and responsibility with regard to matters relating to health and illness. Another explanation for female patients $s^{2}$ more active contribution is the difference in conversational styles between the sexes. Women tend to use a style which focalizes on making connections whereas men use a more instrumental conversational style to protect their independence and negotiate status. Asking questions and presenting problems to the doctor may be less problematic for female patients, as they experience it as a way to strengthen their relationship, while for male patients it means admitting to be dependent.

Female patients' contributions are twice as often negated by physicians than those of men, especially in consultations with male physicians. This finding is related to structures of domination based on both professional power and gendered power. Due to professional power, physicians can determine patients' understandings as irrelevant for further consideration. This may have negative consequences for women in particular, as 
doctors are generally not very well informed about women's lifeworld and its influence on the origin of health problems. Gendered power plays a role as the clash of conversational styles between a female patient and a male doctor will have negative consequences for women, as a result of the power imbalance between the sexes.

Having reviewed the literature on patient participation in medical interviews, we motivate our choice for examining gynaecological interactions. The typical configuration of the gynaecological consultation in the Netherlands, the female patient - male physician dyad, in combination with its medical domain, the pelvic floor, makes it a setting in which structures of domination and subordination based on professional power and gendered power are particularly evident. We may therefore expect communicational problems to be particularly apparent within this context. Nevertheless, few research has been conducted into the actual interaction between the participants of gynaecological consultations.

The overview continues with a review of the literature on the relationship between women's social position and socialization and the origin of women's complaints. In the Netherlands, this knowledge has resulted in the development of 'vrouwenbulpverlening', health care which focuses on encouraging women's autonomy. In order to assess the effectiveness of the interactional patterns observed in this thesis, we draw on two important procedures of 'vrouwenbulpverlening', i.e., taking women's definition of their problems seriousiy and respecting their lay knowledge.

The overview continues with an explanation for choosing conversation analysis as a research method. Conversation analysis provides a systematic approach to the study of talk as a topic in its own right and offers the opportunity to identify the various forms of mutual participation that affect the course and direction of the interaction. Subsequently, the sample and data-collection of the three studies reported in this thesis are described. The data are based on literally transcribed audiotapes of 32 gynaecological consultations of five male gynaecologists and 15 female patients. Moreover, it is shown how the research questions were specified during the phase of data-collection. This specification resulted in three behaviours which were examined in detail in separate studies: seeking information (study 1), expressing concerns about malignancy (study 2) and talking about sexuality (study 3). Whereas chapter 1 discusses the broad outline and main results of these three studies, the chapters 2,3 and 4 discuss these studies in detail.

Chapter 2 offers a systematic analysis of patients' informationseeking actions and physicians' responses. It shows that the patients in our 
data generally try to get information by asking direct questions. Most of these questions are formulated in specific proposal form. General questions are seldom identified. The patients are especially active in asking questions about treatment, particularly about the nature and procedures of a recommended treatment and about the impact of treatment on their lives. Topics such as causal aspects of complaints, results of examinations and the working of the reproductive organs are less frequently the subject of information-seeking. Besides these direct questions, more indirect patient behaviours aimed at acquiring information are observed. Patients try to elicit new information, elucidation or confirmation from doctors by means of story-telling finished with a lay conclusion, interrogative utterances which are expressed at prior 'news' given by the physician, motivations to explain why an earlier question has been asked, repetitions of physicians' statements and tag-questions. Not only are causal aspects of complaints, results of examinations and the working of the reproductive organs less frequently the subject of patients' information-seeking actions, they are also more often addressed by means of these indirect strategies. Patients' initiatives are generally successful in eliciting information from the physicians. All direct requests for information are answered and also the subtle, more indirect requests for information generally appear to be successful in alerting the physician to the need for (more) information or confirmation. Only the indirect requests for information regarding the causes of complaints that are formulated as a story with a conclusion - mostly a lay theory on the cause of the trouble - run the risk of being negated by the physicians. Circumvention especially occurs when patients present such lay-theories on moments that do not 'fit' with the doctor's medical agenda. Patients always react to physicians' negation of their lay theories with new indirect efforts to make their point, which are generally negated again.

Chapter 3 describes how patients express their anxiety for malignancy during the gynaecological consultations that are observed and how gynaecologists react to these expressions of anxiety. Patients generally present their fear in rather indirect ways, e.g., by implicitly alluding to the possibility of having cancer, by mentioning relatives or friends who have (had) cancer, or by pressing for more drastic medical intervention. Physicians have three ways of reacting to patients' indirect anxiety expressions. First, their most common reaction is providing reassurance immediately, in the form of information-delivery. Mostly, the interactional pattern stops after this reassurance, but in some instances patients provide new indirect anxiety expressions regarding malignancy at a later moment in the same consultation. Secondly, another physician reaction in our study sample to 
patients" indirect anxiety expressions is exploration. Explorations always result in more owert exprewions of patients ${ }^{3}$ concerns, which are followed by reascurances, that is, fragnents of information-delivery. Then the interaction switches to another topic, A third physician reaction to patients ${ }^{*}$ indired emotional expressions is negating them. After a negation, we observe patients returning to their point. These new indirect anxiezy expression are once more negated, which again elicits indirect anxiery expressions. In this way an interactional loop is developed which finally ends up with a reasurance from the physician. The physician strategy of negating patients' indirect anxiety-xpressions occurs when the patients" concerns are not 'properly' addressed from a medical point of view.

Chapter 4 describes how the parients and the physicians in our sample use specific procedures to introduce and further address issues relating to sexuality. Four major strategies in discussing this issue are identifed: delay, avoidance, depersonalization and tuning. Patients delay the topic of sexuality by introducing sexual problems after the 'reason-forcontact-complaint' has been discussed. They can also delay the presentation of problems relating to sexual dysfunctioning to follow-up consultations. Physicians sometimes react to patients' presentation of sexual problems by delaying them to a subsequent meeting. Both physicians and patients delay the delivery of potentially delicate terms concerning sexual practices by using 'expressive caution' through pauses and hesitations, before touching upon potentially delicate topics. Another major strategy that people use when talking about sexuality in the gynaecological consultations is avoidance of delicate terms. They avoid the use of explicit terms referring to sexual activities and to the female reproductive organs, they completely omit delicate terms or they only refer in terms of pronouns ('it', 'that') to items relating to sexuality, once these have been mentioned. The interaction between gynaecologist and patient regarding sexuality is also permeated by depersonalization: speech that loosens the link between the person and her most private actions and bodily aspects. The two principles governing the construction of depersonalized talk are nominalizing and the substitution of definite articles for personal pronouns before delicate organs. We have observed both speakers adopting each other's styles of speaking regarding delicate issues - a phenomenon which we called 'tuning'. In that way, the delicacy of the subject of sexuality is jointly produced by both participants of the gynaecological consultations. In this study we observed that the doctors had (and got) the power to determine the vocabulary regarding women's reproductive organs and their sexual behaviours. As a result of the 'tuning' mechanism, physicians' implicit ways of 
speaking seem to discourage women from describing in more detail their problems relating to sexuality.

After summarizing the main results, chapter 1 continues with a general discussion. In this discussion it is argued that, in contrast to the findings of most studies on patient participation, the patients in the present inquiry are active participants of medical interviews. Although they do not dispose of equal interactional resources and skills as physicians, they have all kinds of, more and less direct, methods to influence the course of the interaction. In this way they generally succeed in seeking information, displaying their lay-knowledge and getting attention for their concerns. When their requests for information or concerns are subject to distortion, they continually repeat their understandings, attempting to establish their authority and interactional rights regarding their own health and wellbeing.

The extent of directness of patients' speech seems to depend on the topic under consideration. The patients in our research are more active and direct in seeking information when aspects of treatment are the subject of discussion than in the case of aetiological and diagnostic aspects of their complaints. This finding is explained by referring to women's specific social position, in which they are the people most responsible for the care of household and children. Information about how a treatment, e.g. a laparoscopy or a hysterectomy, will interfere with their social and family life, might be more important for women than information on any other topic, as they need it to decide how daily practical tasks can be continued as normally as possible.

Patients' indirectness in case of aetiological and diagnostic aspects of their complaints is explained by drawing on the power imbalance between patients and physicians based on professional and gender inequality. These topics address the medical domain of knowledge and may challenge the physician's authority. Implicit ritual constraints connected with the power imbalance between professionals and laypersons, may discourage patients from using direct formulations to solicit information regarding aetiological aspects of their complaints. We argue that this is valid for female patients in particular, as women, resulting from their minority position compared to male physicians, will use a conversational style which focuses on confirming the doctor's competence. Another explanation which is given for patients' relatively little and inarticulate speech concerning the cause of their complaints is the psychological process of avoidance. Patients may be ambivalent in talking about these issues. On the one hand they wish to go into them because it could reduce their concerns; on the other they tend to 
repress them, because they are afraid of having their anxious suppositions affirmed. These factors, power based on professionalization and gender and the psychological mechanism of avoidance, are also used to explain patients' indirectness regarding the expression of concerns relating to malignancy.

In our sample of gynaecological consultations, issues relating to sexuality are, in a massively recurrent manner, avoided or approached very carefully by both participants. It is argued that the interactional devices that we identified are ways of speaking to mark 'precarious' topics in interactions. Once a topic is marked as delicate, this topic is turned into a matter which is in need of being formulated cautiously and discretely. This is apparent in our data as patients copy physicians' devices and vice versa. The indirectness that we observed in case of issues relating to sexuality is related to the cultural taboo on talking about sex.

The observations in this select group of physicians do not support the observation in research on patient participation that physicians mostly actively inhibit patients from presenting their views or evade responding to what patients say. Thus, in most interactional patterns that we observed the two criteria of 'vrouwenhulpverlening' underlying this research, that is, respecting women's lay knowledge and taking seriously their problems, were met. However, four patterns are identified in which these criteria of 'vrouwenbulpverlening' did not come out well. This is when physicians disregard patients' information about the nature and cause of their complaints, disregard patients' concerns about having malignancy; switch immediately to information-delivery after patients' presentation of concerns about having cancer without exploring them; use a neutral and veiled vocabulary regarding sexuality. The occurrence of these patterns is explained in terms of professional power and gendered power. It is argued that these interactional patterns do not support the aim of 'vrouwenbulpverlening', i.e. helping women to take more control over their health, as part of taking more control over their life. We assume moreover, that the way women's concerns and knowledge are dealt with within these patterns may finally result in a decrease in patient satisfaction, compliance and even in health outcomes.

After this discussion, some recommendations for future research are given. The findings of the present research generate hypotheses which could be tested in a study with a more representative sample, in which patient and physician gender are varied. The chapter finishes with some recommendations for practice which aim at integrating the objectives of 'vrouwenhulpverlening' within gynaecological practice. 


\section{Samenvatting}

Deze dissertatie vormt het verslag van een beschrijvende pilot-studie waarin is onderzocht hoe patiënten tijdens gynaecologische consulten hun behoefte aan informatie uiten, en hoe zij hun zorgen presenteren ten aanzien van twee cultureel beladen onderwerpen, namelijk kanker en seksualiteit. Vervolgens is bestudeerd op welke wijze artsen reageren op deze initiatieven van patiënten en wat de daaropvolgende reacties van patiënten zijn.

Hoofdstuk 1 geeft een algemeen overzicht van de gehele dissertatie. Het hoofdstuk begint met een samenvatting van de literatuur over participatie van patiënten in medische interacties. Resultaten van correlationele studies hebben aangetoond dat een actieve deelname van patiënten aan de interactie in medische consulten een positief effect heeft op de tevredenheid van patiënten, op hun compliance en zelfs op hun herstel. Observationele studies hebben echter laten zien dat patiënten over het algemeen niet erg actief participeren in medische gesprekken en dat artsen de inbreng van patiënten weinig op prijs stellen en veelal afkappen. Deze fenomenen worden verklaard vanuit de professionele machtspositie van artsen. Deze stelt artsen in staat hun medische expertise te laten domineren over de leken-informatie van patiënten. Patiënten conformeren zich aan deze gang van zaken: zij houden zich, evenals de artsen, aan de 'ceremoniële orde' van de kliniek.

Studies naar sekse-verschillen in de participatie van patiënten aan medische gespreksvoering hebben angetoond dat vrouwelijke patiënten een grotere inbreng hebben tijdens consulten dan mannen. Zij stellen meer vragen en presenteren hun klachten op uitgebreidere wijze. Een verklaring voor dit verschijnsel is het verschil in sociale positie tussen de seksen. De verzorgende rol die veel vrouwen vervullen makt wellicht dat zij een grotere expertise en verantwoordelijkheid hebben ten aanzien van zaken als gezondheid en ziekte. Een andere verklaring berust op het verschil in conversationele stijl tussen de seksen. Vrouwen hebben doorgaans op basis van hun socialisatie een meer emotionele stijl aangeleerd die gericht is op het tot stand brengen en onderhouden van relaties, terwijl mannen een meer instrumentele conversationele stijl hebben aangeleerd waarin het handhaven van onafhankelijkheid en status voorop staat. Vanuit dit gezichtspunt is het stellen van vragen en het presenteren van problemen aan de arts wellicht minder problematisch voor vrouwelijke patiënten aangezien zij dit opvatten als een versterking van de onderlinge relatie, terwijl dit voor mannelijke patiënten juist het erkennen van afhankelijkheid en statusverlies betekent. 
De bijdragen van vrouwelijke patiënten tijdens consulten worden twee maal zo vaak genegeerd als die van mannelijke patiënten, met name in consulten met mannelijke artsen. Deze bevinding uit de literatuur wordt verklaard op basis van professionele macht en macht in termen van gender. Op basis van hun professionele macht kunnen artsen de lekenkennis die patiënten naar voren brengen als onbelangrijk duiden en verontachtzamen. Dit zal bij vrouwelijke patiënten eerder gebeuren omdat artsen doorgaans weinig op de hoogte zijn van de leefwereld van vrouwen en de invloed daarvan op het ontstaan van klachten van vrouwen. Macht op basis van gender speelt eveneens een rol. In gespekken tussen een vrouwelijke patiënt en een mannelijke arts is sprake van een 'clash' van conversationele stijlen. Deze werkt negatief uit voor vrouwen, tengevolge van het machtsverschil tussen de seksen.

$\mathrm{Na}$ deze uiteenzetting over de activiteit van patiënten in consulten en de gender-aspecten daarbinnen, wordt gemotiveerd waarom gekozen is voor het gynaecologische consult als object van onderzoek. In gynaecologische consulten in Nederland zijn de twee gesprekspartners doorgaans een vrouwelijke patiënt en een mannelijke arts. Dit, in combinatie met de notie dat gynaecologische consulten handelen over typisch vrouwelijke klachten, deed ons verwachten dat de inbreng van patiënten in gynaecolische consulten risico loopt te worden verontachtzaamd. Er is echter nauwelijks onderzoek verricht naar de interactie tussen patiënten en artsen binnen deze specialistische context.

Het hoofdstuk vervolgt met een samenvatting van de literatuur over de relatie tussen de sociale positie en socialisatie van vrouwen en het ontstaan van gezondheidsklachten. Het machtsverschil tussen de seksen, de aard van huishoudelijk werk en de plicht tot zorgzaamheid zijn zaken die onderdeel vormen van de dagelijkse werkelijkheid van vrouwen. Deze factoren beïnvloeden het ontstaan van gezondheidsklachten van vrouwen en de wijze waarop zij hiermee omgaan. De kennis op dit terrein heeft in Nederland geleid tot het ontstaan van het fenomeen vrouwenhulpverlening. De in dit onderzoek geobserveerde interactionele patronen worden geëvalueerd aan de hand van een tweetal uitgangspunten van vrouwenhulpverlening, namelijk het serieus nemen van de probleemdefinitie van patiënten en het respecteren van lekenkennis.

Hierna wordt beargumenteerd waarom gekozen is voor conversatie-analyse als methode van onderzoek. Conversatie-analyse biedt een aantal zorgvuldig empirisch onderbouwde analytische concepten waarmee de wederzijdse invloed van de gespreksdeeinemers op elkaars interactioneel handelen zichtbaar kan worden gemaakt. Vervolgens worden de onderzoekspopulatie 
en de methode van dataverzameling beschreven. De data bestaan uit letterlijke transcripties van 32 op audiorecorder opgenomen consulten tussen vijf mannelijke gynaecologen en 15 vrouwelijke patiënten. Tijdens de fase van dataverzameling vond een toespitsing van de onderzoeksvragen plaats die resulteerde in drie afzonderlijke studies. Hoofdstuk 1 behandelt de grote lijnen en belangrijkste resultaten van deze studies. In hoofdstuk 2, 3 en 4 wordt uitgebreid op de verschillende studies afzonderlijk ingegaan.

Hoofdstuk 2 bevat een systematische analyse van de informatiezoekende handelingen van patiënten en de antwoorden daarop van artsen. De analyse laat zien dat de patiënten in onze data meestal aan informatie proberen te komen via het direct stellen van vragen. Deze vragen zijn doorgaans geformuleerd als 'specific proposals'. Ze bevatten een specifieke veronderstelling. De patiënten in ons onderzoek zijn met name actief in het zoeken naar informatie over de aard en de procedure van de behandeling en over de gevolgen van de behandeling voor hun dageliiks leven. Over de oorzaak van de klacht, de resultaten van medische onderzoeken en de werking van de voortplantingsorganen worden veel minder vragen gesteld.

Behalve de directe manier van vragen stellen blijken patiënten ook indirecte strategieën in te zetten om aan (meer) informatie te komen. Dit gebeurt bijvoorbeeld door een verhaal te vertellen dat beëindigd wordt met een leken-conclusie, door vragende uitroepen te formuleren nadat de arts bepaalde informatie heeft gegeven, door een motivatie te geven voor een eerder gestelde vraag, of door een uiting van een arts gewoon te herhalen. Deze indirecte strategieën treffen we vooral aan bij informatie-zoekende handelingen die betrekking hebben op de oorzaak van klachten en op de uitslagen van medische onderzoeken.

De informatie-zoekende initiatieven van patiënten, zowel de directe als de indirecte, worden vrijwel altijd beantwoord. Alleen de indirect geformuleerde vragen die betrekking hebben op de oorzaak van de klacht en die geformuleerd zijn als een verhaal met een leken-conclusie, lopen het risico genegeerd te worden. Omzeiling van dergelijke uitingen vindt met name plaats wanneer zij geformuleerd worden op momenten die niet aansluiten bij de medische agenda van de arts. Uit de data blijkt dat de patiënten op een verontachtzaming van hun lekenkennis reageren met het geven van nieuwe indirecte vragen, waarin ze opnieuw hun opvattingen over de oorzaak van hun klacht verpakken.

Hoofdstuk 3 beschrijft hoe de patiënten hun zorgen over het hebben van kwaadaardige aandoeningen uiten en hoe de artsen hierop reageren. De patiënten blijken hun angst steeds op zeer indirecte wijze naar voren te brengen. Dit gebeurt bijvoorbeeld door impliciet te refereren aan het 
hebben van kwaadaardige afwijkingen, door derden te noemen bij wie kanker geconstateerd is of door aan te sturen op drastischer medisch ingrijpen. De artsen in ons onderzoek blijken drie verschillende manieren te hebben om te reageren op deze impliciete uitingen van bezorgdheid. De eerste, en meest voorkomende manier is direct geruststellen, middels het geven van informatie. De interactie over de zorgen van de patiënt stopt hierna meestal. Soms blijken patiënten later in het consult terug te komen met nieuwe indirect geformuleerde uitingen. Een tweede manier waarop artsen reageren op de bedekte angstuitingen van patiënten is het exploreren ervan. Exploraties blijken altijd te leiden tot het openlijk uiten van zorgen over kanker, waarop artsen weer reageren met het geven van geruststelling in de vorm van informatie. Het gesprek verandert vervolgens van onderwerp en er wordt door de patiënt niet meer op de angst teruggekomen. Een derde type reactie op bedekt geformuleerde zorgen ten aanzien van kanker is het volledig negeren ervan. $\mathrm{Na}$ een dergelijke reactie blijken patiënten altijd nieuwe indirecte angstuitingen te formuleren die opnieuw genegeerd worden. Uiteindelijk eindigt deze interactionele 'loop' met een geruststelling van de kant van de arts. Dit laatste interactiepatroon treedt vooral op wanneer de zorgen van de patiënten gepresenteerd worden op momenten die de medische agenda verstoren.

Hoofdstuk 4 beschrijft hoe de aan het onderzoek deelnemende patiënten en artsen de introductie en verdere bespreking van onderwerpen op het vlak van seksualiteit organiseren. Er zijn vier strategieën in het spreken over dit onderwerp geobserveerd: uitstel, vermijding, depersonalisatie en 'tuning'. Patiënten blijken de presentatie van hun klachten op het gebied van seksualiteit uit te stellen totdat het gespek over hun 'eigenlijke' klacht is afgerond. Soms brengen ze seksuele problemen pas in een later consult naar voren. De artsen stellen de bespreking van naar voren gebrachte seksuele problematiek nogal eens uit naar een later consult. Ook binnen de gesprekken over seksualiteit vindt uitstel plaats. Zowel de patiënten als de artsen blijken systematisch te aarzelen of te pauzeren voor het benoemen van potentiële delicate termen die betrekking hebben op seksualiteit. Een andere strategie die de respondenten in dit onderzoek gebruiken tijdens het spreken over seksualiteit is vermijding. Zij gebruiken eufemismen ('van onder') in plaats van expliciete termen, laten potentieel delicate termen helemaal weg of verwijzen ernaar met behulp van voornaamwoorden ('het', 'dat'). Verder worden de gesprekken over seksualiteit gekenmerkt door depersonaliserend taalgebruik, zoals het hanteren van nominalisaties ('tijdens het gebeuren zelf' in plaats van 'wanneer u gemeenschap hebt') en het gebruik van lidwoorden in plaats van bezittelijke voornaamwoorden 
voor 'delicate' lichaamsdelen ('de vagina' in plaats van 'uw vagina'). Tenslotte is geobserveerd dat de gespreksdeelnemers elkaars wijze van spreken over seksualiteit overnemen - een fenomeen dat als 'tuning' wordt aangeduid - waarmee zij het onderwerp van discussie gezamenlijk als precair definiëren. In deze studie observeerden we dat artsen de macht hebben (en krijgen) om het vocabulaire ten aanzien van de voortplantingsorganen en het seksuele gedrag van vrouwen te bepalen. Hun impliciete taalgebruik resulteert, ten gevolge van de werking van 'tuning', in het nauwelijks bespreekbaar gemaakt worden van klachten op het gebied van seksualiteit.

$\mathrm{Na}$ een samenvatting van de resultaten van deze drie studies vervolgt hoofdstuk 1 met een algemene discussie. In tegenstelling tot de resultaten van eerdere observationele studies, suggereren de resultaten van dit onderzoek dat patiënten wel degelijk actief participeren in consulten, zij het veelal op bedekte wijze. Hoewel zij niet beschikken over gelijkwaardige interactionele middelen als de artsen, blijken patiënten allerlei subtiele strategieën in te zetten om het verloop van de interactie te beinvloeden en om hun kennis naar voren te brengen. Wanneer hun inbreng verontachtzaamd wordt, blijven zij hun standpunten herhalen, daarmee aangevend dat zij hun klachten serieus genomen willen zien.

De mate van directheid van de inbreng van patiënten lijkt samen te hangen met het onderwerp dat besproken wordt. Men is actiever en directer in het zoeken naar informatie wanneer het gaat om zaken die samenhangen met de behandeling dan wanneer het gaat om diagnostische en etiologische aspecten van klachten. Deze bevinding wordt verklaard vanuit de sociale positie van vrouwen, waarin de verantwoordelijkheid voor de zorg voor huishouding en gezin een centrale plaats heeft. Wellicht is informatie over de behandeling voor veel vrouwen belangrijker dan welke andere informatie ook, aangezien zij deze nodig hebben om ervoor te zorgen dat hun dagelijkse praktische taken zo goed mogelijk gecontinueerd worden.

De indirectheid van patiënten waar het etiologische en diagnostische aspecten van hun klachten betreft, wordt verklaard vanuit de werking van professionele macht en 'gender macht'. Impliciete regels samenhangend met de 'ceremoniële orde' van de kliniek maken wellicht dat patiënten voor indirecte strategieën kiezen wanneer het gaat om onderwerpen die direct het medisch domein betreffen. Dit zal in het bijzonder voor vrouwelijke patiënten gelden aangezien zij, vanuit hun minoriteitspositie ten opzichte van een mannelijke arts, zich bedienen van een spreekstij] die gericht is op het bevestigen van de competentie van de arts. Een andere verklaring die wordt genoemd voor de indirectheid van patiënten ten aanzien van oorza- 
kelijke aspecten van hun klachten is vermijdingsgedrag. Aan de ene kant wenst men geïnformeerd te zijn, aan de andere kant loopt men het risico angstige voorgevoelens bevestigd te horen. Deze factoren, macht op basis van professionalisering en gender en het psychologische mechanisme van vermijding, worden ook gebruikt ter verklaring van de indirectheid van patiënten waar het het uiten van zorgen over kanker betreft.

In het spreken over seksualiteit blijken beide gespreksdeelnemers indirecte strategieën te hanteren. Deze strategieën worden gezien als een manier om de delicaatheid van een onderwerp te definiëren. Wanneer een onderwerp eenmaal als precair geduid is door een van de gespreksdeelnemers, dan wordt het een onderwerp waarover voorzichtig en discreet gesproken hoort te worden. De indirectheid in het spreken over seksualiteit wordt verklaard door te verwijzen naar het culturele taboe dat nog steeds op dit onderwerp rust.

De bevinding uit eerdere studies dat de inbreng van patiënten, en met name van vrouwen, tijdens medische consulten veelal wordt genegeerd, kan niet bevestigd worden op basis van onze gegevens. In de meeste gevallen blijken de artsen de vragen van de patiënten te beantwoorden en hen gerust te stellen ten aanzien van hun zorgen. Desondanks is een aantal interactiepatronen geconstateerd waarin de probleemdefinitie en de lekenkennis van patiënten niet worden gerespecteerd. Dit is het geval wanneer indirecte vragen van patiënten over de oorzaak van hun klacht worden verontachtzaamd, wanneer hun zorgen over het hebben van kanker worden genegeerd, wanneer onmiddellijk wordt overgegaan tot het geven van informatie na angstuitingen van patiênten zonder deze te exploreren, en wanneer de gynaecoloog seksuele problematiek duidt in verhullende terminologie. Het optreden van deze patronen wordt gezien als een gevolg van de werking van professionele macht en macht op basis van gender. Betoogd wordt dat deze interactie-patronen niet stroken met de uitgangspunten van vrouwenhulpverlening en wellicht ook een negatief effect zullen hebben op de tevredenheid, de compliance en het herstel van patiënten.

$\mathrm{Na}$ de discussie volgt een aantal aanbevelingen voor verder onderzoek. Onder meer wordt gepleit voor toetsing van de resultaten van dit onderzoek in een grootschaliger studie naar interactie in medische consulten, waaraan patiënten en artsen van beide seksen deelnemen. Het hoofdstuk wordt besloten met een aantal praktische aanbevelingen die gericht zijn op training van gynaecologen in het toepassen van de uitgangspunten van vrouwenhulpverlening. 


\section{Appendix A: Transcription symbols}

[ Indicates the starting point of overlapping talk.

$=$

$=\quad$ Equal signs, one at the end of the line and the other at the beginning of the next speaker's line indicate 'no gap between the two lines'.

(.) Indicates a pause smaller than 0.3 of a second.

(0.7) Indicates a pause of 0.7 of a second.

belly Underscoring indicates some form of stress, via pitch and/or amplitude.

$::: \quad$ Colons indicate prolongation of the immediately preceding sound. The length of the colon row indicates the length of the prolongation.

(laughs) Parentheses are used to enclose a description of some phenomenon, or commentary by the transcriber. 


\section{Appendix B: Dutch transcriptions}

\section{Chapter 2}

(1)

1 G: Had u verder nog vragen?

2 P: Nou eh, op het moment eigenlijk niet. Oh ja de stoelgang en de urine, als dat weer op gang gaat komen, is dat pijnlijk?

3 G: Nee hoor, dat valt wel mee

4 P: Ja?

5 G: Het is zo dat in het ziekenhuis mensen vaak wat moeite hebben met eh stoelgang.

(2)

1 G: U wordt er niet uitgezet als u nog niet fit bent.

2 P: Eh wordt het (=hysterectomie) via de buik of vaginaal gedaan?

3 G: Eh nou bij de curettage is gekeken in hoeverre de baarmoeder de neiging heeft naar beneden te komen. En die neiging heeft hij voldoende om het ook inderdaad via de schede te kunnen opereren.

4 P: Oh prima.

(3)

1 G: Maar dat is wel een mooie brochure om je vragen bij te krijgen.

2 P: Uhem.

3 G: Goed?

4 P: Goed ja. En eh, wanneer gaat dat gebeuren?

5 G: Daar gaan we een afspraak voor maken (gynaecoloog schrijft). Heeft u nog vakantie of andere bezigheden?

(4)

1 G: U hebt nergens last van gehad?

2 P: Nee, alleen maar nou hier hè. Constant hier. Of dat die banden zijn, ik weet niet.

3 G: Ja. 
4 P: En hier

5 G: dat kan natuurlijk toch [nog

6 P: [dat is nou nog al die gevolgen

7 G: omdat je namelijk een beetje trekt aan de baarmoeder, dus dat instrument wordt op de baarmoeder gezet.

(5)

1 G: Als je bij de curettage vindt dat het een hobbelige en bobbelige baarmoederholte is, maar verder geen gekke dingen daar ach[ter zitten

2 P:

[Kunt u dat bij een curettage zien?

3 G: Ja, bij een curettage kun je voelen hoe de baarmoederholte is.

(6)

1 P: Heeft dat wat met kinderen krijgen te maken dat je die vleesbomen krijgt?

2 G: Nee.

3 P: Niets?

4 G: Nee, nee, het is zelfs zo dat eh vrouwen die nooit zwanger geweest zijn, eh nonnen bijvoorbeeld, die eh daar vind je pas echt grote vleesbomen.

5 P: Zo?

6 G: Ja. Dus eh nee dat heeft niks te maken met kinderen krijgen. Waarschijnlijk is zelfs het krijgen van kinderen, beschermt je enigszins tegen het krijgen van een baarmoeder met vleesbomen. Dus eh dat staat er helemaal los van. Maar eh één op de vijf vrouwen heeft een baarmoeder met vleesbomen. Dus het is iets wat zó vaak voorkomt dat je bijna kan zeggen nou als je er geen ongemakken van hebt moet je je er ook niet druk overmaken.

(7)

1 P: Stel dat het uitstrijkje over drie maanden wel goed is 2 G: Ja. 
3 P: bliff je dan toch gewoon onder behandeling?

4 G: Ja wij vinden wel dat als uitstrijkjes afwijkend geweest zijn, dat je tenminste hier twee keer een goede uitstrijk moet hebben, voordat je teruggaat naar de routine van één keer per jaar.

5 P: $\mathrm{Mmmm}$.

6 G: En eventueel bij de huisarts. Maar als u dat wilt, dan hebt $u$ ook alle reden om te zeggen dat u hier komt voor die uitstrijk.

7 P: Want éen keer per jaar doet mijn huisarts dus niet. Die vindt, dat is één keer per drie jaar.

8 G: Ja maar er is natuurlijk nu iets geweest waardoor er een reden is om het vaker te doen.

(8)

1 G: Dat we nu niet op het juiste moment van uw cyclus zaten, dat is geen probleem.

Het was toch goed [te zien.

$2 \mathrm{P:}$

[Dus het

was toch [duidelijk te zien?

3 G: [Ja hoor, dus wat dat betreft is het goed dat het doorgegaan is.

(9)

1 P: Wordt er nog een uitstrijkje gemaakt dokter?

2 G: Dat is niet meer nodig.

$3 \mathrm{P}$ : Oh, is dat niet meer nodig?

4 G: Nee, dat is niet meer nodig.

5 P: Oh?

6 G: Nee dat is eigenlijk nooit meer nodig.

(10)

1 G: Mocht het zo zjjn dat u denkt dat heb ik vergeten te zeggen of iets anders, schrijf het dan even op en dan hoor ik het over vijf weken.

2 P: Ja alleen dan eh dat ik pijn heb, maar ja u zegt dat alles prima [eruit ziet.

3 G: $\quad$ Ja ja goed, ziet er goed uit.

4 P: Nou dan kunnen we er ook niks anders van maken hè? 
1 P: Ja ik heb ook met mijn darmen dus. En dat had ik dan van [tevoren al. Dus ik denk toch dat het eh

2 G: [Ja.

3 P: want ik heb toch, toch wel veel buikklachten.

4 G: Ja.

5 P: En denk dat thet dan toch misschien daar

6 G:

[Nee is dan weer, dan denk ik ook daarvan dan in ieder geval niet.

7 P: Het is niet van de baarmoeder?

8 G: Van die baarmoeder kun je eigenlijk uitsluiten dat het daar wat mee te maken heeft. Die eh die is zeker niet echt abnormaal.

9 P: $\mathrm{Nu}$ heb ik deze maand heb ik nu een halve maand nog niet, dus ik heb eigenlijk de menstruatie gehad, nu eigenlijk veertien dagen eh woensdag, zaterdag veertien dagen geleden. Maar ik heb vorige week heb ik toch, nou die borsten, nu nog trouwens. Verschrikkelijk, maar dat, dat is dat kan denk ik wel eens, is normaal denk ik.

$10 \mathrm{G}$ : Ja met [de (onverstaanbaar) ja en met de hormonen.

$11 \mathrm{P}$ : [Als je misschien ouder wordt, met de hormonen te maken.

12 G: Ja.

$13 \mathrm{P}$ : en nou het is [niet om vol te houden.

$14 \mathrm{G}$ : $\quad[\mathrm{Mmmm}$.

$15 \mathrm{P}$ : Het het is e[cht

$16 \mathrm{G}$ : $\quad[\mathrm{Mmmm}, \mathrm{ja}, \mathrm{ja}$.

$17 \mathrm{P}$ : En dat heb ik dan nu een paar keer gehad maar dat zal dan wel iets, misschien ja dan denk ik dat het misschien iets te maken heeft dat het, met leeftijd.

$18 \mathrm{G}$ : Ja zeker, dat kan. Dat eh dat die eisprong niet meer helemaal regelmatig komt. Dat mag natuurlijk langzamerhand hè! Goed mevrouw B, dus wat ons betreft, gynaecologisch hè, is dat [allemaal

19 P:

[Ta maar die man die dacht dus echt, hij zegt volgens mij is het echt, toch wel iets aan de ha[nd zei hij.

$20 \mathrm{G}$ :

[Ja. 
21 P: Dus ik verwacht[te dat het eh

$22 \mathrm{G}$ : [Nee dat is er dus niet. Nee daar hoeven we ni[ks aan te doen.

$23 \mathrm{P}: \quad$ [Wil ik die klacht eigenlijk, die heb ik al [jaren en nog steeds eigenlijk.

$24 \mathrm{G}$ : []a, ja, nee wat dat betreft kunt u helemaal gerust zijn.

25 P: Goed.

26 G: Goed.

\section{Chapter 3}

(1)

$1 \mathrm{G}:$ Hoe is het met u?

2 P: Het gaat.

3 G: Niet zo [om over te

4 P: [Nee ook een beetje problemen. Ons moeder is weer een week in het ziekenhuis [en

5 G: waarvoor dat?

6 P: Nou die hadden ze toch de nier afgenomen, vorig jaar en nou blijkt ze met haar ogen. Ik denk allemaal dat het uitzaaiingen zijn.

7 G: Uhm.

8 P: Dat komt er allemaal bij.

9 G: Juist, nou de uitslagen bij u zijn allemaal normaal.

(2)

1 P: Maar nu maakte ik me toch wel een beetje ongerust

2 G: U vertelt $u$ had bloedverlies na gemeenschap, had $u$ ook pijn bij gemeenschap gekregen?

(3)

1 P: Oh nee, niet weer al die ellende.

2 G: Nee, maar dat stelt niks voor en zeker niet voor iemand die kinderen heeft gehad. 
(4)

1 G: Bent u er bang voor dat het iets is?

2 P: Nee.

3 G: Wat is de reden precies dat u hier zit? Zeg je van ik wil het uitgezocht hebben?

4 P: Ja ik ben er nou al zo lang mee bezig en het wordt steeds erger en ik vind het voor het gezin ook vervelend om dan sikkeneurig te worden

5 G: Uhem.

6 P: Ik ben er inderdaad gewoon ja wat kriebelig onder.

7 G: Uhem.

8 P: Ervoor, erna en tijdens de menstruatie en ja dat is bijna dan twee en een halve week bij elkaar en ja dat is gewoon teveel voor mijn gezin.

9 G: Dus het is enerzijds een beetje als ik het voel van ik wil er vanaf, hè?

$10 \mathrm{P}$ : Nou ik wi[l

$11 \mathrm{G}$ : $\quad$ IIk wil weten wat het is

12 P: Ik wil weten wat het is dat ik dus gewoon dat het niks kwaadaardigs, daar denk je natuurlijk het eerste aan.

13 G: Dat is juist.

14 P: Maar eh, ja gewoon wat de pijn is en of er iets aan gedaan kan worden, hetzij tabletten of weet ik veel.

$15 \mathrm{G}$ : Nou, we gaan eens rustig naar u kijken. Aan de hand daarvan nog eens kijken of er nader onderzoek nodig is. De meeste dingen zijn onschuldig. Hè, maar dan moet je gewoon een beetje weten wat er aan de hand is. Als dat zo is, kun je in ieder geval uitleggen. Niet aan alle dingen kun je ook wat doen.

16 P: Ja dat weet ik.

17 G: Echte wondermiddelen bestaan niet. Vaak zijn het lastige maar onschuldige klachten.

$18 \mathrm{G}$ : Iets raars is er, of iets geks waar je heel bang voor hoeft te zijn=

$19 \mathrm{P}:=$ is er niet $=$

$20 \mathrm{G}$ : = is uitermate onwaarschijnlijk. Wat ik vind is een normaal grote baarmoeder, zeker geen vleesbomen. 
(5)

$1 P$ : Ja, net alsof er iets zit eh ja jets zit wat er niet deugt.

2 G: Ja, ja er beweegt wat. Is uw buik ook dikker geworden?

3 P: Ja dat vind ik pesoonlijk zo. Dat heb ik wel altijd als ik ongesteld moet worden, dan eh heb ik dan ben ik ook zeker twee kilo zwaarder.

4 G: Ja, maar dat is vaker ook een hormoonkwestie. Je kan je voorstellen dat kort voor de menstruatie zijn er een aantal hormoonveranderingen. En dat gevoel ontstaat doordat je neigt tot vocht vasthouden dan. En met dat je ongesteld wordt, zijn die hormonen weer wat veranderd, waardoor je een boel extra vocht kwijt raakt. Dus zo'n opgeblazen gevoel hebben heel veel mensen. Dat heeft niet speciaal te maken met een baarmoeder met een vleesboom of zo.

5 G: Nou opvallend is dat het eigenlijk met de grootte van de baarmoeder zo bij het inwendig onderzoek nog best meevalt moet ik zeggen.Ik kan hem zo heel goed af voelen. Ik denk dat wij zelf ook nog eens een echo moeten maken, want ik kan hier toch niet direct tot de conclusie komen dat er een duidelijke vleesboom zit.

6 P: Ja maar het moet toch ergens vandaan komen?

7 G: Oh maar het komt zeker van de baarmoeder. Maar het is soms zo dat je kan zeggen dat is duidelijk een grote vleesboom en voor dat soort problemen heb je dan ook één, twee, drie een oplossing. En soms ligt dat wat anders. Niet echt een inwendig onderzoek waarvan ik denk van nou dat is nou de verklaring voor de klachten. Dus je moet op dit moment niet stellen dat er sprake is van een grote baarmoeder met grote vleesbomen. Ik zou graag hier de echo nog een keer herhalen, dat we zelf even kijken hoe die eruit ziet. Dat hij ook even precies gemeten wordt hoe groot hij is. En we zouden ook, vanwege die moeheid en ja alle klachten die samenhangen met het vloeien, uw bloedgehalte moeten controleren. 
1 P: Maar moet ik ook bij zeggen dat ik ook een beetje met mijn oudste zuster een beetje. Nou dat houdr je eigenlijk toch bezig.

2 G: Hoe heet ze ook weer?

3 P: K.M., u weet wel, die is ook bij u onder behandeling geweest. Die heeft toen ook in dit ziekenhuis gelegen. Mijn oudste zuster.

4 G: Wat was er ook weer mee want dat heb ik niet goed onthouden?

5 P: Daar hebben ze dus alles eh

6 G: weggehaald.

7 P: weggehaald. In verband dus met kanker.

8 G: Ik weet het weer ja.

9 P: En dat zit mij ook wel een beetje eh

$10 \mathrm{G}$ : Maar gaat het niet goed dan of zo?

$11 \mathrm{P}$ : Ja maar dan toch als ik veel pij[n heb

$12 \mathrm{G}$ :

$[O h, j a, j a, j a, j a, j a$.

$13 \mathrm{P}$ : Ja het is met mij wel goed. Maar zij is de oudste en ik ben de jongste dus mijn vader heeft het ook eh longkanker gehad en eh ja dan denk je daar toch wel aan.

14 G: Nou, had de huisdokter nog een uitstrijkje gemaakt dat $\mathrm{u}$ weet of niet?

15 P: Jawel, maar dat weet ik niet meer hoe lang dat geleden is hoor. Want ik ben zelf wat dat betreft liefst twee keer per jaar als één keer in het jaar een uitstrijkje.

$16 \mathrm{G}$ : Nou dat heeft geen zin. Kijk als u het twee keer in het jaar doet dan hebt $u$ alleen maar een schijnzekerheid, dat zegt gewoon helemaal niks. Als de uitslag normaal is dan maakt dat helemaal geen biet uit.

$17 \mathrm{P}$ : Nee maar voor jezelf hè?

18 G: Voor jezelf, ja maar goed normaal is zeg maar één keer in de twee jaar voldoende hè. Want als je het echt veel meer doet dan krijg je toch een beetje dat je je[zelf voor de gek houdt.

19 P: [Dat het een soort fobie wordt of zo of toch niet? 
$20 \mathrm{G}$ : Nou, nou we moeten toch niet overal zo zwaar aan tillen zeg, je moet een beetje lol hebben in het [leven.

$21 \mathrm{P}$ :

oh maar ik heb plezier [genoeg dat wel, maar

[]a,

$22 \mathrm{G}$ : [Jawel, jawel, hoe oud bent u nou?

$23 \mathrm{P}: 34$.

$24 \mathrm{G}$ : Bij buikpijn is er een relatie met zorg, als je zegt mijn oudste zuster en nog eens wat, ik maak me daar zorg over dat het mij ook overkomt, dat leidt tot allemaal buikklachten,

$25 \mathrm{P}: \mathrm{Ja}$, is van psychische aard.

26 G: Nou dat is hetzelfde voor mannen met maagzweren. Het komt natuurlijk niet zoveel van eten maar van de stress.. De buikpijn zal ook zeker samenhangen met het feit dat u geopereerd bent in uw buik. De vergroeiing geeft wat buikklachten. en bovendien zal het ook samenhangen met het feit dat uw buik zo ongelooflijk over het schaambeen hangt.

\section{Chapter 4}

(1)

1 G: En over dat, ja het seksuele gebeuren, het chagrijnig

2 zijn, het feit dat u er minder zin in hebt, ik vind

3 dat altijd heel lastig om dat in het eerste gesprek te

4 bespreken. Überhaupt is het lastig hoor.

(2)

1 P: Want het is best wel, vind ik, nou niet vervelend 2 om er over te praten maar je kan er nooit met ie3 mand over praten want daar praat je niet over hè.

4 G: Nee daar ligt nog echt een taboe op hè. 
(3)

1 G: Zullen we het eens proberen met die vitamine

2 preparaten, eens kijken hoe het gaat en ja (1.0)

3 P: Want misschien dat het dan ook helpt, maar e:h

$4 \quad(0.9)$ ik heb helemaal geen zin in sex hè.

$5 \quad(0.8)$

6 Absoluut niet.

(4)

1 G: Dus de ontlasting gaat goed (0.8) en met seksueel

2 contact hebt u geen problemen?

$3 \quad(0.4)$

4 P: Ja

5 G: Wat dan?

6 P: Altijd al gehad hè.

(5)

1 G: U gebruikt niet de pil?

2 P: Nee

3 G: Hoe is de anticonceptie dan geregeld? Gebruikt u

4 con[dooms of

5 P: [Nee, nee e::h (0.5) we gebruiken [niets

6 G: [Een beetje

7 oppassen?

8 P: Nou, nou we [hebben een kind dus het mag best

9 G: [Of ook niet oppassen?

$10 \mathrm{P}$ : een tweede of zo zou welkom zijn

(6)

1 G: Wat is er gedurende deze twee jaar gebeurd?

2 P: Eh daar is eigenlijk mee begonnen dat de menstruatie helemaal wegbleef. Dus (0.6) drie maanden ongeveer heb ik het helemaal niet gehad. En toen ben ik dus naar de huisarts gegaan want ik wist dus niet wat er aan de hand was. Nou die zei volgens mij bent u met de overgang bezig. En die heeft toen tabletten voorgeschreven om het toch weer op gang

9 te brengen. Het waren van die rode tabletten. En

$10 \quad(0.6)$ ja het is er dus weer van op gang gekomen zeg 
maar. Maar het is wel heel onregelmatig. Soms al om de veertien dagen. Want nou heb ik het dus begin juni, afgelopen vrijdag had ik het dus weer.

14 En het is maar een heel klein beetje maar het groot-

15 ste probleem vind ik zelf dus eh ontzettend chagrij-

16 nig. En (0.3) ge kunt dus helemaal niks hebben e::h

17 (1.2) eh geen gemeenschap dus met je man. Dus ook

18 al sinds twee jaar geen gemeenschap.

19 G: Uhem

(7)

1 P: Ja, ja mijn man zal (lacht) met vreemde ogen staan

2 hè.

3 G: Ja?

4 P: ja ja dat [eh

5 G: [hij vond dat een raar idee om zaad in te leveren?

$7 \mathrm{P}: \mathrm{Ja}$, dat, dat vinden de meeste mannen.

$8 \mathrm{G}$ : De meeste mannen vinden dat, dat is waar.

(8)

1 G: E::h ik wil nog wel even noemen dat eh (1.5) er is

2 één ding wat eigenlijk heel onzeker is aan het opere-

3 ren van een baarmoeder en dat is namelijk hoe het

4 daarna met sex gaat. Er zijn eh vrouwen die (0.9) eh

5 vinden dat na een operatie, het verwijderen van een

6 baarmoeder, het veel prettiger is met vrijen. Dat

7 speelt dan, kennelijk (0.6) speelt dan een rol dat je

8 niet meer bang bent voor te vloeien, dat je (0.4) eh

9 (0.7) misschien niet meer pijn hebt bij gemeenschap.

10 dat soort redenen zouden het kunnen zijn. Dus die

11 zijn heel tevreden. Er zijn ook vrouwen die zeggen

12 nou (0.4) ik mis toch iets (0.8) nu (0.4) met het

13 klaarkomen met name. Dat eh er zijn vrouwen die

14 zeggen achteraf merk ik nu mijn baarmoeder ver-

15 wijderd is, dat eh (1.3) dat het klaarkomen toch

16 minder (1.1) intens is om het zo maar te zeggen. 
(9)

1 G: $\quad$ Er is ook niets gebeurd (0.7)

2 met onderzoek of

$3 \quad(1.4)$

4 problemen thuis

$5 \quad(1.0)$

6 broers of

$7 \quad(0.7)$

8 P: Nee

9 G: Nooit nee.

$10 \mathrm{P}$ : Ik was eh (0.3), 'ns kijken, toen its naar de huisarts

11 ben gegaan heb ik eh voor de [eerste keer eh een

12 gynaecologisch onderzoek gehad.

13 G: [dat het

14 gynaecologisch onderzoek werd uitgevoerd.

(10)

1 P: Nou doordat ik (0.8) dus regelmatig pijn ervaar

$2 \quad$ [tijdens gemeenschap]

$3 \quad(1.0)$

4 G: Uhem, uhem

5 P: Heb ik er ook geen behoefte aan. Want het is niet

6 gezond één keer in de drie vier maanden /gemeen.

7 schap] hè? Maar goed

(11)

1 G: Eh het derde is zeg maar het seksueel contact.

2 (1.8)

3 Was al voor de zwangerschap. Ja, ik, zo u nakijkend

4 is de grootte [van de vagina] normaal, dus helemaal

5 niet zo dat je zegt [de vagina] is te klein, is te klein

6 of te nauw of er zitten speciale ribbeltjes in waar-

7 door het [vrijen] pijn doet enzovoorts dat niet. Maar

8 ik kan me best voorstellen dat dat klachten geeft. 
(12)

$1 \mathrm{G}$ : Wat is dan het probleem bij seksueel contact?

$2 \quad(1.0)$

3 Is het [dat

4 P: [Nou dat is niet prettig, dat doet ook zeer.

$5 \quad(1.0)$

6 G: Altiid?

7 P: Nou meeste tijd wel

8 (1.7)

9 G: En wat doet [dan

10 P: [en ik heb er ook een beetje angst voor

11 om te e::h ja

12 G: Uhem en wat doet dan zeer, het naar binnen gaan

13 of het gebeuren zelf of erna

$14 \quad(0.8)$

15 hebt u krampen erna bijvoorbeeld

$16 \quad(1.0)$

17 [of

$18 \mathrm{P}$ : [het zijn heel felle steken hè.

19 G: Maar tijdens het seksueel contact doet het pijn? =

$20 \mathrm{P:}=\mathrm{Ja}$.

21 G: En dat had u al voordat u zwanger werd?

22 P: Mmmm

$23 \quad(4.6)$

24 Ik denk dat ze me wat dat betreft niet goed afge-

25 maakt hebben (gegrinnik).

$26 \quad(3.0)$

27 G: Maar is niet zo dat u zegt, god moet u eens luiste-

28 ren het is, het is na de zwangerschap is het erger

29 geworden of zo?

$30 \quad(1.2)$

31 Want (.) het is natuurlijk (0.7), dat moet u goed

32 realiseren, dat van onder $(0.8)$ is er door de zwan-

33 gerschap niet heel veel gebeurd. $U$ bent nog nooit

34 (1.3) normaal bevallen hè $=$

$35 \mathrm{P}: \quad=$ Heeft er eigenlijk niks geleden hoor.

36 G: Nee dat is dus gewoon hetzelfde gebleven om het zo maar voorzichtig uit te drukken. Dus (.) ik kan me heel goed voorstellen dat als u voor die tijd wat 
problemen had daarmee dat die problemen nog steeds bestaan. Maar (.) moet u voor u zelf maar eens nagaan met uw man of het probleem is een technisch probleem, dat $u$ zegt het is wat aan de nauwe kant, of het is erg (onverstaanbaar) of stroef, of dat het meer een probleem is dat (0.6) u er wat minder zin in hebt of dat u zegt [god

dus regelmatig pijn ervaar

48 G: U:hem, u:hem.

49 P: heb ik er ook geen behoefte aan. Want het is niet

50

51

[Nou doordat ik gezond één keer in de drie vier maanden hè? Maar goed.

(13)

G: En wat doet dan pijn het naar binnen gaan of het gebeuren zelf of erna (0.8) hebt u krampen erna bijvoorbeeld (1.0) of

(14)

G: Er zijn ook vrouwen die zeggen, nou (0.4) ik mis toch iets (0.8) nu (0.4) met het klaarkomen met name.

G: Draagt u wel eens een tampon in de vagina?

G: U hebt ook geen afscheiding uit de borsten?

P: Wat ik nou wel heb dar heb ik gemerkt, toen ik de pil had had ik geen pijn aan de borsten voordat ik ongesteld moest worden en dat heb ik nou wel iedere keer. 
(18)

1 P: Maar ik ik vind het zelf eigenlijk zo vreemd (1.6)

2 e:h dat ik dus sinds twee jaar e::h ja geen gevoel heb

3 voor gemeenschap of zo.

4 G: Maar het gevoel voor gemeenschap, dat dat weg is

5 of dat dat veranderd is, heeft natuurlijk te maken

6 met eh uw leeftijd. 


\section{Curriculum vitae}

Wies Weijts was born in 's-Hertogenbosch on February 13th, 1964. In 1982 she got her diploma Gymnasium B at the Stedelijk Gymnasium in 's-Hertogenbosch. She started studying Health Sciences in 1982 at the University of Limburg in Maastricht, specializing in Health Education. She also received pedagogical training in health sciences. After graduating in 1987, she worked from January 1988 to January 1992 as a Research Assistant in the women's studies' section of the Faculty of Health Sciences, University of Limburg. Since January 1992 she has been working in this section as a postdoc. Besides the research that is described in this thesis, she has published about the integration of 'vrouwenhulpverlening' in somatic health care and about qualitative research methods. 

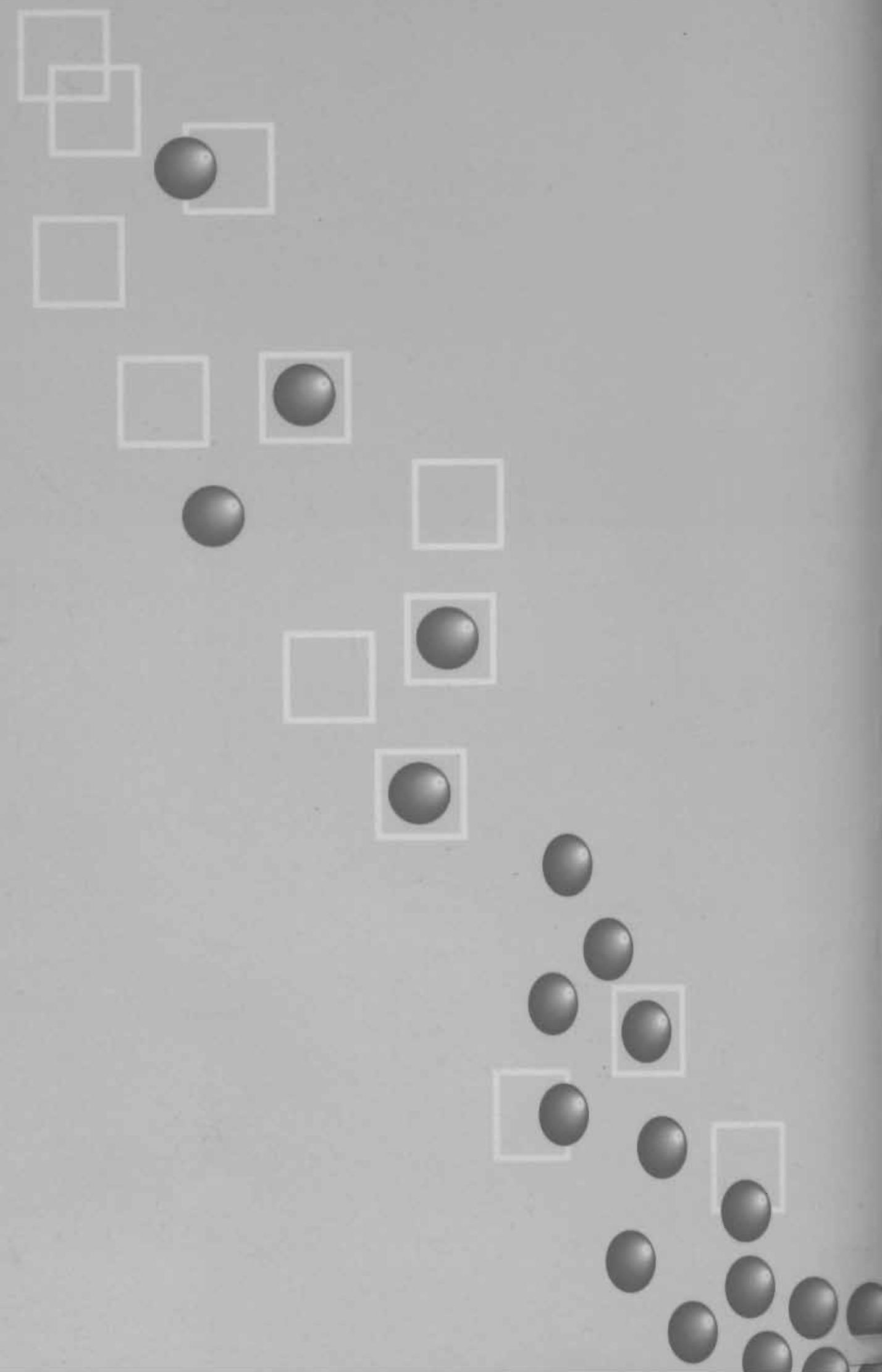